University of Louisville

ThinkIR: The University of Louisville's Institutional Repository

Electronic Theses and Dissertations

$5-2020$

\title{
White moves first: unearthing white privilege in the modern board game.
}

Darrell A. Johnson

University of Louisville

Follow this and additional works at: https://ir.library.louisville.edu/etd

Part of the Other Arts and Humanities Commons

\section{Recommended Citation}

Johnson, Darrell A., "White moves first: unearthing white privilege in the modern board game." (2020). Electronic Theses and Dissertations. Paper 3426.

https://doi.org/10.18297/etd/3426

This Doctoral Dissertation is brought to you for free and open access by ThinkIR: The University of Louisville's Institutional Repository. It has been accepted for inclusion in Electronic Theses and Dissertations by an authorized administrator of ThinkIR: The University of Louisville's Institutional Repository. This title appears here courtesy of the author, who has retained all other copyrights. For more information, please contact thinkir@louisville.edu. 
WHITE MOVES FIRST:

UNEARTHING WHITE PRIVILEGE IN THE MODERN BOARD GAME

By

Darrell A. Johnson

B.A. University of Louisville, 2003

B.A. University of Louisville, 2008

M.A. University of Louisville, 2009

M.A.T. Bellarmine University, 2019

\begin{abstract}
A Dissertation
Submitted to the Faculty of the

College of Arts and Sciences of the University of Louisville in Partial Fulfillment of the Requirements

for the Degree of
\end{abstract}

Doctor of Philosophy in Humanities

Department of Comparative Humanities

University of Louisville

Louisville, $\mathrm{KY}$

May 2020 



\title{
WHITE MOVES FIRST:
}

\section{UNEARTHING WHITE PRIVILEGE IN THE MODERN BOARD GAME}

\author{
By
}

Darrell A. Johnson

B.A., University of Louisville, 2003

B.A., University of Louisville, 2008

M.A., University of Louisville, 2009

M.A.T., Bellarmine University, 2019

Dissertation Approved on

April 14, 2020

By the following Dissertation Committee:

Dr. Simona Bertacco (Comparative Humanities)

Dr. David Owen (Philosophy)

Dr. Michael Johmann (Comparative Humanities)

\section{Dr. Ann Hall (Comparative Humanities)}




\section{DEDICATION}

This dissertation is dedicated to my father,

Darrell Johnson,

who taught me that you are never too old to be a kid at heart.

His love of books and games inspired my appreciation for them.

He taught me puzzles and games, and he will always be the greatest puzzle I never solved. 


\section{ACKNOWLEDGEMENTS}

I would like to thank my dissertation advisor, Dr. Simona Bertacco, for all her assistance, valuable time, and unending support. Her patience as this project came into sharper focus and her suggestions has been invaluable. I would also like to thank my other committee members, Dr. David Owen and Dr. Michael Johmann, who shared their time, expertise, and suggestions throughout the drafts of this dissertation. Along with my outside reader, Dr. Ann Hall, they offered perspectives that shaped how I would look at the overall project, and without them, this would be a different work.

I offer thanks to my Ph.D. peers who were always there as soundboards to my ideas and questioned my premises throughout, pushing me to think from different angles. Particularly, I extend my gratitude to John Darowski, Will Simpson, Kate Lafferty, Erin O’Reilly, Bamba Ndiaye, and Kelly Hill, who listened, offered feedback, and remained supportive throughout the project.

I offer my deepest thanks to my family whose assistance has been crucial. Particularly, my wife, Amy Hinkle-Johnson, who worked so many long hours and remained supportive despite the difficulties. Without her, this work would not have been possible. 


\begin{abstract}
WHITE MOVES FIRST:

UNEARTHING WHITE PRIVILEGE IN THE MODERN BOARD GAME

Darrell A. Johnson
\end{abstract}

April 14, 2020

This dissertation focuses on the design choices in the modern board game and argues that game designs emerge from and constitute dominant ideologies that endorse and secure white male superiority. This dissertation utilizes Michel Foucault's archaeological method to "unearth" ideologies that cultural artifacts both emerge from and constitute. The project considers three central questions: 1) How does the locus of production and consumption impact the dominant ideology underlying game design? 2) How do design choices secure and constitute an ideology of white male dominance? 3) What impact does the normalization of white dominance have upon the broader community? This dissertation is organized around different analytical frameworks with each chapter focusing on one of these frameworks through several case studies. Chapter one introduces readers to the history of the modern board game from World War II to the present and offers a rubric for understanding the interrelated elements in game design. Chapter two focuses on how board games can present as discursive artifacts that reveal the ideological premises they emerge from and constitute. Chapter three inspects how board games reveal a dominant Eurocentrism that is demonstrated and shaped by geographical representation. Chapter four analyzes the role of racial representation for 
nonwhite characters and bodies to show a proclivity toward the diminished importance and debasement of nonwhite roles. Chapter five looks at the normalization and invisibility of white racial politics that maintains a power disequilibrium through space and representation. Chapter six aligns the endorsements of white dominance implied by game design with exclusionary community practices that secure barriers to play. Collectively, the privileging performances of board games frustrate the industry's aims to amass a wider and more diverse population of players. 
TABLE OF CONTENTS

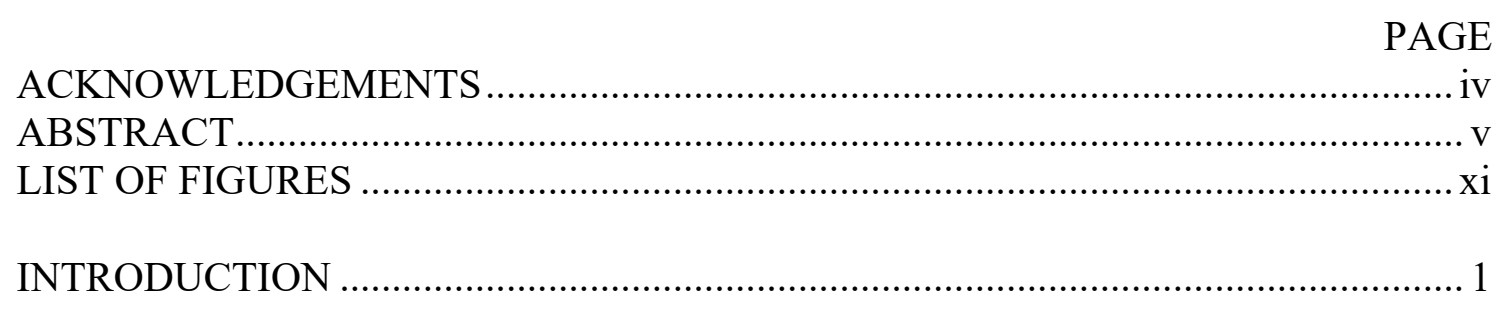

0.1 DISCIPLINARY APPROACHES ...................................................... 4

0.2 METHODOLOGY AND RESEARCH FOCUS ........................................ 5

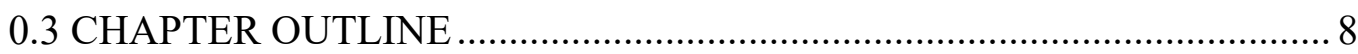

CHAPTER I-THE STATE OF PLAY: A RUBRIC AND HISTORY FOR THE

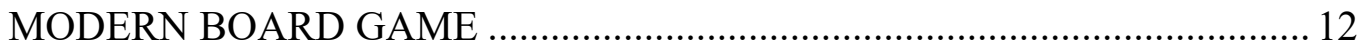

1.1 GAMES, PLAY, AND THE ORDINARY: TOWARD A DEFINITION OF

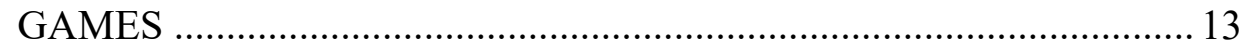

1.2 A BRIEF HISTORY OF THE MODERN BOARD GAME ....................... 25

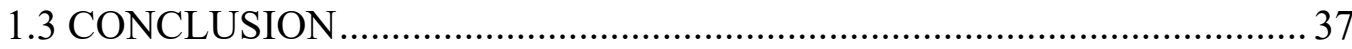

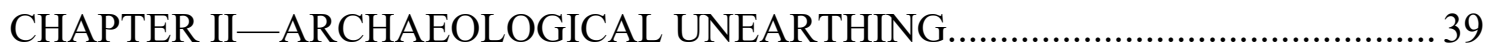

2.1 THEORIES AND CONCEPTS ......................................................... 41

2.1.1 Episteme and Unearthed Ideologies: Foucault .......................... 41

2.1.2 Reproduced Ideology: Gramsci and Althusser .......................... 43

2.1.3 Contested Ideologies: Williams and Hall ...................................48 
2.2 AMERICAN-STYLE GAMES AND THE RELOCATION OF CONFLICT:

COSMIC ENCOUNTER (1977) AND ANDROID:

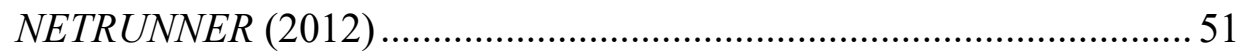

2.2.1 Cosmic Encounter (1977) …………………………………...... 52

2.2.2 Android: Netrunner (2012) ........................................................59

2.3 EUROPEAN-STYLE GAMES AND THE ABSTRACTION OF CONFLICT

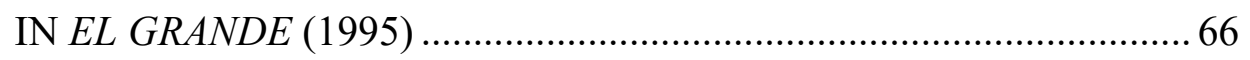

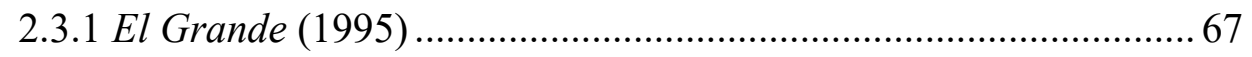

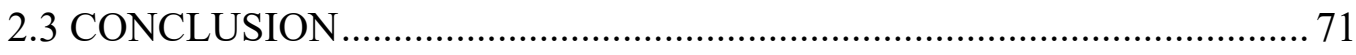

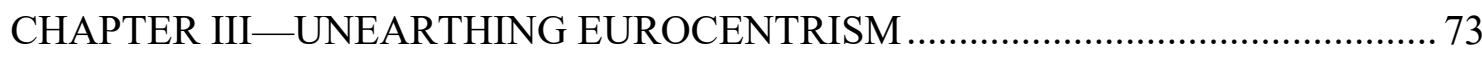

3.1 THEORIES AND CONCEPTS ……………………………………….... 76

3.1.1 The Social Construction of Space: Lefebvre, Soja, Foucault, and de

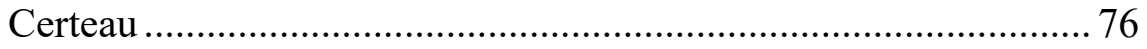

3.1.2 Cartographic Silence: Harley ......................................................... 84

3.1.3 Thereness: From Said to the Tourist's Gaze …………………….... 85

3.2 THE ISSUE OF “THERENESS” IN ISTANBUL (2014) .............................. 89

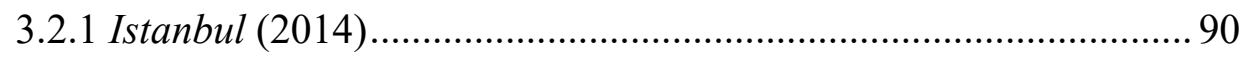

3.3 GEOGRAPHICAL MISREPRESENTATIONS IN JAMAICA (2007) AND

PUERTO RICO (2007) ……………………………...................... 96

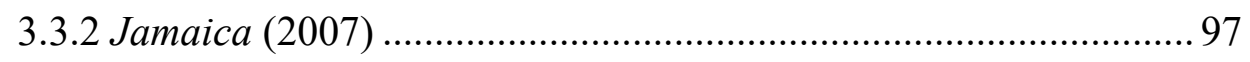

3.3.3 Puerto Rico (2002) .................................................................... 100

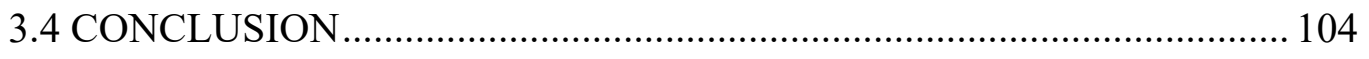

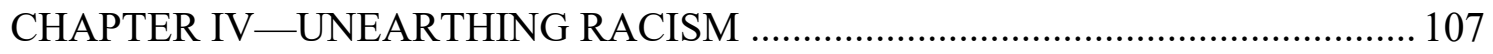


4.1.1 Constructed Docility and the Gaze: Foucault, Butler, and

Fanon.

4.1.2 Semiotic Fixity: Yancy and Hall

4.1.3 Pollution and Liminality: Douglas and The Black Image in the

White Mind.

4.1.4 Commodified Otherness: hooks and Nakamura 121

4.2 PLAYING AS/ PLAYING WITH RACE IN SMALL WORLD (2009) AND

ELDRITCH HORROR (2013). 122

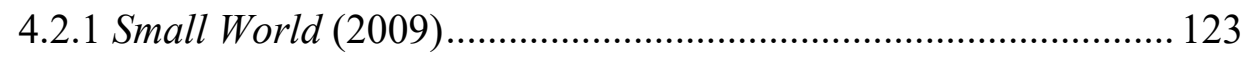

4.2.2 Eldritch Horror (2013) ....................................................... 128

4.3 SANITIZING THE PRESENT IN FREEDOM: THE UNDERGROUND

RAILROAD (2012) AND FIVE TRIBES (2014) ................................ 136

4.3.1 Freedom: The Underground Railroad (2012) ......................... 137

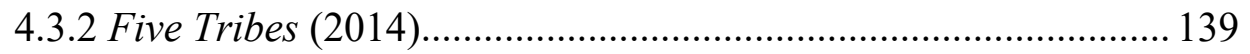

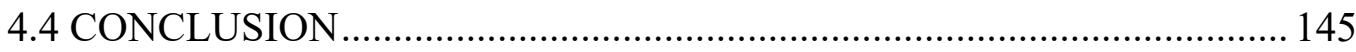

CHAPTER V_UNEARTHING WHITE DOMINANCE ..................................... 147

5.1 THEORIES AND CONCEPTS ............................................................ 150

5.1.1 Spatialized Whiteness: Mills and Fanon................................. 151

5.1.2 Phenomenology of Whiteness: Fanon and Yancy ..................... 153

5.1.3 Invisibility of Whiteness: Yancy, Dyer, Hall, and Foucault........ 155

5.1.4 Racialized and Politicized Whiteness: Mills and Alcoff ............ 157

5.2 CURIOUS OMISSIONS IN THROUGH THE AGES (2015) ................... 159 
5.3 THE DICHOTOMY BETWEEN EXPLOITATION AND ECONOMY IN

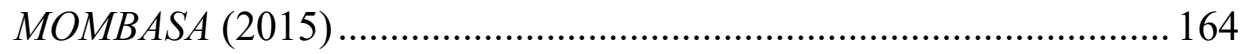

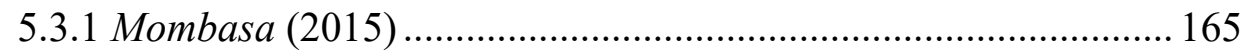

5.4 INVISIBLE POWER AND VISIBLE CONSTRAINT IN CONCORDIA

(2013) AND BORA BORA (2013) ……………………………….... 172

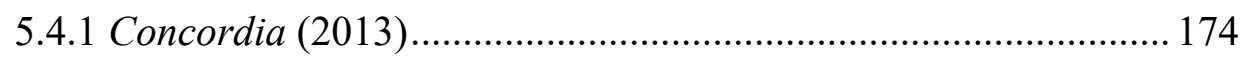

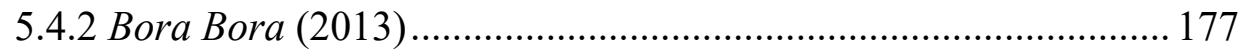

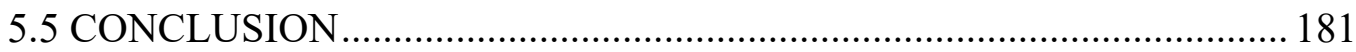

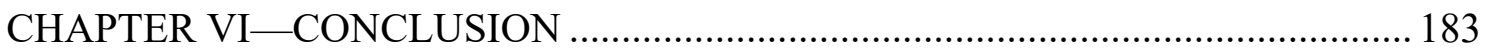

6.1 INCLUSION AND EXCLUSION IN THE COMMUNITY ........................ 186

6.2 A “WELCOME MAT” FOR WHITE PRIVILEGE................................... 191

6.3 OTHERS UNWELCOME: JUDEN RAUS (1938) AND SECRET

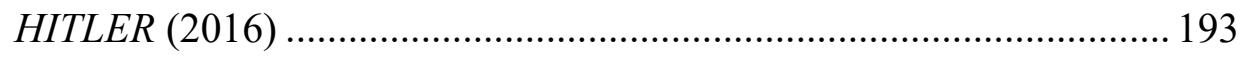

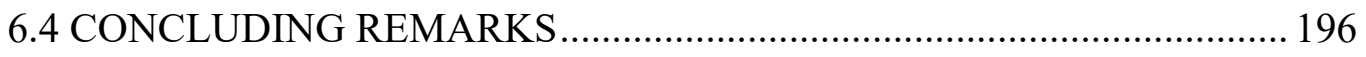

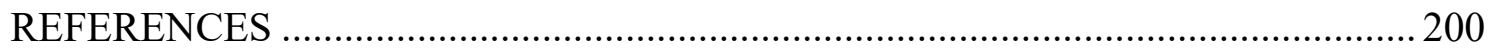

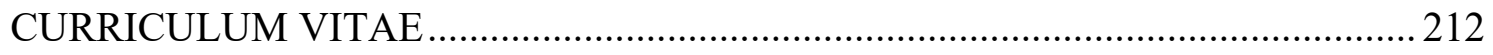




\section{LIST OF FIGURES}

FIGURE

PAGE

\section{CHAPTER II}

1. Figure 2.1 The "Kamikaze" alien faction from Cosmic Encounter....................55

2. Figure 2.2 "Astroscript Pilot Program," an agenda from Android: Netrunner... 62

3. Figure 2.3 The board for El Grande, depicting the nine regions and tiered

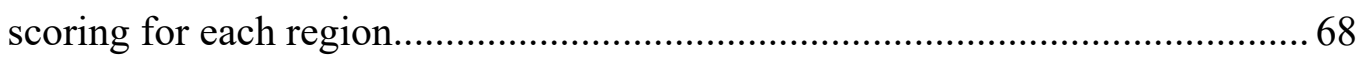

\section{CHAPTER III}

4. Figure 3.1 Contrast between Carcassonne, France, and the board game

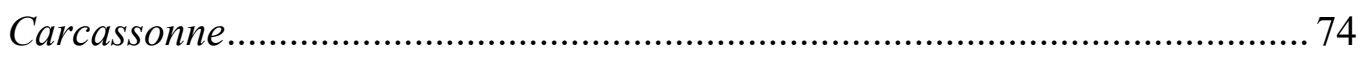

5. Figure 3.2 Santorini box art, depicting gods looking down upon the

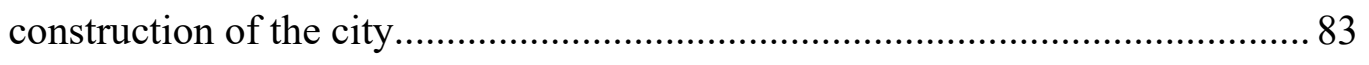

6. Figure 3.3 Istanbul board setup, depicting the sixteen bazaar locations ............90

7. Figure 3.4 The Sultan's Palace tile, depicting the increasing number of

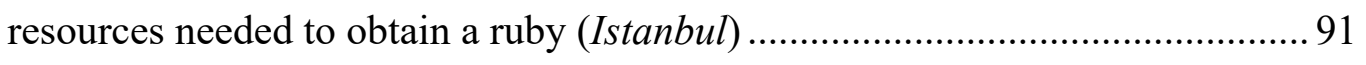

8. Figure 3.5 Jamaica in the game functions as a hub and material placeholder for player actions

9. Figure 3.6 Puerto Rico player board, mid-game, showing a green blankness gradually replaced by industry. 


\section{CHAPTER IV}

10. Figure 4.1 Operations Expert attires associates the role with the working class (Pandemic) 108

11. Figure 4.2 Small World setup, featuring the crowded terrain regions and the selection of available races

12. Figure 4.3 Jim Culver's roles is associated with jazz and magic, and his unique abilities offer support for other players (Eldritch Horror)

13. Figure 4.4 Akachi Onyele is exoticized as a mystical African shaman with a spiritual connection to the supernatural realm (Eldritch Horror)

14. Figure 4.5 A tile tracks the number of slaves recaptured or killed (Freedom:

The Underground Railroad)

15. Figure 4.6 Five Tribes setup, featuring the location tiles, available djinns, and the slaves available at the market. 140

16. Figure 4.7 Fakirs replaced the slave cards in subsequent printings of

Five Tribes 142

\section{CHAPTER V}

17. Figure 5.1 The white male leadership on the box art for Through the Ages.... 161

18. Figure 5.2 Leaders in Through the Ages are whitewashed and dominantly male 162

19. Figure 5.3 European enterprise spreads inland across a blank Africa in Mombasa 166

20. Figure 5.4 Mombasa's box art depicts a Manichean separation of labor and power 168 
21. Figure 5.5 White expansive power is unchecked and unremarkable

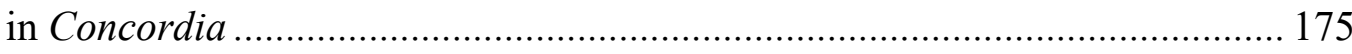

22. Figure 5.6 The hypervisible exoticism of Bora Bora …................................ 178

\section{CHAPTER VI}

23. Figure 6.1 The symbolic, inclusive power of the meeple on a YouTube title

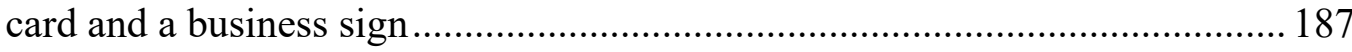

24. Figure 6.2 The words "Jews get out" and "Off to Palestine" adorn this 1938 board

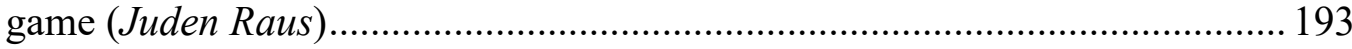




\section{INTRODUCTION}

\section{All play means something. \\ -Johan Huizinga ${ }^{1}$}

The modern board game industry has witnessed a 'boom' in recent years, with more games and players entering the hobby, heralding what some have called a board game 'renaissance. ${ }^{2}$ With titles boasting more than thirty million players, ${ }^{3}$ being translated into forty different languages ${ }^{4}$ and appearing on popular television shows like The Big Bang Theory and Parks and Recreation, ${ }^{5}$ the hobby's recent widespread appeal has been largely good news. Despite this resurgence in popularity, the board game community generally remains dominated by white males, and sentiments that more diverse players will join the hobby have yet to be realized. Game narratives and representation in both play and publishing continue to reflect the dominant demographic rather than expand to reflect a broader cultural diversity.

\footnotetext{
${ }^{1}$ Johan Huizinga, Homo Ludens: A Study of the Play-Element in Culture (1949, repr. Kettering, OH: Angelico Press, 2016), 1.

2 Diana Kruzman, "Bored with Digital Games? Join the Board Game Renaissance," USA Today, July 31, 2017, https://www.usatoday.com/story/life/2017/07/31/bored-digital-games-join-board-gamerenaissance/476986001/

${ }^{3}$ Neima Jahromi, "The Twenty-Five Year Journey of Magic: The Gathering," The New Yorker, August 28, 2018, https://www.newyorker.com/culture/culture-desk/the-twenty-five-year-journey-of-magic-thegathering ${ }^{4}$ Catan: The Official Website for the World of Catan, Catan Gmbh, last modified March 2, 2020, https://www.catan.com/about-us/partners\# ${ }^{5}$ Calvin Wong, "10 Things You Didn't Know about The Settlers of Catan," Boardgameprices.com, September 13, 2016, https://www.boardgameprices.com/articles/10-things-you-didnt-know-about-TheSettlers-of-Catan
} 
While there are quantitative studies that investigate white male dominance within the board game hobby ${ }^{6}$ and investigations of problematic narratives in game design, ${ }^{7}$ there, to my knowledge, has been no broad case-studies approach to investigating problematic design elements. What follows is an interdisciplinary approach to board game designs that utilizes several in-depth case studies to show how inscribed elements of narrative, mechanism, abstraction, space, and representation all work toward the security and constitution of white privilege. In this way, this dissertation contributes to the ongoing academic conversation within cultural studies and ludic studies regarding gameplay, community, media representation, and identification.

There has been an observable rise in the participation of women and people of color within the community ${ }^{8}$ however, the current demographic analysis available suggests that men make up nearly seventy percent of the community and those who identify as white constitute ninety percent. ${ }^{9}$ This persists despite public efforts to make the community more diverse. ${ }^{10}$ As game designer Jay Africa has noted, it is "important [for games] to reflect all aspects of society, not only because it provides ownership, but

\footnotetext{
${ }^{6}$ Tanya Pobuda, "Assessing Gender and Racial Representation in the Board Game Industry," Analog Game Studies, December 2, 2018, http://analoggamestudies.org/2018/12/assessing-gender-and-racialrepresentation-in-top-rated-boardgamegeek-games/

${ }^{7}$ Cornel Borit, Melania Borit, and Petter Olsen, "Representations of Colonialism in Three Popular Modern Board Games: Puerto Rico, Struggle of Empires, and Archipelago," Open Library of Humanities 4 no. 1 (2018): 1-40.

8 "The Women and Men that Lead Games," Best 50 Years in Gaming, 2020, http://best50yearsingaming.com/exhibits/show/runninggames/leadinggames

${ }^{9}$ Paul Booth, "Who's at the Table? Board Game Players and Communities," Meeple Mountain, August 27, 2019, https://www.meeplemountain.com/articles/whos-at-the-table-board-game-players-andcommunities/.

${ }^{10}$ Pobuda, "Assessing." She states: "Media, such as board games, shape our cognition. [... I]f the overwhelming majority of imagery, of the faces we see in board game design, in production, at conventions, in board game stores are white males, the implicit message is that white males are the ingroup, an in-group nurtured and supported by the explicit and implicit messages being shared within the hobby."
} 
also because it allows us to broaden our own horizons. [. . . ] It provides us with opportunities to understand one another in potentially active ways[.]" ${ }^{11}$ Any discernible rise in diverse participation within the hobby has been slow and remains nonrepresentative of the population. This issue extends beyond authorial representation or imagery. ${ }^{12}$ The exclusionary practices in the community also need to address what game designs task players to do and what, ideologically, they endorse.

The modern board game is a medium that allows white male privilege to flourish unchecked. A focus on the formal aspects of these games - narratives, mechanisms, and systems of rewards and goals - highlights how the feats of white men are continually valorized. This endorsement of white privilege and the exclusion of others is rarely explicit nor is it intentional. Privilege and exclusion, instead, operate implicitly, with many designs serving as a metaphorical "welcome mat" for their white male players while simultaneously making others feel diminished and unwelcome. Among the varied ways in which games imply belonging, racial and ethnic identification are of particular interest here. Through the abuse of geographic space, the disparaging representation of nonwhites, and the invisibility and normalization of white dominance as a racialized political structure, modern board games secure and endorse a sense of white privilege that emerges from and constitutes the white dominance of the industry. When considered through this lens, the exclusionary practices within the broader community are in part explained by exclusionary performances within game designs.

\footnotetext{
${ }^{11}$ Carr, Sax, "A Talk About Inclusion in Gaming," Geek \& Sundry, Dec. 16, 2016, https://geekandsundry.com/a-talk-about-inclusion-in-gaming/ 12 Pobuda, "Assessing." More than ninety percent of the top 200 ranked board games on boardgamegeek.com have been designed by white males. She also reflects on the visual dominance of white men in design.
} 


\subsection{DISCIPLINARY APPROACHES}

To best comprehend how formal design elements in games can have implicit and untoward consequences regarding race and ethnicity, this dissertation takes a qualitative interdisciplinary approach under the broad framework of cultural studies. Particularly, within that framework, employing concepts and theoretical principles from ludic studies, media studies, critical race theory, postcolonial theory, and critical geography help to elucidate the implicit signifying practices in board game design that correlate to secure white privilege amongst its dominant demographic of players.

Ludic studies enables an inspection of the formal design choices in games and demonstrates how these conventional elements can have implicit and untoward consequences. While overlap between video and analog games exist, they remain distinct, so elements within ludic studies regarding definitions of games and the roles of narrative and mechanism prove most useful to my analyses. As games are a form of popular media entertainment and highly visual in their presentation, the manifestation of ideological premises in visual media studies helps the analyses demonstrate the problematic use of representation in board games. Critical race theory and its subcategory whiteness studies are useful for showing how representations and assumptions about racial identification manifest in visual forms and social environments. These allow the following analyses to probe the normalization of whiteness and the diminished significance of other races as filtered through white dominated production and consumption. Since board games tend to emphasize an escapist experience that allows players to simulate both historical and fictional events, postcolonial criticism helps to demonstrate the distillation of ethnically, racially, and geographically othered persons down to stereotypical assumptions that are 
filtered and maintained by a white status quo. Lastly, board games often use verisimilar geographical representations in their designs, and these can promote problematic perceptions of distance and otherness. Critical geography offers the analytic tools to investigate how geographic space is represented in board games and what significance emerges from that subjective representation. Together, these disciplinary approaches correlate to reveal varied and complicated ways in which white dominance is generally practiced, secured, and valorized within the medium and the broader community.

\subsection{METHODOLOGY AND RESEARCH FOCUS}

Given the premise that exclusionary practices operating within game designs and within the broader community are implicit and largely unintentional, this dissertation requires an unconventional methodology to reveal these presumptions and attitudes. From a broad perspective, this dissertation treats board games as discursive texts, in that they reveal and constitute ideological premises of a given social context, and as discourse, Michel Foucault's archaeological method proves useful in revealing the underlying ideologies board games both emerge from and constitute. Foucault's sense of archaeology was not to be taken literally. As explained in The Archaeology of Knowledge, the archaeology proposed is not simply an unearthing of cultural practices, although that metaphor is useful, but it is a method of revealing unwritten regulatory practices that allow for cultural expression to occur in the first place. As such, archaeology, as Foucault saw it, was interested in seeing how practices emerged from and constituted regulatory frameworks of knowledge. ${ }^{13}$ In a similar vein the method is used

\footnotetext{
${ }^{13}$ Michel Foucault, The Archaeology of Knowledge and The Discourse on Language (1972, repr. New York: Vintage, 2010): 138-139.
} 
here. Board games are cultural expressions, but instead of understanding what they express or reveal what players and producers 'felt' about a time and place, archaeology allows for us to probe beneath the material elements of production to reveal the ideological principles that underlie the design.

The complicated ways in which board games endorse privilege has required a very diverse array of theoretical concepts. To discuss notions of ideology and hegemony I rely heavily on the work of Antonio Gramsci, Louis Althusser, and Raymond Williams. For concepts of social space I turn to the work of Henri Lefebvre, Edward Soja, and Michel de Certeau, while Frantz Fanon, George Yancy, and Stuart Hall helped me clarify the visual signifiers of racially marked bodies. Finally, my discussion of the structuring principle of whiteness is informed by the work of Charles Mills, Linda Martín Alcoff, and Richard Dyer. While this body of theorists may seem random and diverse, it is actually brought together in the formal and thematic analysis of board games design and justified in the theoretical introduction of each chapter.

A Foucauldian archaeology of board games is achieved through several methodological practices: particularly frame analysis, sociological analyses within textual criticism, and syntagmatic analysis within semiotics. As distilled and packaged forms of entertainment, board games contain intentional messages and meaning for their consumers. As such, frame analysis offers a means of demonstration the process of selection and curation in board game design to translate historical or fictional events into an appreciable game medium. How these meanings interrelate with the consumer and the broader social contexts surrounding production and consumption is important for showing how game designs connect to broader real-world issues, so a sociological 
analysis informed by textual criticism helps to show the connection between game elements and the culture in which they are produced and played. Board games, because of the temporal and narrative constraints on their play space, necessarily abstract elements from the events they simulate, relying heavily instead on signifiers to relay intentional meaning. Because of this, a syntagmatic analysis within semiotics helps to show how these signs within game design contribute to a narrative understanding within the player. Imbedded within this method is the notion of performativity, in which performance acts are read as signifiers within a broader negotiation with normativity and affect. These analyses of signifiers help to show both intentional and unintentional meaning construction within the medium. A collective approach of these methods helps to dismantle the constructed intentionality of board game designs to reveal their unintentional and untoward consequences.

This dissertation focuses on the modern board game medium as its primary locus of inspection. As a subset of broader concepts of play and games, the modern board game requires clarification. Indeed, the modern board game is a distinguishable constituent within the broader concept of board games, which includes traditional abstracts and mass-market games not thoroughly explored here. Board games participate in a broader conceptualization of play and games, which have applicable considerations within arenas of sports, roleplaying, performance, and pretense. Further, games embrace both digital and analog platforms, and even some board game designs have been translated into a digital medium allowing players to interact at distances. For both clarity and brevity, I have chosen to focus on only the analog and social medium of the modern board game. 
The games explored here are finite simulations that utilize both mechanism and narrative and require social face-to-face interaction within the play environment.

Given the complexity of the field, imposing some constraints was necessary in order to carry out this project. Apart from considering only analog media and not their digital counterparts and necessarily constraining the focus to the "modern" category within the broader field of board gaming, I have focused on three interrelated avenues of inspection and analysis. These include Eurocentricity through geographical analyses, racism through representational analyses, and the normativity of whiteness through spatial and representational defaults. These are not the only problematic areas of interest within game designs. Selection and curation are necessary so as to keep the arguments here concise and focused, but this selection and curation is not intended to ignore or delegitimize other avenues toward scrutinizing game design. For example, patriarchal gender roles, toxic masculinity, ableism, ecocriticism, neoliberal economics, and heteronormativity all present as valid avenues toward revealing how board games normalize a very narrow and limited worldview. ${ }^{14}$ Since my primary concern has been how modern board games secure and valorize white privilege both within play and the broader community, I have chosen three avenues of inspection that logically progress toward that goal.

\subsection{CHAPTER OUTLINE}

The central argument that modern board games task players to perform and endorse white dominance and thereby bestow privilege upon the community's dominant

\footnotetext{
${ }^{14}$ This list is not exhaustive and presents here as a sampling rather than a totalizing of possibilities.
} 
demographic relies on several fundamental premises that cannot be taken as truisms.

Those premises are as follows:

1) The formal design conventions of the modern board game require revisions to historically accepted definitions of games.

2) Modern board games present as discursive artifacts that emerge from and constitute ideological premises of the time and space of their production and consumption.

3) The use of geography naturalizes and normalizes power disequilibria between the map's users and the map's subject matter in game play.

4) Semiotic practices regarding racial identities in board games that marginalize and stabilize racially distinct persons.

5) The valorization of white racial identity and whiteness is rendered invisible and universal in game designs.

6) The security of white dominance in board game designs contributes in part to racial, ethnic, and gender exclusionary practices within the community.

These premises require expansion and argument and are explored separately in the following chapters. Structurally, each chapter first situates the argument within the broader theoretical concepts that facilitate the analyses presented before applying those concepts to the case studies.

Chapter One looks at the broad definitions of games and play that have been historically accepted by scholars within game studies. These, however, do not accentuate some of the formal design features of modern board games, so a rubric for games is presented that highlights the design elements of games that will be crucial to understanding the possibilities and constraints afforded by both the materials and marketability of games. In order to better situate what is meant by the "modern" board game, a brief history of board games since World War II is explored. Doing so 
demonstrates what makes the modern board game categorically "modern" and explains two divergent design philosophies that have separately and distinctly emerged.

Chapter Two serves as a methodological chapter wherein a Foucauldian archaeological method is applied to both American and European designs. This method demonstrates that each style addresses the concept of conflict differently and how that understanding of conflict reveals socioculturally distinct ideologies underlying their respective designs. The case studies draw contrasts between both time and space to further show how these design choices evolve in accordance with their cultural contexts.

Chapter Three explores how board games use geographical concepts and representation to marginalize racially and ethnically distinct cultures. The itinerant "silences" of maps, along with their presumed objectivity, stabilize exoticized and pejorative views of others. Consequently, the significance of racially and ethnically distinct others are diminished while the absent presence of white identity is normalized.

Chapter Four inspects the semiotic practices in board games as they relate to minority racial identity. Conceptually, the notion of race is prolific in game design and promotes assumptions that race and racial attributes are both chosen and malleable. Additionally, visual representations of race are distilled to disparaging and stereotypical images that are largely produced and consumed within a homogenous racial identity, promoting a problematic avenue toward identity tourism that deflates the significance of race while eschewing serious conversations about race. What the case studies presented in this chapter ultimately show is that the image of racial minorities is constrained and filtered by white producers and players. This constraint disempowers racial minorities 
while exculpating its white players and producers from the resulting power disequilibrium.

White identity, in contrast to racially and ethnically marked identities, is relatively unremarkable in board game design, presenting as a universalized default of human experience rather than a specific understanding of white experience. Chapter Five explores how white presence in board game design is rendered invisible by its unquestioned inclusion. Spatialized power, consequently, is presented as natural, normal, and part of a broader historical heritage. When this invisible whiteness is compared to the stagnation and marked exoticism of other cultures, the white dominance that board games employ comes into sharper focus. Board games, by design, are a privileged and privileging space for its white consumers.

Chapter Six incorporates the arguments of the preceding chapters to better understand the broader board game community_-its demographics as well as its inclusionary and exclusionary practices. What this chapter finds is that the semiotic performative practices within board games are similar to the exclusionary practices within the community. Players who feel rejected and unwelcome in the hobby attest to implicit gestures that bar them from enjoying the hobby. By contrast, white (and by extension male) players are unconditionally welcomed into the hobby. The symbolic violence within the community assuredly emerges from a variety of sources, but given the correlation to symbolic violence employed within game design, we can say the white dominance players are tasked to perform in part contributes to this exclusion. 


\title{
CHAPTER I
}

\section{THE STATE OF PLAY: A RUBRIC AND HISTORY FOR THE}

\author{
MODERN BOARD GAME
}

Games described as "Euro" typically focus their design on innovative and intuitive mechanics, then develop a theme that fits-an approach more common in European releases. "Ameritrash" design tends to focus on theme first, then it uses gameplay and mechanics as a vehicle to express the narrative-an approach more common in American games.

Board games, generally, comprise an expansive history not only temporally but spatially. Games designed in Germany are distinct in play and aesthetic from games designed in America, so parameters for the forthcoming analyses are necessary. To best focus the forthcoming arguments, this dissertation centers on modern board game designs from Europe and America, but this focus raises questions: what makes a board game “modern," what makes a modern game different from traditional or mass-market games, and how and why are American and European designs so significantly different? This chapter addresses these questions to create a common understanding of modern board games. To do so requires an understanding of what games are and do-a rubric for games - as well as a brief history of the modern board game.

\footnotetext{
${ }^{15}$ Mike Mihealsick, "Eurogames Vs. Ameritrash: What's the Difference?" Board Game Resource, Apr. 28,
} 2016, https://www.boardgameresource.com/eurogames-vs-ameritrash/ 
Given the broader purpose of this dissertation to unearth how board games simulate, endorse, and secure dominant worldviews and disparaging presumptions of those who do not identify as the dominant board game consumer, it is important to note how game designs compare to others within the industry and to observe the differing motivations of players and designers. Form, presentation, and intended experience differ greatly amongst modern board games, and these attributes function to highlight or conceal the ideological apparatus undergirding the design. Understanding the differing characteristics of the current state of play is necessary to observe the varied ways ideological perspectives are employed through design. Therefore, the rubric and history provided here paves the way for games to be analyzed for their sociocultural politics, politics of representation, and selective negotiations with real-world events.

\subsection{GAMES, PLAY, AND THE ORDINARY: TOWARD A DEFINITION OF GAMES}

Creating common ground for what games are and how modern board games negotiate those definitions is essential prior to observing the entanglements between ideologies and design. A rubric for gameplay is necessary to clarify the tools of analysis that will be used on games themselves as well as real-world aspects that constrain design. There is no standard definition of games that theorists have agreed upon, and prevalent definitions that have arisen within the literature unsatisfactorily apply to the modern board game. Largely missing from these definitions of gameplay is how simulated events are necessarily curated and distilled down to "essential" or "important" qualities while leaving other attributes as abstract and presumably negligible. Further, the manner in

which games utilize mechanical— that is, the game elements that progress play toward its 
conclusion - and narrative elements together to create a play experience is largely overlooked and deserves to be highlighted. Negotiating past theoretical concepts of games and putting forth a pragmatic rubric for board game play will bound the parameters of the forthcoming analyses.

In his 1969 book, A Gamut of Games, American game designer Sid Sackson describes a very simple game. It is a party game called The No Game ${ }^{16}$. During The No Game, the host of a party distributes ribbons and instructs that guests should wear them throughout the party's game. The aim of the game is simple: By a specified time, be the player to have acquired the most ribbons. The player who does so wins a prize. You acquire ribbons by provoking another guest to say the word 'no.' Other variations of the word, like 'nah' or 'absolutely not' or a slap in the face, ${ }^{17}$ are all allowed. Only the word 'no' is forbidden. If the guest says the forbidden word, he or she relinquishes the ribbon to the other player, and whoever acquires the most by the end of the specified time wins the game.

Questions arise: Is this a game or simply a playful activity or icebreaker? What is the difference between a game, play, and ordinary real-world experience? To some, the lack of materials and the free-form mechanisms of play may contradict The No Game as a game. Indeed, there is no board to focus upon. In order to best address this disparity between games, play and context, it is necessary to explore the different approaches to games. A substantial body of scholarly work has been devoted to the definition of gameplay, from Johan Huizinga's seminal work Homo Ludens, which posited that culture

\footnotetext{
${ }^{16}$ Sid Sackson, “The No Game," A Gamut of Games, (1969, repr. Mineola, NY: Dover, 2011): 184-185.

${ }^{17}$ Sackson, 185.
} 
and the ordinary are distinct and separate from play, ${ }^{18}$ to game theorists writing today. In this dissertation, games are defined as a rule-based, goal-oriented, voluntary experience that is a subset of play and competition, through which players are offered a state of play that can be manipulated as well as space for making choices that are systematized into varying degrees of reward, which facilitate an assessable disequilibrium among players for determining the attainment of said goals. Further, games negotiate the boundaries between play and ordinary experience in often complex ways. As examining previous definitions of games and play will demonstrate, this definition builds upon preceding definitions while also diverging from those definitions.

In Homo Ludens (1949), Huizinga defines play as

a free activity standing quite consciously outside 'ordinary' life as being 'not serious', but at the same absorbing the player intensely and utterly. It is an activity connected with no material interest, and no profit can be gained by it. It proceeds within its own proper boundaries of time and space according to fixed rules and in an orderly manner. It promotes the formation of social groupings which tend to surround themselves with secrecy and to stress their difference from the common world by disguise or other means. ${ }^{19}$

Huizinga's five characteristics of play-i.e. that play is voluntary, not real, separated from the real world, ordered by rules, and offers no material gain — have set the groundwork for subsequent arguments of game play. The vision of play Huizinga offers specifically demarcates play from physiological necessity or real-world consequence while simultaneously being a facet of cultural reproduction. In other words, rather than simply culture informing play, play manifests through ritualistic performances of

\footnotetext{
18 Johan Huizinga, Homo Ludens : A Study of the Play-Element in Culture, (1949, repr. Kettering, $\mathrm{OH}$ : Angelico Press, 2016), 8.

${ }^{19}$ Huizinga, 13.
} 
culture. ${ }^{20}$ Huizinga suggests that in "play there is something 'at play' which transcends the immediate needs of life and imparts meaning to the action. All play means something." ${ }^{21}$ Reality offers a framework for play without the real-world consequences of exercising the possibilities of that activity. Examples abound to affirm Huizinga's definition, such as the mass-market game Battleship $(1931,1967)$ wherein players simulate a naval battle, commanding a fleet of ships while firing upon an obscured enemy. While the simulation of naval warfare is extracted from reality, the play space avoids the real-world consequences of that event. While this notion of play clarifies the separation of the game state from the ordinary, a division that has been subsequently understood as the "magic circle,"22 Huizinga's assertion that play manifests and informs cultural rituals underestimates cultural influence on play and real-world consequences of play. Game theorists have contended against Huizinga's argument that there is no material gain in play.

Roger Caillois, for one, disagrees with Huizinga's claim, suggesting that Huizinga's definition of play neglected gambling activities, that play in certain manifestations "is designed to be extremely lucrative or ruinous." ${ }^{23}$ Caillois offers the correction that there is material gain, but games are definitively unproductive: that is, "Property is exchanged, but not goods are produced. ${ }^{24 "}$ Caillois offers six characteristics

\footnotetext{
${ }^{20}$ Huizinga, 46.

${ }^{21}$ Huizinga, 1.

${ }^{22}$ Cf. Eric Zimmerman, "Jerked Around by the Magic Circle - Clearing the Air Ten Years Later," (web blog), gamasutra.com (Feb. 7, 2012), https://www.gamasutra.com/view/feature/135063/ jerked_around_by_the_magic_circle_php. While the notion of the magic circle is commonly attributed to Huizinga, the term originates from an interpretation of Huizinga's work. Huizinga never explicitly characterized play as a magic circle; instead, the magic circle was an example of the demarcation of play from reality. ${ }^{23}$ Roger Caillois, Man, Play, and Games, trans. Meyer Barash (1958, repr. Chicago: University of Illinois Press, 2001), 5.

${ }^{24}$ Caillois, 5.
} 
of games, suggesting games are voluntary, have a fixed separation from the ordinary in both time and space, contain outcomes that cannot be determined beforehand, unproductive, governed by a rules set that momentarily suspends ordinary laws, and players agree that the reality of the game space is separate from the ordinary ${ }^{25}$.

Caillois also suggests that games can be analyzed through four different rubrics, what he terms agon, alea, mimicry, and ilinx. Agon represents games of competition "in which equality of chances is artificially created, in order that the adversaries should confront each other under ideal conditions ${ }^{926}$ while alea represents games of chance such as lotteries, slots machines, or dice. Mimicry would best be understood as acting, performance, and role-playing, and ilinx would best be understood as a self-inclined attempt to momentarily disrupt "the stability of perception" in favor of a sense of disturbance or vertigo. ${ }^{27}$ Through these four categories of games, Caillois notes these forms of play can be situated on a continuum between unstructured, spontaneous, and playful activities (paidia) and the rule-governed structure of games (ludus). ${ }^{28}$

The popular games Chess (circa 1475) ${ }^{29}$ and Dungeons \& Dragons (1974) exemplify the continuum Caillois puts forth. a game like Chess would attract a certain player for its attentiveness to equalizing competition while eschewing the role of chance. In Caillois' framework, Chess would fall under the category of agon and lean toward the ludic pole on the continuum between play and games. However, a role-playing game

\footnotetext{
${ }^{25}$ Caillois, 9-10.

${ }^{26}$ Caillois, 14.

${ }^{27}$ Caillois, 23.

${ }^{28}$ Caillois, 13.

${ }^{29}$ Cf. David Hooper and Kenneth Whyld, The Oxford Companion to Chess, $2^{\text {nd }}$ ed. (New York: Oxford University Press, 1992), 173-175. The history of Chess dates back to the $2^{\text {nd }}$ through $6^{\text {th }}$ Century C.E. but I use 1475 , since the significant modifications to token movement closely resemble the modern rules used today.
} 
such as Dungeons \& Dragons would offer players opportunity to engage with mimicry as well as luck. Role-playing games, with their open world explorations and numerous ways to manipulate the play space, would lean more heavily toward what Caillois calls paidia, save for the spontaneity itinerant to that extremity. Caillois' assertion of a continuum of play proves useful for board game analyses in that it allows for mechanically-focused games to be analyzed alongside thematically-focused games.

The point of contention that arises when addressing Caillois' typology is the escapist notion Caillois implies when characterizing games as make-believe. By this he means that players enter the play space acknowledging that the laws regulating the game need not reflect those of reality and that a "second reality" 30 may emerge as a result of play. Drinking an invisibility potion in a role-playing game, for instance, adheres to the game's second reality—i.e. the played character becomes invisible_-distinct from the primary reality - i.e. invisibility potions do not exist. But the emphasis on separate or even second realities risks problematic assumptions that game effects are innocuous to the real world. Rather, the game state can have both beneficial and detrimental real-world consequences for the players involved.

The presumption that games offer a means of escape from the ordinary or reality is common. ${ }^{31}$ Numerous examples support this assumption: King of Tokyo (2011) is a Kaiju-inspired king-of-the-hill game where players combat others until only one player remains, and players attempt to save the world from disease in Pandemic (2008), but escapism requires clarification. As Caillois has suggested, games are "nearly always

\footnotetext{
${ }^{30}$ Caillois, 10.

${ }^{31}$ Cf. John Tynes, "Prismatic Play: Games as Windows on the Real World," Electronicbookreview (Mar. 26, 2008), https://electronicbookreview.com/essay/prismatic-play-games-as-windows-on-the-real-world/
} 
spectacular or ostentatious," but "nearly" should be emphasized. ${ }^{32}$ There are games that simulate the gravity of annihilation while there are also games that explore themes many might associate with the banal or labor-intensive. For instance, players can simulate farming in Agricola (2007), coal mining in Coal Baron (2013) or Haspelknecht (2015), and even establishing postal service routes in Thurn and Taxis (2006). The escapist assumption offers a convenient concretization of boundaries between reality and play, but it risks misleading how incompletely this boundary divides the two and consequently paints gameplay narratives as irrelevant to real-world issues. The means by which games negotiate reality has gained interest among contemporary game theorists.

Video game scholar Ian Bogost, for one, has emphasized the rhetorical power of gameplay. In his Persuasive Games, he suggests an understanding of games through what he terms a "procedural rhetoric." 33 This terminology, he suggests, amounts to a "practice of using processes persuasively[ ... .]"34 Asserting that games are a form of "procedural rhetoric" allows for games to be understood not only from a visual media framework but also as an interactive medium, one that allows players to make choices and follow through with systematized plans. As such, the interactive procedures itinerant to games can reveal qualities about ideology. ${ }^{35}$ What can and cannot be accomplished is constrained by rules and interactions as well as what should and should not be done. In effect, games then offer a platform for the effective expression of ideas, whether moral, political, or otherwise. While Bogost's claims are restricted to videogame analyses, his assertions are applicable to board games as well, as can be seen in such examples as The

\footnotetext{
${ }^{32}$ Caillois, 4.

${ }^{33}$ lan Bogost, Persuasive Games: The Expressive Power of Videogames (Cambridge: MIT Press, 2007), ix.

${ }^{34}$ Bogost, 28.

${ }^{35}$ Bogost, 3.
} 
Game of Life. Therein, the player's ability to navigate the game's possibilities are suggestive of real-world attitudes toward such facets of life as education, the workplace, family, and wealth. What is valued is rewarded, and what is not valued within the ideology of the game frustrates a player's progress.

Implicit in Bogost's assertion about the persuasive power of videogames is the ability for games to have real-world effects. This is not exclusive to Bogost, as others within videogame studies have made similar assertions. Jesper Juul, for one, has posited a revised definition of games utilizing six fundamental features. For him, a game "is a rulebased system with a variable and quantifiable outcome, where different outcomes are assigned different values, the player exerts effort in order to influence the outcome, the player feels emotionally attached to the outcome," and games can be played "with or without real-life consequences." ${ }^{36}$ As a result, games for Juul can be observed for formal qualities - as systems of rules and obstacles - interactive qualities — how players relate to the facilitation of play—and contextual or supra-game qualities—how players position play in relation to real-world consequences. While's Juul's model for games is useful in that it demonstrates the multi-tiered ways in which players negotiate and relate to the play space, it emphasizes that real-world consequences are activated by player choice. ${ }^{37}$ Players choose to activate real-world stakes, such as betting. What makes Ian Bogost's assertion more useful here is that the notion of procedural rhetoric implies that the persuasive elements of game design need not rise to the level of conscious awareness to maintain effectiveness.

\footnotetext{
${ }^{36}$ Jesper Juul, Half-Real: Video Games between Real Rules and Fictional Worlds (Cambridge, MIT Press, 2011), 36.

${ }^{37}$ Juul, Half-Real, 41.
} 
These definitions and frameworks for understanding gameplay are useful in many ways to understanding modern board games, but they fall short in encapsulating some of the nuanced experiences of playing modern board games. For instance, the relationship between a game's mechanisms and narrative is de-emphasized here but is central to board game play. Further, since games simulate reality in some way, it is important to emphasize that games necessarily abstract qualities of the reality being simulated for the sake of gameplay. For instance, games can and do simulate societal progression over hundreds and thousands of years, but it is implausible for a game simulation of that event to take a comparable amount of time. Reality is necessarily curated for the concision of game play. Therefore, in order to obtain a pragmatic definition of games for the analyses that will follow, an updated rubric is necessary.

I offer here a ten-part rubric that characterizes the modern board game. ${ }^{38}$ Largely building on the preceding notions of gameplay, this rubric combines those important characteristics with attributes that deserve emphasis. As a result, this pragmatic rubric offers a conceptual foundation for what games are, what games do, and how players relate to the game space that is critical to the forthcoming analyses. To elaborate, games

1) Are voluntary. Players agree to submit to the game. This does not suggest external pressures to play are nonexistent, but choosing to play is up to the players.

2) Are a subset of play and/or competition but are not synonymous with the two.

\footnotetext{
${ }^{38}$ The modern board game is a category of gaming that participates within a broader spectrum of play and games, including but not limited to roleplaying, sports, make-believe, and both digital and analog platforms of games. Because of this far-reaching complexity and application of what a game is and what it means to play, this rubric focuses on the modern board game to highlight crucial aspects of the medium that may be overlooked in general definitions of games and play. While this rubric may be applicable to other aspects of gaming, its application is focused on the material, and thereby social, form of the modern board game.
} 
3) Are rule-based. The boundaries of allowances and performance are constrained by a set of rules separating games from other games and from ordinary experience.

4) Necessarily abstract the events being simulated. Games distill qualities of events, actions, time, and stories down to aspects deemed important to the simulation.

5) Offer space for player choices. ${ }^{39}$ Players should, in other words, feel they have room to explore options of varying outcomes rather than feel their experience is scripted to constrain those choices.

6) Systematize choices into varying degrees of reward. These may include the absence of reward and in-game punishment as a result, as well.

7) Valorize a specified set of goals. ${ }^{40}$ Winning, for example, is a common preferable outcome, however defined by the rules, and at times smaller goals are desirable to facilitate larger goals.

8) Change game states to present an assessible disequilibrium among players in the final game state. In other words, the initial setup of the game is distinct from the final presentation, and players have manipulated the game state over the course of the game to achieve a verifiable disequilibrium at game end.

9) Negotiate the boundary between the play space and the ordinary in complex, often subtle ways. The game is separate from the ordinary experience, but this separation is not complete or impermeable. Games interact with the worlds they separate from in ways that elucidate cultural, moral, and material values, as well as ideological distinctions.

10) Operate on a spectrum between mechanism and narrative on what I call a ludonarrative gradient. Games will present as a negotiation of mechanisms and theme, often favoring one end of the spectrum without completely divorcing from the other.

\footnotetext{
${ }^{39}$ This assertion focuses on in-game choice rather than the choice to play a game, as described by item one. The room for players to exercise choice is largely characteristic of games but is not absolute. A rare example of a game exhibiting no in-game choice for the player would be Chutes and Ladders (1943). Players progress along a prescribed track according to the value given by an in-game randomizer. Once landing upon a space, players follow the benefits or repercussions of landing there. As such, Chutes and Ladders presents less as a game, as I and others would describe them, and more as a didactic moral activity. Anomalies such as this are so rare as to be considered negligible for the overall argument regarding games.

40 "Goals" is used rather loosely here. Following Juul (p. 35) that goals need not be explicitly addressed in the game state-as the videogame The Sims exemplifies-the player has a goal in interacting with the game-that is, to achieve entertaining or beneficial results from doing something.
} 
Demarcated from preceding definitions, this rubric emphasizes the relationship between gameplay and reality as well as the relationship between the mechanisms that facilitate play and the narrative being revealed through play. The term ludonarrative gradient is informed by Caillois' continuum of games between pretense (paidia) and mechanics (ludus), but it is not exclusively informed by it. In video game studies, two critical camps have emerged as dominant avenues toward scrutinizing gameplay, one emphasizing the mechanical systems of play and the other seeing video games as a natural evolution of narratology. ${ }^{41}$ While the division has been largely amicable, the two camps have been historically disconnected from one another, and critics have suggested that understanding how these two critical lenses cooperate with one another is central to understanding the appeal of games as a human activity. While this disparity between mechanical and narrative understandings of games is prevalent within the board game community, the debates that emerge are polarized and at times volatile. ${ }^{42}$ Rather than inspecting games as wholly one or the other, the notion of a ludonarrative gradient suggests that games negotiate both game interests to varying degrees between both poles without being completely absent of the other.

Another point of emphasis in this rubric is that games necessarily abstract elements of the events they simulate. This may be implied in games by definition, but I wanted to underscore its importance. When combined with the ludonarrative gradient, the

\footnotetext{
${ }^{41}$ Cf. Matthew Wilhelm Kapell, "The Ludic and Narrative as Dialectic About 'What Games Do,'” introduction to The Play Versus Story Divide in Game Studies: Critical Essays, ed. Matthew Wilhelm Kapell (Jefferson, NC: McFarland, 2016), 1-15.

${ }^{42}$ Cf. "AmeriTrash Vs. EuroGame: Are They Just Names for Genres, or Fact?" Boardgamegeek.com (Apr. 25, 2012), https://boardgamegeek.com/blogpost/9913/ameritrash-vs-eurogame-are-they-just-namesgenres. While the initial post refrains from intentional volatility, the comments and replies quickly turn abrasive and polarized.
} 
abstracted omissions prove telling about how players should and do relate with the game state. By curating the events for gameplay simulation, the designer and consumer highlight what should be deemed as important versus negligible. In a comparable manner, the degree by which a game aspires for players to focus on the mechanisms of play conversely draws attention away from the narrative, and vice versa. As a result, these abstractions and the game's position on the ludonarrative gradient work to reveal and conceal associations between the game state and reality.

Returning to The No Game exemplifies these parameters. In The No Game, players willingly enter into the play space, presumably having the choice of not playing. The No Game is rules-based, though those rules are few and simple: players attempt to elicit others to say 'no' and those who do relinquish their ribbon to the provoking player. The game provides space for players to make choices for possible reward (gaining ribbons) or punishment (handing over ribbons). Achieving the goal of most ribbons wins the game, which both valorizes the goal while presenting an assessable disequilibrium to gauge player performance. Players begin with equal access to the game-winning condition, but as the game progresses, the play space is manipulated as the number of ribbons each player holds changes. And the boundaries between the ordinary and the game space are incomplete. Focusing on social interaction rather than material mechanisms of play, foreknowledge of other players or topics outside of the game space, what is commonly referred to as a metagame, ${ }^{43}$ may afford players with advantages and disadvantages. Players may utilize their knowledge of another's attitudes and feelings to

\footnotetext{
${ }^{43}$ Cf. "What Does Metagame Mean?" (web blog) boardgamegeek.com (Feb. 11, 2008),
} https://boardgamegeek.com/thread/292324/what-does-metagame-mean 
inspire a "no" when others might prove more resilient. In this sense, the boundary between reality and play becomes blurred.

\subsection{A BRIEF HISTORY OF THE MODERN BOARD GAME ${ }^{44}$}

Two distinct styles of play have emerged as dominant in modern game design: the Eurogame, which is more mechanically focused, and the American-style game, which is more confrontational and narrative-focused. The disparity of these game styles alone is insufficient for understanding why modern board games present in the manner they do. To best understand how these design philosophies diverge from one another, a brief history of board gaming leading to the modern era is necessary. Important events in history have shaped how board games are both designed and consumed, and those events require attention.

Outside traditional abstract games like Chess (circa 1475) and Go (circa 2200 $\mathrm{BCE}$ ) and gambling games involving dice, the twentieth-century board game along the likes of Monopoly and Clue has roots in the industrial revolution, booming with mass production in the $1800 \mathrm{~s}^{45}$. Germany and the U.S. were prolific producers of these games, with such powerhouse publishers as Parker Brothers and Milton Bradley in the U.S. and Ravensburger in Germany. The surviving majority of these games resemble our contemporary mass-market games, designed initially for children's play. As historian

\footnotetext{
${ }^{44}$ Assuredly, a history of the modern board game would be an extensive text in and of itself. My intent here is to provide a foundation for arguments regarding mechanisms, narrative, and conflict. A more comprehensive history can be found elsewhere in Stewart Woods' Eurogames: The Design, Culture and Play of Modern European Board Games, and this discussion leans heavily upon Woods' extensive mining of that history. ${ }^{45}$ Stewart Woods, Eurogames: The Design, Culture and Play of Modern European Board Games (Jefferson, NC: McFarland, 2012), 48.
} 
David Hamlin has noted, mass-produced toys of this ilk were didactic, in that they "allowed [children] to be children but simultaneously [children] were to be educated to be good middle-class citizens. ${ }^{46 "}$ This didacticism can be found in American board games from the late 1800 s into the $20^{\text {th }}$ century. The mass-produced Chutes and Ladders (1943), for instance, builds on similar Snakes and Ladders designs from Britain and India as well as Milton Bradley's The Checkered Game of Life (1860), encouraging entertainment while also "teaching consequences of good and naughty deeds." 47 Mechanically, the games of this era are similar; players use a movement randomizer, e.g. dice, and if provided, perform actions of the reached space.

It is not until after World War II that mechanics and themes in board games internationally begin to diverge. While both the U.S. and Germany were producing warthemed games during the war, exemplified by Conflict released by Parker Brothers in 1940 and the simulation of Germany's surrounding of England in Wir Fahren Gegen Engeland (1940), after the war, games emphasizing combat and war shrank in popularity in Germany. The U.S. continued to produce games emphasizing conflict—from Tactics (1954) to popularizing the French-designed Risk in 1959—while continuing to publish family style games such as Clue (1944), Scrabble (1948) and the ever-popular Monopoly (1933).

However, the strategic war-themed games produced in the U.S developed into a hobby gaming community ${ }^{48}$. In 1958, the game publisher Avalon Hill produced its first

\footnotetext{
${ }^{46}$ David Hamlin, "The Structures of Toy Consumption: Bourgeois Domesticity and Demand for Toys in Nineteenth-Century Germany, Journal of Social History 36 no. 4 (1999): 859.

47 Suzanne Slesin, “Currents: At 50, Still Climbing, Still Sliding," New York Times, July 15, 1993, https://www.nytimes.com/1993/07/15/garden/currents-at-50-still-climbing-still-sliding.html 48 Woods, 22.
} 
game under that company name, Tactics II, a revised version of Tactics. Tactics II established the standards for the non-electronic war-themed board game, with hexagonal grids, stacked units (chits), and a complex Combat Resolution Table (CRT) that measured the success or failure of attempted actions. In 1959, Diplomacy further complicated war-themed board games by simplifying and de-emphasizing combat in favor of diplomatic negotiations; integrating an open-form discussion of strategies, tactics, and alliances that could be upheld or betrayed; and by instituting a simultaneous action phase wherein players choose their actions secretly before revealing. The warthemed hobby board game industry continued to produce successful titles in the U.S. (e.g. Squad Leader, 1977, Combat Commander, 1978) while combat simulations diminished in postwar Germany.

What is generally thought of as the German game or the Eurogame has roots in neither Germany nor Europe more generally. Rather, the American designers Alex Rudolph and Sid Sackson, commissioned by the Minnesota Mining and Manufacturing Company (or 3M), became the catalyst for a new style of board game. Their work, according to Stewart Woods, "marked a significant turning point in the history of board games[.]"49 Standing out from these early designs was Sid Sackson's Acquire (1964) ${ }^{50}$, a strategic marketing game where players invest in and grow businesses while trying to hold the majority of stock in an effort to acquire the greatest wealth by the game's end. The rules were relatively simple, and the play time was under two hours, comparable to

\footnotetext{
${ }^{49}$ Woods, 33.

${ }^{50}$ Cf. Joe Huber, "How Acquire Became Acquire," OpinionatedGamers, blog, May 29, 2014, https://opinionatedgamers.com/2014/05/29/how-acquire-became-acquire/. There is some debate regarding the publication date of Acquire. The original box art states a copyright of 1962, and this error has been repeated in other publications, such as Woods' Eurogames. This challenges other publications and accounts that state the publication as 1964, including Sid Sackson's diaries.
} 
family-style games like Clue and Monopoly rather than war games like Risk, Tactics II, or Diplomacy, which could take several hours to complete.

Game design in Germany between 1945 through the mid-1960s, prior to 3M's innovative releases, was relatively muted. Although board games were still a staple to family tradition in Germany, ${ }^{51}$ the fare released throughout these years were similar to mass-market titles and abstracts popular in the U.S. The wargaming hobby market did not pick up the same interest in Germany as it had in the U.S., and present-day German designers are not surprised. Prolific board game designer Reiner Knizia notes that "Germany is extremely critical towards war games. That comes from the history and the experiences of the Second World War. The majority of people, the family game culture, doesn't really like to play war games. It's modern fairy tales they want to play. ${ }^{52}$ ",

This proclivity toward abstracts and casual games changed, however, in 1966, when 3M began marketing games in Europe, including Sackson's Acquire. The 3M designs were appealing for their simple rule sets and confined play time, as opposed to war-themed games, and "Acquire has . . . been recognized as the seed" of what would eventually be called the German game ${ }^{53}$. As David Shapiro has noted: "The significance and impact of Acquire cannot be overstated. It was the first of what 40 years later would be deemed German style games [....] Sid Sackson was the founding father of the

\footnotetext{
${ }^{51}$ Tim Harford, "Why We Still Love Board Games," FTMagazine, July 16, 2010, https://www.ft.com/ content/1aab09a4-8fb2-11df-8df0-00144feab49a

${ }^{52}$ Stephen Glenn, "Interview with Reiner Knizia-Fall 2002", http://www.convivium.org.uk/kgfgi, quoted in Stewart Woods, Eurogames: The Design, Culture and Play of Modern European Board Games (Jefferson, NC: McFarland, 2012), 56.

${ }^{53}$ Woods, 34.
} 
German style game. ${ }^{54 "}$ And by the late 1960s, German media such as Die Zeit were including game reviews in their publications.

One of the major watershed moments in board gaming occurred in Germany in the late 1970s when a group of German critics established an award for excellence in board gaming design. In 1978, the first Spiel des Jahres (Game of the Year) was awarded to Hare \& Tortoise (1973). Specific criteria were established for games to qualify for the award that included innovation, clarity of rules, appropriate for families, and a concise playing time ${ }^{55}$. but winning titles may pay a fee to include the award logo on promotional materials of the game, but the award has no other monetary compensation. Despite this, games nominated for the Spiel des Jahres can expect sales to increase by tenfold and in some cases more ${ }^{56}$. The Spiel des Jahres winners Carcassonne (2000) and Ticket to Ride (2004) boast sales in the millions and the most popular Spiel des Jahres winner, The Settlers of Catan, as of 2014, had sold over eighteen million copies in several different languages ${ }^{57}$. Although other awards exist, the prestige surrounding the Spiel des Jahres has made it one of the most coveted of board game awards. Given the award's prestige and lucrative possibilities, designers from the late 1970s to today have been experimenting with innovative designs aimed at families as they attempt to gain the prize.

\footnotetext{
54 David Shapiro, "To Boldly Go. . .", The Games Journal, August 2003, http://www.thegamesjournal.com/ articles/ToBoldlyGo.shtml

${ }^{55}$ Woods, 51. See also the Spiel des Jahres official website at http://www.spiel-desjahres.com/cms/front_content.php?idcat=123\&changelang=4.

56 Tom Werneck, "The Impact of the Award "Spiel des Jahres" on the Development of the Board Games Market in Germany," vilaweb, n.d., https://www.vilaweb.cat/media/continguts/000/055/359/359.pdf. Werneck is one of the co-founders of the award and has served as a jury member of the award, ${ }^{57}$ Adrienne Raphel, "The Man Who Built Catan," The New Yorker, February 12, 2014, https:// www.newyorker.com/business/currency/the-man-who-built-catan
} 
As the award continued to boost sales and attract designers toward its criteria, designers became more recognized for their efforts in creating innovative and streamlined game designs. As Woods has suggested, the Spiel des Jahres is in part responsible for the board gaming hobby moving away from a publisher's medium toward a designer's medium $^{58}$. In recent years, the name of the designer is prominently displayed near the game's title on most modern board game box art. Prolific designers such as Klaus Teuber, Wolfgang Kramer, and Reiner Knizia would become household names in the board gaming community, and many would leave their main careers to become full-time game designers. ${ }^{59}$.

The prominent production and consumption of these games in Germany, along with the reshaping of the industry done in part by the Spiel des Jahres, popularized the new style in what would become known as the 'German game' for many years. These games were different than the hobby board games emerging from the United States. These games featured precise rules, a confined play time, and conflict emerged only through indirect confrontations with other players. Carcassonne (2000) exemplifies this style well. In the base game, two to five players build the city of Carcassonne and its surrounding area by drawing a playing tiles. The initial game state is only one tile in size, roughly three centimeters square, and the rest of the 'board' is built slowly over several turns. Each tile consists of one or more landscape features, such as a road, a monastery, a castle, or a field. When placing new tiles, players must continue a feature from the existing 'board'-i.e. a road must be placed next to a road, a river to river, a castle space

\footnotetext{
58 Woods, 52.

${ }^{59}$ Raphel, "Catan." Interestingly, before he designed Settlers of Catan and became the managing director of the multi-million-dollar company Catan $\mathrm{GmbH}$, Klaus Teuber worked as a dental technician, designing games in his off-time.
} 
to castle space, and so forth. Players score points by placing one of their wooden player tokens on a feature, and in most cases, when a feature is completed-e.g. a castle area is completely surrounded by walls - the token returns to the player's supply for future use and scores points. The game ends when the last 'board' tile has been placed. The highest scoring player wins. The minimal confrontation between players exists in frustrating players' plans by placing tiles adjacent to their claimed feature in such a way that would make the feature difficult or impossible to complete, making the dynamics of play different than the confrontational games being produced in the United States.

While Acquire is noted as providing the seeds of inspiration that would bring about this new style of game, the United States did not follow in the same path despite Acquire's publication in both countries. Much of this can be attributed to the Spiel des Jahres, but some disparity can also be attributed to the different cultural attitudes toward games in the different countries. In Germany, games are a family tradition, and the country sparks interest in its board gaming market through published criticism of games as well as radio shows that feature board game commentary. The country also hosts the world's largest games fair each year in Essen, Germany. In the U.S., apart from a niche hobby market of adult-targeted games, most games produced are aimed to attract children with simple mechanics and short demonstrations of play. As game critic Tom Werneck noted in 2008, "In the U.S. there is no culture of game critics and you will hardly find a game retailer who knows what's in the boxes [as opposed to Germany]. Market communication in the U.S. is done in a different way: TV. Since it is almost impossible to explain a complex game" in a common televised advertising timeframe "major producers in the states focus on games which have either a very simple structure which 
can be demonstrated in a few seconds or they must include a sort of mechanic which can be shown on TV. ${ }^{60 "}$ While this argument conjures remembered television spots for games like Mouse Trap (1963), Operation (1965), Fireball Island (1986), it also suggests that the gaming industry in the United States has been historically divided into a niche community of strategy gamers on one side and a prevalent mass-market gaming market aimed toward children and adolescents on the other. Television has cultivated the imaginary amongst many American consumers that board games are for children ${ }^{61}$ or for families with children ${ }^{62}$ while also frustrating the potential growth of a hobby gaming market.

This does not mean the small hobby market in the U.S. did not continue to grow and evolve in innovative ways. In contrast to the innovative mechanics and rule structures of German designs, the innovations in the United States would seek different ways of facilitating a narrative experience, handling player interaction, and addressing player elimination. A few more watershed moments in American game design should be noted. The first is Dungeons and Dragons (1974, commonly referred to as D\&D). Although not typically considered a 'board' game, the tabletop Role Playing Game (RPG), developed by wargaming hobbyists Gary Gygax and Dave Arneson, would inspire later board games. Distinct from the war games Gygax and Arneson played previously, $D \& D$ offered players control over a specific character with characteristics and traits. Facilitated by a

\footnotetext{
${ }^{60}$ Quoted in Woods, 59.

61 Woods, 1.

${ }^{62}$ Cf. Gwen Dewar, “Board Games for Kids: Can They Teach Critical Thinking?”, Parenting Science, November 2012, https://www.parentingscience.com/board-games-for-kids.html. This, like Megan Zander, "The Surprising Benefits Your Kids Get from Board Games" (Nov. 22, 2019) on Scholastic.com perpetuate the myth that board games are intrinsically designed for children or for children's development. Any mention of the family is as a facilitating medium for childhood development. The games discussed are Monopoly, Clue, Chess, and Mastermind.
} 
Dungeon Master, who moderates the game's play space, the group of adventurers use their imaginations to embark on adventures involving environmental perils, encountered character dilemmas, and treasures discovered in enemy-infested dungeons. The gameplay also offered players a chance to earn experience points (or XP) which could be used to improve a character's abilities and traits. Although this distillation does not do service to the overall complexity of the game, the fundamental principles behind the game's design illustrate the breadth of $D \& D$ 's influence on later games. The fantasy-themed characters and interactions, the varied player abilities, the experience-building system, and the simple conflict resolution afforded by the game's die-rolling system can be seen in American designs from the late 1970s to present day. The influences of D\&D can be seen in popular board game titles such as Talisman (1983) and HeroQuest (1989).

Other innovations to American game mechanics would follow. In 1977, for instance, Cosmic Encounter would be published as what its designers called the anti$R i s k^{63}$. Frustrated by long play times and player elimination in games like Risk, designers Bill Eberle, Jack Kittredge, Bill Norton, and Peter Olotka set out to create a game experience that would capture the confrontational essence of Risk and other war games but do so in a shorter play time and without player elimination. Cosmic Encounter features dozens of unique alien race avatars, each with a specific ability that 'broke' the game's core rules. Players begin the game as one of these alien races commanding numerous spaceships. The goal of the game is for one or more players to establish colonies on foreign planets. Using a randomized deck of cards, the game chooses which

\footnotetext{
${ }^{63}$ Rick Lane, "The Making of Cosmic Encounter, the Greatest Boardgame in the Galaxy", Eurogamer.net, June 3, 2016, http://www.eurogamer.net/articles/2016-03-06-the-making-of-cosmic-encounter-thegreatest-boardgame-in-the-galaxy
} 
player each player will encounter, and that offensive player may open negotiations or a threat of attack. Both offensive and defensive players may ask for allied help from other players, who benefit if their side of the encounter is successful. Using cards in hand, players choose the power of their attack or their willingness to resolve the encounter peacefully. Those who resolve peacefully typically exchange resources or allow for colonies on their home planets. The player or players who establish the game-winning number of colonies on foreign planets wins the game.

Simple in its design, Cosmic Encounter also offers an infinite amount of possibilities, given the freeform rules of encounters and the several alien races available in the base game alone. It is notable for its influence on future American game designs because it is generally considered the first 'asymmetric' board game, meaning the initial board state is not equivalent or balanced for all players. As David Shapiro notes: 'Prior to Cosmic Encounter every player in every game played by the same rules set; equality was assured. With Cosmic Encounter every player began with an identical set up and a card that allowed them to 'break' one of the rules of the game. This was revolutionary. ${ }^{64 "}$ In such games as Summoner Wars (2007) and Android: Netrunner (2012), with their similar variable player powers, players can observe the continued influence Cosmic Encounter has had over the industry in the U.S.

The year 1980 would offer another point of innovation for U.S. game design. In 1980, Francis Tresham's Civilization ambitiously attempted to simulate the growth of civilized culture over the span of eight thousand years in six hours of play time. In the game, players not only strengthened their military (like the war games of preceding

\footnotetext{
${ }^{64}$ Shapiro, "To Boldly Go. . ."
} 
decades) but also enhanced their technologies and culture. This was done through an innovative 'technology tree' concept, wherein cultural enhancements would be separated into a branching visual implementation of possibilities. Satisfying one technological upgrade, for example, would open up 'paths' to future upgrades while closing off opportunities to upgrade along other 'paths' of development. While this 'tech tree' would become influential in video game design, it would continue to influence American-style board games, especially those within the family of games known as ' $4 \mathrm{X}$ ' games-i.e. Exploration, Expansion, Exploitation, and Extermination. Large scale civilization games, such as Through the Ages: A New Story of Civilization (2015), and epic sci-fi games, such as Twilight Imperium Fourth Edition (2017), continue to use the 'tech tree' developed in Civilization.

One of the most influential and innovative of American style board games was the collectible card game Magic: The Gathering (1993). Designed by Richard Garfield, Magic: The Gathering is a player-versus-player (PVP) card game that allowed players to create a unique deck of cards before gameplay (known as deckbuilding) that would best facilitate that player's chance of success. This deck comprises the player's arsenal of weapons, artifacts, spells, and creatures that will aid in the fight. The aim of the game is simple: deplete your opponent's strength from twenty to zero before your opponent can do the same to you. Utilizing cards from their decks that are associated with the five categories of 'magic,' players use both defensive and offensive tactics to spawn protections against and assaults upon the other player. The customizability of the player's decks, the expansive amount of cards available for purchase, and the popularity of the genre have led to a paradigm moment within board game design. Other collectible card 
games (CCGs) flourished throughout the 1990s, including Netrunner (1996) and Pokémon (1996) among countless others. Although many have become defunct as the CCG market leveled off, ${ }^{65}$ Magic: The Gathering has continued strong production and consumer support over the years, boasting more than twenty million players as of 2014 . Apart from the lucrative paradigm within the board game industry, the influence of the CCG genre can be seen in non-CCG games like Dominion (2009), which customizes a player's deck throughout gameplay, and Star Wars X-Wing Miniatures Game (2012), which utilized a CCG marketing strategy to disperse an ever-expanding supply of game materials across several calendar cycles.

With the international success of Magic: The Gathering in the mid-1990s and the international publications of Spiel des Jahres titles from Europe, namely The Settlers of Catan, the board game entered into a 'modern age' where designs and the lucrative potential of these designs breached national borders to reach a global audience. As each of these crossed their respective borders to gain new players, conceptual constraints of game design collapsed and the demand for more games increased quickly and exponentially. As these modern games continue to influence designers, we can now see a new "hybrid" style of board game that combines the gameplay appeals of the distinct markets. For example, Scythe (2016), designed by Jamie Stegmaier in America, utilizes direct conflict and area control itinerant to the American style of games but also uses the constrained play time and resource management popular amongst European titles. Likewise, the Eurogame Archipelago (2012) uses resource economy alongside a narrative of direct confrontation.

\footnotetext{
${ }^{65}$ Woods, 30.
} 
Several factors were in place to facilitate a board game 'boom' ${ }^{66}$ or a 'renaissance' ${ }^{67}$ as it is often called—-such as conventions like Alan Moon's Gathering of Friends established in 1990 to nurture interest in European games in the states ${ }^{68}$, and publishers like Mayfair Games who had decided to produce English-language translations of popular foreign titles ${ }^{69}$ (Settlers of Catan being one of the first) - but the rise of internet communications occurring concurrently cannot be overlooked ${ }^{7071}$. The internet allowed devoted hobby gamers to explore titles from smaller publishers along with foreign markets. In 2000, the database website boardgamegeek.com was launched, further offering gamers access to reviews, trades, and forum discussions. Today, media content for board games burgeons on YouTube, Facebook, and podcasts. Board game critics and review avenues such as The Dice Tower, Shut Up and Sit Down, Rahdo Runs Through, and The Secret Cabal have reached a celebrity status akin to the designers of the board games they review ${ }^{72}$.

\subsection{CONCLUSION}

The implication in the board game community that American-style games are characterized by conflict and thematic elements, while Eurogames are 'themeless' and

\footnotetext{
${ }^{66}$ Luke Graham, "Millenials are Driving the Board Games Revival", CNBC, December 22, 2016, https:// www.cnbc.com/2016/12/22/millennials-the-board-games-revival-catan-pandemic.html ${ }^{67}$ Leon Neyfakh, "Inside the Board Game Renaissance," Boston Globe, March 11, 2012, https:// www.bostonglobe.com/ideas/2012/03/11/inside-board-game-renaissance/XXRfSOBle3X9BGgrZIA7wO/ story.html Nov. 25, 2014, https://www.theguardian.com/technology/2014/nov/25/board-games-internetplaystation-xbox

72 Rhiannon Ochs, "The Confusing Hierarchy of the Board Game Community," (web blog), Whose Turn Is It Anyway, October 29, 2014, http://whoseturnisitanyway.com/the-confusing-hierarchy-of-the-board-gamecommunity/
} 
isolate players from direct interaction is of interest here. The two are recognizably distinct in their game play, but it would be erroneous to suggest one eschews conflict, given that games are largely about competition. Instead, it is suggested here that the two styles have developed over time with differing attitudes and approaches to conflict, but despite these distinctions, the two styles are better understood as differing avenues toward a similar result. The ludonarrative gradient is important here. The ludic end of the spectrum emphasizes gameplay mechanisms while the narrative end of the spectrum emphasizes thematic associations, but games on this gradient have the same goal in mind, as described by the rubric of games - that is, an assessable disequilibrium among players that demonstrates victory in the competition.

When considered in such a manner, the disparity between the Eurogame and the American-style board game is less a contention over whether the Eurogame is 'themeless' or lacks conflict in comparison to the American-style, it is more about the level at which narrative has been de-emphasized in the Eurogame and the conflict abstracted by mechanisms of play. These ludonarrative tensions in game design, then, shed light on the selectivity of abstraction within the narrative, a point that allows the possibility of using games to reveal sociocultural values implicit in their respective design. 


\section{CHAPTER II}

\section{ARCHEAOLOGICAL UNEARTHING: \\ BOARD GAMES AS DISCURSIVE ARTIFACTS}

Like novels, games don't come out of the blue. They come from a given designer, at a given time, in a given social situation. -Bruno Faidutti, designer of Citadels $(2000)^{73}$

The ways in which board games relate to the outside world are at times subtle and easily overlooked, and a Foucauldian archaeological method reveals the ideological premises underlying design. Here, three board games-Cosmic Encounter (1977), Android: Netrunner (2012), and El Grande (1995) — are broken down into their respective mechanics and narratives to demonstrate how they can be analyzed as sociocultural texts of a given time and space. The two American-style games-Cosmic Encounter and Android: Netrunner — not only reflect how attitudes toward confrontation have changed and evolved over the decades of American design choices but also reveal different real-world views of conflict from the two distinct eras. The Eurogame $E l$ Grande demonstrates the aversion to direct conflict adopted by many European designs, and the particular way in which the aversion to conflict manifests through the ludonarrative gradient elucidates an antimilitaristic ideology held and practiced by Germany.

\footnotetext{
${ }^{73}$ Shannon Appelcline, "Bruno Faidutti: Professor of Chaos," Mechanics-and-meeples.com (May 22, 2006), https://www.mechanics-and-meeples.com/2006/05/22/bruno-faidutti-professor-of-chaos/
} 
The suggestion that modern board games can present as discursive artifacts for an archaeological inquiry raises several pertinent questions. These include how a game interacts with the sociocultural framework that contextualizes the game's release, consumption, and design. How do real-world attitudes, assumptions, and values contribute to a game's design, if they do at all? What elements within game design demonstrate these attitudes and how? This chapter aims to address these questions. As the epigraph preceding this chapter shows, several factors influence how games are designed, from designer intentions to the world at large. The latter is of greatest interest here. When examining the mechanism, narrative, and the general ludonarrative gradient of game designs, characteristics emerge that are indicative of reflecting or even endorsing sociocultural values and beliefs of a given time and space. Games like Cosmic Encounter, Android: Netrunner, and El Grande can be viewed as innocuous escapes from the everyday. But unearthing how power manifests and knowledge and attitudes about the world are shaped through design, they can present as artifacts of culture. Read in such a manner, Cosmic Encounter proves as much to be a science fiction narrative of intergalactic conquest as it is a commentary on American military involvements and proxy warfare, Android: Netrunner is as much dystopian fantasy as it is a reflection of anxieties concerning corporate corruption and cybersecurity, and El Grande's distant and curated narrative demonstrates an aversion to conflict mirroring Germany's policies on military and foreign involvement. In short, games speak volumes about the world surrounding the players if we observe what they embrace versus what they eschew and if we take them seriously as potential artifacts of culture. 


\subsection{THEORIES AND CONCEPTS}

The notion of ideology and how ideologies are reproduced and disseminated inform this argument, as does the notion of culture and how it is represented. Particularly, the work of Antonio Gramsci on hegemony, Louis Althusser's assertions about the ideological state apparatus, Michel Foucault's notion of the episteme, and Raymond Williams' "structures of feeling," are of interest here because they show how ideology is manufactured and maintained through media and performance. Fundamentally, approaching these concepts utilizes Foucault's archaeological method that is useful in unearthing power dynamics within the context of a given discourse and the reproduction of that power through discursive formations.

\subsubsection{Episteme and Unearthed Ideologies: Foucault}

Foucault's notion of the episteme ties directly to the production of board games in that it dislodges presumptions of individualized subjectivities to focus on contextual pressures that present conditions for possible thinking and significant practices in a given era. As he has described in his The Order of Things, an episteme is the interrelationship of many social variables that collectively constrain the possibilities of knowledge within a given epoch, a "table" of sorts upon which knowledge and theory can be constructed. ${ }^{74}$ Rather than accepting knowledge and historical changes as the result of individual subjectivities, the production of knowledge is governed by the contextual conditions of

\footnotetext{
${ }^{74}$ Cf. Michel Foucault, The Order of Things: An Archaeology of the Human Sciences (1966, repr. New York: Vintage, 1994), xxi. In The Archaeology of Knowledge, as well, Foucault articulates the episteme as "a general stage of reason" and an anonymously written legislation that totalizes the possibilities within a given worldview. Cf. Michel Foucault, The Archaeology of Knowledge and the Discourse on Language (1971, repr. New York: Vintage, 2010), 191.
} 
the episteme. Most importantly, the episteme orders and curates the world of knowledge production into a hierarchy without the necessary consciousness of those producers. ${ }^{75}$ The episteme, in short, governs what should be investigated with seriousness versus what should be abandoned or ignored completely. Not to deflate the importance of Foucault's work but epistemes can be observed in board game design, whether those design choices are conscious decisions or not. A case in point would be the mechanism commonly known as roll-and-move. Collecting a wide array of games, roll-and-move mechanisms allow a player token's movement on a board as the result of some randomizer (e.g. dice, a spinner, etc.). This mechanism is prominent in classical designs ranging from Monopoly to The Game of Life, but it is a rarity in modern board game designs. This rarity is not the result of some paradigmatic choice but of an evolution of preferences over the years. As options for player movement have become more varied-for example, through action point allowance (Tikal; 1999) or worker placement (Caylus, 2005)—roll-and-move mechanisms have become unacceptable, ${ }^{76}$ whether consciously acknowledged or not. Apart from mechanisms and formal design choices, the notion of the episteme proves useful for demonstrating how board games also reproduce ideologies within a given epoch.

Another important takeaway from Foucault's notion of the episteme is that it diverts attention away from individual agency. Rather, the ability to create meaning is constructed through a complex relationship of contextual forces. There is no locus of

\footnotetext{
${ }^{75}$ Foucault, 168. Foucault states, "In any given culture and at any given moment, there is always only one episteme that defines the conditions of possibility of all knowledge, whether expressed in theory or silently invested in a practice."

${ }^{76}$ Cf. "Alternative to Roll and Move," boardgamegeek.com (Jun. 26, 2017), https://boardgamegeek.com/thread/1802679/alternative-roll-and-move
} 
power and knowledge that is centralized on one individual. Seen as such, linearity and directionality of power and knowledge are destabilized.

\subsubsection{Reproduced Ideology: Gramsci and Althusser}

Naturally, discussions of the episteme bring Foucault's predecessors, Antonio Gramsci and Louis Althusser, to the fore, and indeed, their positions on the reproduction of ideology inform this argument. Antonio Gramsci put forth his assertions regarding what he termed cultural hegemony in his Prison Notebooks. As he notes, hegemony can be characterized as "a continuous process of formation and superseding of unstable equilibria [.. .] between the interests of the fundamental group and those of the subordinate groups [...] equilibria in which the interests of the dominant group prevail, but only up to a certain point." ${ }^{\text {77 }}$ Hegemony, as Gramsci saw it, was the idea that a dominant class could control others through the varied systems in place to maintain power through a manufactured "universalization" of interests - that is, the interests of the subordinated and the empowered are conflated as a "national" interest. ${ }^{78}$

These methods of control would not only include institutions of force but also institutions of ideas. Ideas, for Gramsci, proved efficient in the establishment and maintenance of power if consented to by the structural base of the cultural hierarchy. Subtle and seemingly innocuous practices can perform and maintain these ideas and beliefs from the bottom up, creating an "organic" quality of ideas that promotes a commonsense notion of what is good, right, and beneficial that affirms the hegemonic

\footnotetext{
${ }^{77}$ Antonio Gramsci, Selections from the Prison Notebooks, 1971, repr. (New York: International Publishers, 2014), 182.

${ }^{78}$ Gramsci, Selections, 182.
} 
aims of the ruling class. Through this sense of consensual subjugation by the structural base, the hegemonic worldview of the dominant class becomes the normative worldview of the base. Unwittingly, those subjugated and disempowered by hegemony enter into a consensual agreement to not only maintain that power but to believe the maintenance of that power serves their interests.

A natural critique of Gramsci's notion of cultural hegemony lies in its monolithic directionality. Societal and cultural change, largely, would manifest only as revolution, concessions of the dominant group, or by the transformed interests of the hegemony. This is where Louis Althusser, influenced by Karl Marx and Gramsci, enters to clarify the reproduction of power through his concepts of the repressive state apparatus, the ideological state apparatus, and interpellation. In his view, state power is divided into the structural entities of a repressive state apparatus and an ideological state apparatus. The former is a mobilization of coercive power - that is, the military, the government, the law, and so forth — using force primarily and ideas secondarily to maintain the reproduction of power by the ruling class. ${ }^{79}$ Ideological state apparatuses-e.g. schools, church, family — operate primarily through the selection and dissemination of ideas and secondarily through force. ${ }^{80}$ The latter is of greater interest here.

In Althusser's view, ideological state apparatuses, existing as a diverse plurality, work to constrain the conditions of knowledge and praxis. They are, in his words, the sites of teaching the "know-how" of a given aspect of culture. ${ }^{81}$ Given the practical usefulness of the knowledge they provide - e.g. presenting the boundaries of socially-

\footnotetext{
${ }^{79}$ Louis Althusser, "Ideology and Ideological State Apparatuses," in Lenin and Philosophy and Other Essays, trans. Ben Brewster (1971, repr. New York: Monthly Review Press, 2001), 97-8.

${ }^{80}$ Althusser, 98.

${ }^{81}$ Althusser, 88.
} 
accepted behavior - they operate largely through implication and invisibility, in contrast to the highly visible forms of submission itinerant to repressive apparatuses. Relating this to the Marxist conceptions of superstructure and infrastructure, Althusser suggests that "the reproduction of labour power requires not only a reproduction of its skills, but also, at the same time, a reproduction of its submission to the rules of the established order [. . .] so that they, too, will provide for the domination of the ruling class 'in words." ${ }^{82} \mathrm{As}$ such, the ideological state apparatuses are contested spaces for hegemonies, and which hegemonies control the ideological state apparatus helps to steer the determinism of the ruling ideology, ${ }^{83}$ because "it is ultimately the ruling ideology which is realized in the Ideological State Apparatuses[. . .]" 84 It is through the ideological state apparatuses that individuals become subjects of a larger ordering principle, albeit under the guise of subjective autonomy.

This security of the ruling ideology within the ideological state apparatuses is largely done through performance and subtle actions. Through what Althusser terms interpellation, subjects constitute and are constituted by ideology. Subverting the common assumption that people act as a result of their beliefs, values, etc., Althusser suggests that beliefs are predicated upon actions. ${ }^{85}$ (He offers the example of kneeling in church as a ritual that is done less as a response to a belief but as an action that affirms a belief. ${ }^{86}$ In other words, ideology manifests through materiality despite the fact that

\footnotetext{
${ }^{82}$ Althusser, 89.

${ }^{83}$ Althusser, 102-4. Althusser provides the example of the school and how at different times different hegemonies controlled the education function in a society-e.g. the church during the Middle Ages and the bourgeoisie during capitalism-and thereby redirecting the ruling ideology.

${ }^{84}$ Althusser, 98.

${ }^{85}$ Althusser, 115.

${ }^{86}$ Althusser, 120.
} 
ideology connects subjects to their reality in an imaginary way. In a cyclical sense, a subject expresses their ideas through material actions that are defined by an ideological apparatus "from which derive the ideas of that subject." ${ }^{87}$ The illusory sense of autonomy felt by a subject, then, is predetermined and constrained by the material parameters set forth by the apparatus. Furthermore, Althusser asserts that individuals constituted as subjects of an ideology are "always already" constructed as subjects as his example of unborn children being given the father's name or, by extension, the gender reveal rituals of today would suggest.

Gramsci's notion of a commonsense reproduction of hegemonic power and Althusser's ideological state apparatus, while being directed toward institutions such as capitalism, connect to the world of board games. Games, as cultural products, are ideological. They exhibit both narrative and mechanical manipulation of events. Players make choices to manipulate the game state, but those choices are necessarily confined within a rule-set and thematic framework. They are spaces bound by these constraints. Material performance within a game state is presented as a commonsense action that serves the player's interests while simultaneously being limited by the confines of what the game narrative has demarcated as potentially interactive. Their actions, then, while appearing autonomous, are in accord to the interest of the game's narrative, as defined by its producers. Think, for instance, of all the games that present with the end-game goal of having the most money (e.g. Monopoly). Player choice is less about autonomous decisions on the part of the player as it is about performing and reperforming material

\footnotetext{
${ }^{87}$ Althusser, 114. Italics original.
} 
rituals that correlate with the game's predetermined goals and interests. Those interests are both ideological.

It is important to clarify that when we discuss the modern board game industry generally, the presumption that board game producers are large companies that calculatedly control the output of their respective designs is largely erroneous. Board game publishers, by and large, are small companies with few employees. They are not, generally speaking, Hasbro. While large publishers exist-Asmodee, Wizards of the Coast, and Games Workshop come to mind - they are not representative of the board game publishing industry as a whole. For example, the company Stronghold Games lists three full-time employees on their official Boardgamegeek page, ${ }^{88}$ and it is common to see their president and owner, Stephen Buonocore, engaged with the community via convention appearances and YouTube gameplays. ${ }^{89}$ Similarly, reputable Spiel-desJahres-nominated game designer Bruno Faidutti (Citadels, 2000) of this chapter's epigraph has maintained a teaching job alongside designing board games. ${ }^{90}$ In other words, board game producers do not personify the colloquial image of corrupt corporations but instead herald from within the community itself. They are players as well as producers. When we think of how ideologies are reproduced through board game design, this clarification helps to show how producers and players are part of a system that collectively and often unconsciously mediates the ideologies they espouse.

\footnotetext{
88 "Stronghold Games: Overview," Boardgamegeek.com (n.d.), https://boardgamegeek.com/boardgamepublisher/11652/stronghold-games

89 Cf. The Dice Tower, "HAVOK in Homestead Gaming Marathon, Part 1," YouTube Video, May 21, 2016, 3:53:19, https://www.youtube.com/watch?v=bofPt3YQ2mQ

90 Cf. "Designing with a Full-Time Job?" boardgamegeek.com (May 21, 2018), https://boardgamegeek.com/thread/1996796/designing-full-time-job. As of 2018, Faidutti acknowledged in the comments that he was working part-time as a teacher while also promoting and designing board games.
} 


\subsubsection{Contested Ideologies: Williams and Hall}

Board game players and producers are caught up in a system of representation and parameters that constrain that representation. The work of Gramsci and Althusser implies both a pessimism about the reproduction of power dynamics as well as a deterministic directionality. While we can argue this to a point for board game designs, it is more useful to think of players and producers as practicing a relative autonomy within a deterministic framework. For this, the work of Raymond Williams and Stuart Hall prove useful.

Raymond Williams famously stated that "[c]ulture is ordinary." ${ }^{\text {11 }}$ By this he meant that culture could not be easily dichotomized into a presumed "high" culture versus a "low" culture but rather that culture was a lived experience entangled in signifying practices of everyday life and the signifying practices of materialism. As he suggests, "The making of a society is the finding of common meanings and directions, and its growth is an active debate and amendment under the pressures of experience, contact, and discovery, writing themselves into the land." What sets Williams apart from his Marxist predecessors is his departure from presumptions of deflated autonomy in the production and reproduction of cultural ideologies. Instead, Williams offers what he terms "structures of feeling" to describe the varied arenas in which ideologies manifest. Instead of viewing the reproduction of ideology as a unidirectional monolith of state power (as Gramsci and Althusser imply) or of the economic base (in Marxist terms),

\footnotetext{
${ }^{91}$ Raymond Williams, "Culture is Ordinary" (1958) in Resources of Hope: Culture, Democracy, Socialism (Brooklyn: Verso, 1989), 4.
} 
Williams was interested in the process of the production of culture through lived experience as governed by these structures of feeling.

Williams suggests that processes of culture can be viewed through three distinct frameworks - as dominant, emergent, and residual ideologies. The dominant ideology Williams describes is a set of values and practices exhibited by the majority of a given society, while residual ideology "has been effectively formed in the past, but it is still active in the cultural process . . . as an effective element of the present." $92 \mathrm{He}$ distinguishes the residual from presumptions of the archaic in suggesting the difference between the two is their availability to affect the present. ${ }^{93}$ And that which would best be understood as emergent culture are new values and practices arising as an alternative to the dominant, as opposed to novel extensions of the dominant culture. ${ }^{94}$ Implicated here is that at a given space and time these three ideologies can be seen operating in various degrees, and that such a framework enriches how we might view cultural identities. Not only are we able to view how cultural materials adhere in complex and overlapping ways among these ideologies, we are also able to localize culture. What cultural processes at work within one place may be distinctly different, given their sociohistorical contexts, to another. And this extends toward understandings of culture that are not only nationally bound but ethnically and racially bound.

The concepts Williams puts forth are useful in our observations of board game designs. Not only does Williams clarify that cultural products should not be differentiated by a dichotomy of high or low cultures, the latter of which some may presume a fitting

\footnotetext{
92 Raymond Williams, "Dominant, Residual, and Emergent," in Marxism and Literature (1977; repr., Oxford: Oxford University Press, 2009), 122.

${ }^{93}$ Williams, "Dominant," 122.

94 Williams, "Dominant," 123.
} 
place for board game analyses, but he also gives us an avenue to comprehend how competing ideological frameworks can be represented within the medium, and how those frameworks may differ when time and space are considered. In US designs, the mechanism of play may remain stabilized over several years and productions while the narrative in question strives to capture interest and novelty. For example, the combat resolution table $(\mathrm{CRT})$ is a mechanism that has been popularized in varied forms from wargames (Squad Leader, 1977) to roleplaying games (Dungeons \& Dragons, 1977), whereby a chance result is checked against a table that describes the narrative consequences of the action, is still used in board games produced today but for differing narratives such as Lovecraftian horror (Arkham Horror: The Card Game, 2016) or storytelling adventures (Near and Far, 2017). By contrast, what we see in European designs is largely the opposite, where narratives are stabilized and reproduced but new productions seek innovations in mechanism. There are countless games that simulate nautical exploration, discovery, and settlement (Vasco da Gama, 2009; Navegador, 2010; and Amerigo, 2013 to name a few) but the mechanisms that facilitate the narrative experience vary widely from programmable movement ${ }^{95}$ to action selection ${ }^{96}$ to drafting. ${ }^{97}$ Borrowing from Williams' concepts, residual, dominant, and emergent ideologies present in the development of board games and offers a lens for us to look

\footnotetext{
${ }^{95}$ Also known as an action queue mechanism, where players "set" their available actions in a prescribed order that are carried out despite possible changes to the game state between actions.

${ }^{96}$ The example given, Navegador, utilizes an action selection mechanism known as a rondel, where available actions are depicted on a "pie" chart but moving between actions are constrained by resources or a player's position on the "pie."

${ }^{97}$ Drafting is a mechanism by which available actions or resources are available to multiple players, as a common "pool" or via passing/receiving materials to/from other players. The concept behind drafting is that players need to be aware of other player's strategies and tactics in order to best make a choice. At times, a player's selection is in their own best interest, while at other times, materials may be drafted to frustrate another player's access to those same materials, a tactic commonly referred to as "hatedrafting."
} 
beyond formal design choices of sustaining narratives or mechanisms to investigate how designs can present avenues for understanding how a locus of production and consumption, constrained by national and cultural values, views itself at a time and place as well as its view of the world more generally.

When these ideas are employed together, these theories and concepts prove useful to board game analyses in the manner in which they allow for cultural ideologies to emerge from within a presumably closed system ${ }^{98}$ of mechanisms and storytelling. While the goals of the game are made explicit by the product's ruleset and may express a cultural value in some way, the subdued and unremarkable material choices within board game production and play prove to express values and hostilities within a locus of cultural production. When viewed as such, players and producers of games are encouraged to practice those values as well as those hostilities in varying degrees through play. The result is a dissolution of the presumed boundaries between play and reality that unearths how real-world ideologies, inclusive and disparaging alike, are in part performed and endorsed through the "innocuity" of gameplay.

\subsection{AMERICAN STYLE GAMES AND THE RELOCATION OF CONFLICT:} COSMIC ENCOUNTER (1977) AND ANDROID: NETRUNNER (2012)

Two case studies of American style games demonstrate how each separately views the concept of conflict differently and how those differing viewpoints may be illustrative of broader worldviews as constrained by prevalent real-world contexts. While each game, Cosmic Encounter (1977) and Android: Netrunner (2012), can be viewed as

\footnotetext{
${ }^{98}$ I refer to the popular understanding of games as a "magic circle."
} 
science-fiction and firmly located outside of the reality in which players play, both reveal ideas about conflict that are prevalent within the real-world contexts surrounding their locus of production and consumption. Not only do their explicit goals say something about the world in which they are produced but the available actions and rewards for those actions illustrate attitudes and tensions felt within their real-world contexts. Cosmic Encounter, apart from being an intergalactic colonization game, probes the stability of international alliances and the justification of proxy wars. With America's involvement in Vietnam in recent memory, the game offers a commentary on international relations among superpowers and how those powers are secured equally through direct force and proxy. Likewise, Android: Netrunner is as much a dystopian "cyber punk" narrative of corporate power beset against the vigilantism of hackers as it is a commentary on neoliberal economics and a conceptual rebalance of power. Given the span of years separating these games, we also can observe a relocation in conflict from external sources toward internal sources. With growing metaphorical wars on domestic issues ranging from drugs to poverty and literal threats apparent in terrorist actions on US soil, this shift to encompass the destabilized domestic sphere is ideologically telling as well.

\subsubsection{Cosmic Encounter (1977)}

Informed by the wargaming market of the time and popular titles such as Risk (1959), a small group of players set out to design a game that would be antithetical to the long-playing time and player elimination characteristic of Risk. ${ }^{99}$ And out of this

\footnotetext{
${ }^{99}$ Rick Lane, "The making of Cosmic Encounter, the Greatest Boardgame in the Galaxy," Eurogamer.net, June 3, 2016, http://www.eurogamer.net/articles/2016-03-06-the-making-of-cosmic-encounter-thegreatest-boardgame-in-the-galaxy
} 
frustration with the current trend in American game design, these players would create Cosmic Encounter (1977). In the game, players take on the role of one of several different alien races who are vying to influence and colonize foreign planets. Each player begins the game with five home worlds and a finite number of ships that represent both their military and colonial presence. Through card play and freeform negotiation tactics, players attempt to meet the game's win condition - to establish five colonies on foreign worlds.

Mechanically, Cosmic Encounter is a simple game. On a player's turn, they are presented with a foreign encounter as revealed by drawing a card from the 'destiny' deck, which collects and randomizes all the present players. The offensive player deploys ships to the encounter, and both offense and defensive players can request allied help from other players, which earns allied players benefits if their side of the encounter is successful. The defensive allies deploy ships to the encounter. The resolution of the encounter is computed by adding the number of ships involved in the encounter with the numerated strength on played cards. The resolution can be modified in a back-and-forth fashion with reinforcement cards and activated powers until one side can no longer withstand the force of the opposing encounter. Once the encounter is resolved, the losing side loses their ships to the "warp" and are unavailable to boost military or colonial presence while "lost." Offensive victories are awarded colonies on the attacked planet, and defensive victories are rewarded with replenished ships from the warp or more cards drawn into hand. Players involved in the encounter can also choose to negotiate and reach a peaceful conclusion rather than an aggressive approach, choosing to play a "negotiate" card. This verbal agreement, however, is not concrete and players may choose aggressive 
maneuvers (e.g. play attack cards) when verbalizing peaceful negotiation. If both players do play negotiate cards, they have one minute to reach an amicable deal—often mutual colonization or exchanged resources - or they each lose ships to the warp. The player or players to first establish five colonies on foreign worlds wins the game.

There are several material and mechanical distinctions within Cosmic Encounter that set it apart from games of the time. First, the game lacks a central board upon which players move their tokens. A subtle change, but the lack of a central board alters the spatialized play amongst players. Rather than engaging over a shared terrain akin to Risk or Diplomacy (1959) the players are removed from one another. This connotes not only a yawning spatial distance between player but metaphorically connotes diverse interests and a general lack of comradeship amongst players. A central board might imply a base commonality or shared interest; its absence suggests the alien races are radically different from one another.

The alien powers also make the game unique from preceding designs. Most games before Cosmic Encounter began on an equal playing field, what Roger Caillois has collected under his Agon rubric, meaning that play offers an artificial control of variables to present the most equal opportunity amongst players to achieve the game's goal. ${ }^{100}$ In Cosmic Encounter, the alien avatar for each player possesses one unique ability that allows a player to 'break' one of the game's core rules. In essence, players 'feel' different from one another. The base game alone offers over forty different races that approach the core rules differently. The Philanthropist race, for example, can give cards, even less valuable ones, to other players, and the Oracle can foresee the opponent's played card

${ }^{100}$ Caillois, 15. 
prior to an encounter. Players access win conditions not simply by having better cards in hand but by using the knowledge of their adversaries and allies to gain an advantage.

Cosmic Encounter is not a notable paradigm for its use of science fiction, for scifi-themed board game designs reach as far back as the turn of the century. The theme, however, is important for understanding how the game negotiates the real world. Science fiction, for all of its itinerant escapism, offers a medium through which creators can explore real world problems. As Elisabeth Anne Leonard has made clear, science fiction offers the opportunity for creators to tackle earthbound issues such as race, racism, and ethnicity. Often, she claims, the genre perpetuates problems of race and ethnicity by ignoring it altogether ${ }^{101}$ or by making humanlike aliens inferior to the human main character. ${ }^{102}$ Further, the use 'race' as a differential for alien factions can be read as a means of discussing different identities within humanity. For instance, the Kamikaze race in the game is a direct association to ethno-racial distinctions of humanity. As such, Cosmic Encounter is as much an escapist space colonization narrative as it is about real-world cultural relations.

Given its direct connection to real-world cultural identities, we can interpret Cosmic

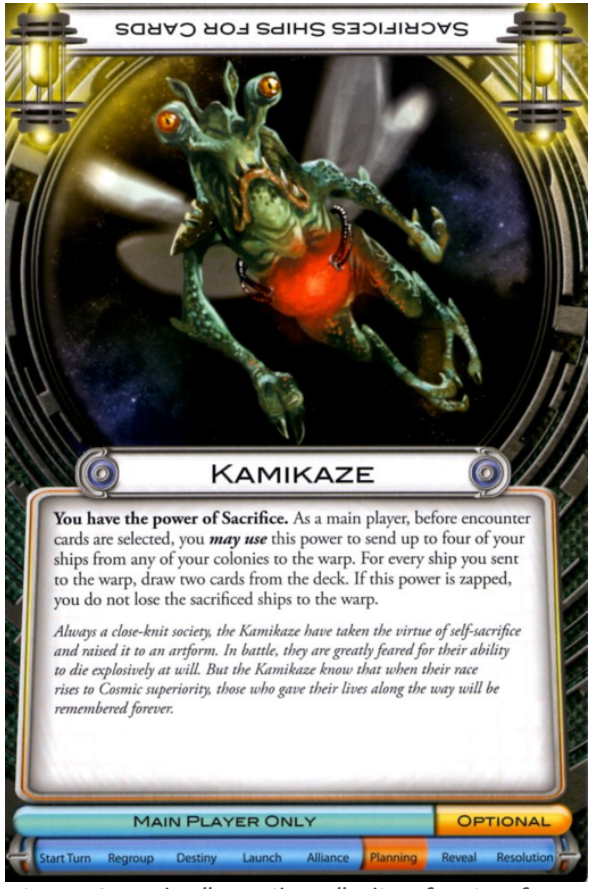
Figure 2. 1 The "Kamikaze" alien faction from Cosmic Encounter

Encounter as a metaphor for real-world

\footnotetext{
${ }^{101}$ Elisabeth Anne Leonard, "Race and Ethnicity in Science Fiction," 1988, repr., in The Cambridge Companion to Science Fiction, ed. Edward James and Farah Mendelsohn (New York: Cambridge University Press, 2003), 254.

102 Leonard, 255.
} 
international politics, and the mechanisms of play prove particularly telling from this viewpoint. Not only do players endure combat, but they also talk, negotiate, deceive, and boast. For instance, the material practice of committing ships to an encounter is a signifying practice akin to poker, whereby the choice conveys information about confidence, strength, or willpower while the resources and ability to act upon this show of strength is concealed by cards in hand. Much like the bet, call, or raise is a signifying practice in poker, this material performance is used to posture intimidation or a willingness to negotiate.

With the Cold War hovering as a continual tension at the time, and hostilities among superpowers playing out during the Vietnam conflict in recent memory, comparisons within the game's mechanical metaphors cannot be overlooked. The material act of allied powers converging to threaten another on a literal arrow ${ }^{103}$ directing this aggression. Such a pointed threat draws comparisons to real-world tensions between superpowers like the US installation of nuclear warheads in Turkey threating the Soviet Union or the consequential Cuban missile crisis. In this way, Cosmic Encounter can be read as an affirmation of what Williams would call a dominant ideology. Through talks, betrayal, and presumably unprovoked aggression, Cosmic Encounter presents as a metaphorical stage on which players can simulate international aggression or diplomacy. Indeed, the game allows for multiple winners as opposed to one, suggesting that one superpower need not survive the game's narrative as the sole figure of substantial power. As unresolved as the international relations between the US and the Soviet Union were at the time, the game can end without a definitive single victor.

\footnotetext{
${ }^{103}$ In the game, encounters are arranged on a triangular board, the apex of which is pointed toward the vulnerable planet.
} 
Given the contextual pressures of the time period in which the designers were creating Cosmic Encounter, we can see how the game is operating under an identifiable boundary of knowability and possibility. The game operates under what Foucault has called the episteme. This episteme, as the delocalized basis from which theory and knowledge emerge, constrains choices and actions given a wider context of feasible possibility. ${ }^{104} \mathrm{We}$ are conditioned, in other words, by the inclusion and exclusion of choices governed by a priori rather than an individual subjectivity. The episteme orders possibility on unconscious bases of what is acceptable. How we dress for formal engagements, wearing clothes at all, how we select and design rooms for our homes, for example, are less constrained by individual subjectivities within decisive offices as they are constructed by a largely unconscious accordance with the 'ground rules' of the episteme.

Cosmic Encounter presents as an example of game design that manifests under given contextual constraints. The intentionality of the game's metaphors is a moot point, for the conditions of intergalactic foreign policy are grounded by a priori of lived experience. Combat, negotiations, and deceit are informed not by its space narrative, but by its real-world contexts, and we can see as a result a game that "speaks about" as well as "performs" aspects of foreign policy observable in the game's contemporaneous reality. The manner in which players secure allies, bolster their defenses, and posture is akin to what Althusser called interpellation. The material and signifying practices of the game assuage any sense of individualism on the player's part and instead interpellate players as subjects of an ideology. Their choices, as constrained by the goals, rules, and

\footnotetext{
${ }^{104}$ Cf. Foucault, Order, xxii-xxiii.
} 
rewards of the game, already subject them to an ideology attesting that international conflict is inevitable ${ }^{105}$ and conflict and expansive presence are demonstrations of state power. In a cyclical sense, the game's ruleset defines the goals and the parameters of choices for the players involved, but the material practice of player choice works to affirm the goals as predetermined by the ruleset. As such, players do less to affirm or deny ideological differences than they are offered a confined set of choices that ultimately confirm the dominant ideology. ${ }^{106}$

Another telling signifying practice in the game is the use of proxy wars. Shifts in power occur not only during a player's attack or defense but can also occur during other players' turns or on foreign worlds. By allying with the offense or defense, a player has an opportunity to bolster their own interests with minimal physical risk within the encounter itself. This involvement in foreign disputes draws similarities to the Vietnam conflict and other proxy wars of the Cold War. ${ }^{107}$ In the game, a player's power can be expressed both in direct conflicts as well as on foreign terrain amidst foreign disputes.

When these contexts are clarified and brought to the fore, we can see that a game like Cosmic Encounter has a dual existence. It is on the one hand a science-fiction game simulating intergalactic conflict, but on the other, it presents as a metaphor of real-world hostilities between world powers. Examining its available mechanisms and narrative

\footnotetext{
${ }^{105}$ Encounters are largely prescribed by a randomized draw from a "destiny" deck rather than by player choice. While this endorses a metagame ideology against "ganging up" on others or "turtling" to avoid conflict, it simultaneously endorses a belief of inevitable conflict.

${ }^{106}$ This is not to say that the game is devoid of endorsing a critical awareness, for we can observe the material losses of these encounters as not just spaceships but as lives. The material stakes of the conflicts in the game present as lives of fighters and colonists, and materialistic reward for entering into a conflict is abstracted from the narrative. In this way, we can see the game as offering a critical commentary to US foreign policy in which real lives were lost through the accumulation of power.

107 Michael Lind, Vietnam: The Necessary War (1999, repr. New York: Simon \& Schuster, 2002), 263.
} 
reveals that game can be "read" as a cultural text that in some way "speaks about" and asks players to "perform" an ideological framework localized on that particular time and space.

\subsubsection{Android: Netrunner (2012)}

While Cosmic Encounter and games of that ilk focus their notions of conflict on external forces - that is, assaults come from or are directed toward an entity that exists "elsewhere" - games have evolved over time to incorporate other visions of conflict. From the early 2000s onward, for example, we see games that simulate dissolutions within a societal system through betrayal, disease, or general suspicion which might in fact be metaphorically indicative of real-world concerns ranging from disease outbreaks (the Pandemic line of games, 2008-present, Dead of Winter, 2014) to embedded terrorist cells (Shadows over Camelot, 2005; Arkham Horror, 2005; Homeland: The Game, 2015), as well as other domestic anxieties. We might best understand these titles as simulating internalized conflicts - that is, conflicts that emerge from within a closed societal structure. A popular title that demonstrates this relocation of conflict inward is Richard Garfield's Android: Netrunner (2012), a game that simulates class disparities amidst a cyberspatial conflict.

Android: Netrunner is a two-player asymmetrical game that pits one player, donning the role of a large corporation, against another, who takes on the role of a computer hacker or "runner." Each role satisfies the game's winning conditions in different ways, but goals for both roles center on obtaining and scoring "agendas," which represent projects the corporation is trying to research and bring to fruition. The 
corporation wins if they "advance" agendas equal to or exceeding seven points, and the runner wins if they infiltrate and steal seven or more points worth of agendas. The game is played through cards and counters on the table space between the two players. This table space is best conceptualized as a virtual interface connecting the runner and the corporation through a cyberspatial network. Constrained by both time and money, players attempt to move quickly and efficiently to actualize their respective goals.

At its core, Android: Netrunner is a card game. Each player begins the game with a deck of cards that is distinct from the other player, and cards played in the space between players represent both material and virtual resources for each player. The runner's deck, for instance, holds material resources such as income from jobs or hacker allies along with that player's hardware and assortment of viruses. The corporation's deck, by contrast, holds assets such as lucrative side projects, the point-scoring agendas, and cybersecurity programs known as "ICE." The layout of the corporation's deck, discard, and hand represent their central servers, such as research and development, archives, and headquarters, and programs can be "installed" face down in front of these cards to protect them from cyberattacks. Additionally, the corporation player can install programs, protections, and assets into additional servers known as "remote servers." This arrangement creates a series of virtual pathways, and runners can attempt to access the sensitive material stored within by engaging with the programs and securities that protect a given server. If the choice is made for the runner to interact with a program, it is turned face up, and the runner must overcome obstacles to bypass the securities. If runners access the server, the protected information is shown and may be a trap, an asset, or an agenda. Accessed agendas are stolen and scored. 
By contrast, the corporation aims to obtain agendas, install them in a remote server, and advance them over several visible steps. While the corporation's efforts are time-consuming, the corporation additionally attempts to frustrate a runner's ability to infiltrate their servers by trashing programs, corrupting hardware, or enlisting henchmen to go after the runners physically. When a corporation meets the prescribed criteria for advancing an agenda, it is scored. While much more complex and nuanced than presented here, this is the gist behind the gameplay of Android: Netrunner.

In a similar way to Cosmic Encounter, Android: Netrunner presents as a discursive artifact, in that the narrative and performed actions reveal something about how people think and act and from what bases those actions spring, but its relocation of conflict demonstrates attitudinal shifts in the American ideology of security. Whereas hostilities were projected away from the self in Cosmic Encounter, Android: Netrunner describes a world in which the hostilities arise from within the same space. In this case, the contenders are private corporate interests versus public interests. Observing the mechanical and narrative constraints of the game reveals a commentary about urgency, power, and the control of information.

Mechanically, both sides of the conflict are constrained by money and time, "credits" and "clicks" respectively in the vocabulary of the game. Each has a specified allotment of "action points" they can "spend" in a given turn. For example, the corporate player can advance a card by using one click and one credit but to purge a virus from a piece of software requires three clicks, the corporation's total turn allotment of clicks. Over the course of the game, the corporation must commit to multi-step processes to bring their policy agendas to fruition, and that takes both time and money. Further, the 
need to install securities to protect its servers from cyberattacks also requires time and money. To be in the best position to shore up its defenses, the corporation player needs to create a sustainable income. By contrast, the runner needs only to access an agenda to score it, so the runner has an early game advantage in that three servers- the deck (R\&D), discard (archive), and hand (HQ) — will have few defenses, if any, at the start of the game. Mechanically, the task of the runner becomes more difficult as more time passes and the corporations become more powerful. Added to this any agendas that the corporation may score can have ongoing detrimental effects for the runner. The metaphor for reality is demonstrated through these mechanisms of play, in that corporate power exponentially increases if left unchecked, widening the gap of potential agency amongst the "haves" and the "have nots."

The game's notion of who checks and balances power proves telling as well. The corporations, the rulebook informs, control all aspects of society from the way people consume to what they think, and the agendas they advance ultimately accrue more power for the corporations. For instance, the agenda "Astroscript Pilot Program" would facilitate the ability to project advertisements of their brand on orbiting objects, such as the moon. Doing so would increase revenue and drown out contenders for consumer choices. The game does not suggest a government entity that regulates or

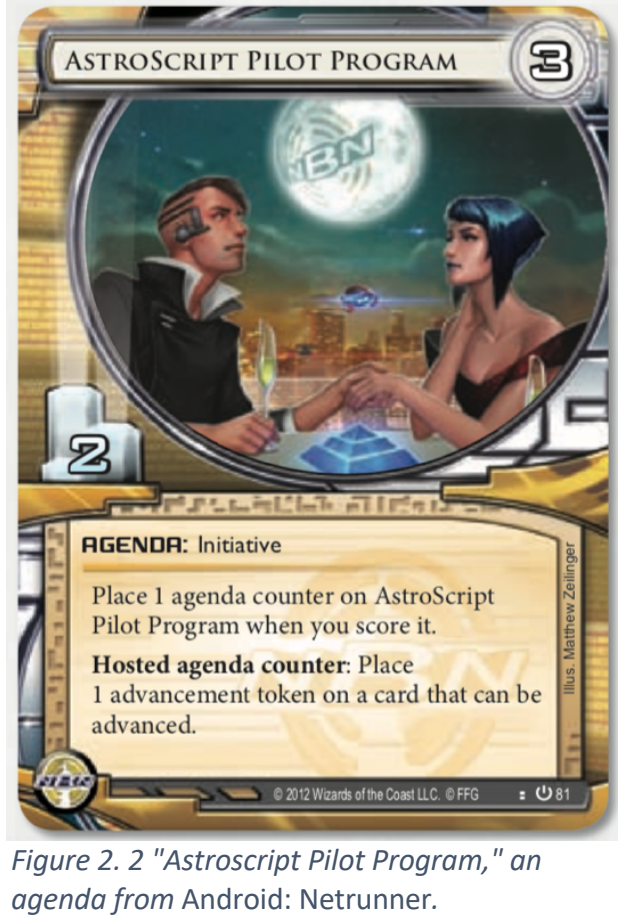
agenda from Android: Netrunner. 
checks the power of these corporations, and if one exists, it is presumable to suggest the corporations have influenced those powers to such a degree that government interests and corporate interests are one in the same. Instead, the possible check on power is held by the public, those who are exploited and victimized by corporate corruption. Access and transparency are the most substantial threats to the corporate interests, and those who have the hardware and resources to access this information and make it public serve as a check on the system as a whole.

While the game embraces certain science-fiction elements such as the colonization of Mars and biologically grafted technologies, these operate as ancillary décor enriching the narrative experience. Fundamentally, the competition between the classes is familiar to reality, and as such, Android: Netrunner can be interpreted as a critique of neoliberal economics. Indeed, the deceit and deflated regulatory practices recall such prolific scandals as Enron in 2001 or the financial housing crisis of 2008, both of which hover as contexts surrounding the game's 2012 release. In the narrative of Android: Netrunner, when commodifiable information is both secretive and controlled by unregulated interests, exploitative corruption results. The mechanisms on the part of the runner emerge from ideological bases that corporate greed should be checked and policies should be transparent. In an Althusserian sense, the mechanisms of the game become subjecting actions that construct the beliefs of urgent public action and corporate transparency that challenges the deflated regulation of neoliberal economics. In so doing, Android: Netrunner relocates the struggle for power away from notions of "there" and "here" toward an internalized conflict between the "haves" and "have nots." 
Ideologically, the game tasks players to perform and consequently accept that arenas for conflict should be expanded to include domestic confrontations.

Within that expanded arena, who controls information in the game's narrative speaks of attitudes toward real-world ideologies. At the outset of the game, agendas are solely within the possession of the corporation, and they control how that information flows and is distributed. Additionally, the corporation generally operates in secret, advancing cards - which could be agendas or assets designed to enrich themselves or harm their adversaries - while face down. They only become visible or public when it is in the corporation's interest or when a runner has accessed the information. From a Williams perspective, we see two competing ideologies presented in the narrative. On the one hand, there is the narrative of neoliberal capitalism, a deregulated industry focused on profits that is largely representative of the dominant manner of thinking about corporations in American capitalism. On the other hand, we observe an ideology that strives to challenge that authority, to reclaim control over the flow and distribution of information.

What Williams would recognize as a dominant ideology and an emergent ideology—what he refers to as the "new meanings and values, new practices, new relationships and kinds of relationships [. . .] being created"108 —are being played out in the game's narrative. We observe the status quo but also a novel opposition to that dominant mode of thinking. A new structural relationship amongst the social strata are being reconceptualized, one that destabilizes a commonly accepted existing framework. Given the game's assertion that both sides of the conflict are inherently criminal to some

${ }^{108}$ Williams, “Dominant," 123. 
degree, ${ }^{109}$ the game also suggests that the domestic issues depicted in the narrative do not come with totalizing and easy solutions. Rather, the game, when observed as a discursive artifact, speaks about its time and place to suggest that conflict not only exists abroad but also within the domestic structure of power as well. But instead of proposing an obvious path forward toward some societal improvement, it paints a picture of an unstable world in perpetual and unresolved conflict. As a discursive artifact, then, Android: Netrunner not only presents a material contribution to a culture's ideas and attitudes from within a given time and place but also presents the regulatory framework from which these attitudes and actions emerge.

When Cosmic Encounter and Android: Netrunner are compared alongside one another, we can observe two distinct discourses that "speak" about the ideas, interests, and actions of their given timeframes. Naturally, given the span between their respective publication dates, the worlds, interests, and actions are observably different from one another. Cosmic Encounter, for instance, depicts a "world" of superpowers vying for expansive influence through conflict, strategic alliances, deceit, and negotiation. As such, the game can be read superficially as an example of sci-fi escapism, but it also presents as a performative stage upon which players can simulate the hostile realities of US foreign policy during the time. By contrast, Android: Netrunner pushes against the focus on political intrigue and conflict of its predecessors to formally relocate the arena of conflict. Therein, conflict emerges from economic regulatory practices as well as the stratification of the classes. Separately, they function as discursive artifacts that "speak" about their

\footnotetext{
${ }^{109}$ Indeed, one of the factions of runners steal information not to expose corporate interests but for profit.
} 
time and place, not only in terms of experience and action but also the ideological $a$ priori from which those experiences and actions emerge.

\subsection{EUROPEAN-STYLE GAMES AND THE ABSTRACTION OF CONFLICT}

European-style games differ significantly from their American counterparts in their prevalent aversion to conflict. Whereas the interest of many American designs is for a game to facilitate a narrative experience, the interest of many Eurogames is to promote innovative mechanisms that allow players different ways to manipulate the game state. Given the variety of choices and different impacts of interactive tokens, the narrative serves to distinguish these effects more simply and coherently. The narrative, in Eurogames, tends to function as a connective element that brings clarity to its mechanism rather than the other way around. ${ }^{110}$ In short, in American-style games, mechanisms cohere the narrative while in Eurogames, narratives cohere the mechanisms. For discursive analyses, this selectivity and abstraction of narrative in Eurogames proves particularly telling about the interests, ideas, and actions of the players and producers surrounding the game's locus of production.

The purpose of this section, then, is to analyze a European design to demonstrate how its mechanisms foreclose its narrative implications and what those narrative implications might suggest about the culture surrounding its production. While there are countless titles that could serve as case studies to demonstrate this, the German design $E l$ Grande (1995) proves particularly useful in demonstrating how a game's ludonarrative

\footnotetext{
${ }^{110}$ To use traditional games as an example, there is no need for narrative in a game such as Checkers because the pieces move and function indistinguishably, for the most part. By contrast, a game like Chess is aided by its narrative veneer since the pieces move and interact in different ways. The narrative helps to establish the role and importance of each piece in the game, even though the game is largely abstract.
} 
gradient both conceals and discloses cultural ideologies informing its design choices. By selectively excluding narrative elements and mechanically abstracting the conflict that undergirds its narrative, El Grande presents as a discursive artifact that reveals a performance space in which the ideologies of the status quo are affirmed.

\section{El Grande (1995)}

El Grande is an area-majority game in which two to five players compete to have the most points at the end of the game. The game is set in Medieval Spain during the $13^{\text {th }}$ through $15^{\text {th }}$ centuries. Players in the game take on the roles of "Grandes" who control a faction of thirty Caballeros. These Caballeros, through game actions, occupy marked regions on the game's board. At prescribed and triggers moments within the game, the regions on the map of Medieval Spain are scored according to which players have a majority presence within that area, with up to three tiers of points being awarded to players present in the region. ${ }^{111}$ Apart from visible and predictable scoring moments, players can also initiate scoring through card play. After nine rounds and three prescribed scoring periods, the game ends and the player with the most points wins the game.

How players place and move their Caballeros is the focus of the game's design. Caballeros occupy three general areas of play over the course of the game: 1) regions on the map, 2) the court - the area before the player from which Caballeros may be drawn to occupy the map, and 3) the provinces - a "supply" pile of Caballero tokens that are

\footnotetext{
${ }^{111}$ Another area of the game, the Castillo, a cardboard tower, accumulates tokens from players over the course of the game but conceals the number of Caballeros from view. It is also scored according to majority presence at different moments in the game.
} 
generally considered out-of-

play unless first collected

into the court. At the

beginning of the game, a

player's "Grande" token

occupies a randomized home

territory, and two Caballeros

are added to this home

territory. Seven Caballeros

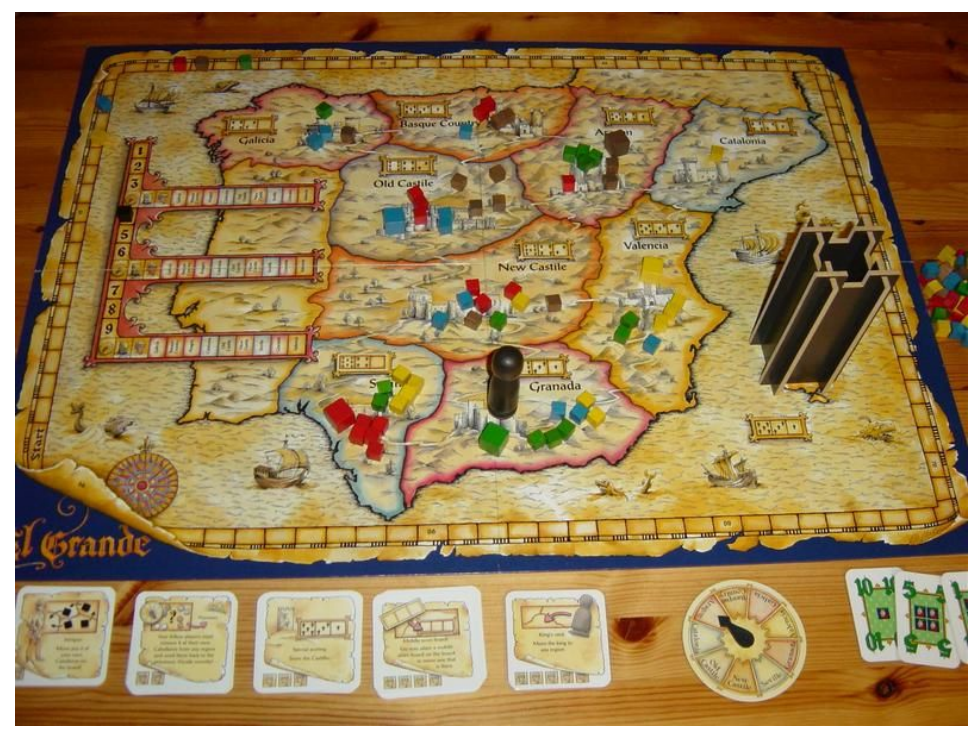

Figure 2. 3 The board for El Grande, depicting the nine regions and tiered scoring for each region.

are within the court, and the remainder are placed in the provinces-i.e. out of play. A king token is also placed on the map. When adding Caballeros to the board, players may only place in regions adjacent to the king but not in the region occupied by the king. ${ }^{112}$ Card actions can move the king or "break" this fundamental rule. To move Caballeros from the province to the court or from the court to regions on the board, players select one of thirteen "power" cards from their hand of cards. Power cards detail how many Caballeros may be added to the court, and its depicted "strength" establishes turn order for the remainder of the round. In addition to playing "power" cards, players choose one of five "action" cards available in a common display. These detail the number of Caballeros that may be added to the board and a special action that allows a player to perform such actions as "evicting" competitors' Caballeros from a region or an "intrigue" card which allows that player to relocate Caballeros into different regions. In this manner,

\footnotetext{
${ }^{112}$ Additional rules apply to the Castillo. The Castillo, representing service abroad, has little impact on this discussion of the game's mechanism or narrative, so it is abstracted for the sake of brevity.
} 
the Caballeros, Grandes, and the king move between the board's regions with players hoping to change the game state in such a manner they benefit most when scoring occurs.

As its mechanisms suggest, the narrative underlying this game could have been any number of scenarios, for the narrative functions to clarify the distinguishing roles and actions of the playable pieces rather than to tell a story. But this conscious selection of a narrative setting and its consequential abstraction of play informs us of attitudes the players and producers of the game have not just to notions of conflict, but of space and complicity.

Conflict, if it can be said to exist in the game, manifests in the form of frustrating other players' access to point-scoring objectives. Players can force players to relocate their tokens to other areas of the board or out of play, but there is nothing in the game that represents physical conflict. In this manner, El Grande aligns with the proclivity of Eurogame designs to avoid direct confrontation. And this avoidance, as a mechanical performance, affirms the ideological and political approach to conflict real-world Germany ascribes to. Since the violence and atrocities of World War II, Germany has adopted an antimilitaristic approach to conflict, maintaining their national military forces for defensive and deterrent measures rather than offensive. ${ }^{113}$ Rather than using force under a national banner, Germany has employed military forces generally in multilateral involvements under the banner of allies or NATO since its reunification. ${ }^{114}$ This "hands off" approach to conflict is concretized through the mechanical performance of $E l$ Grande and similar games where conflict is indirect and deters others from their goals.

\footnotetext{
${ }^{113}$ Cf. Thomas U. Berger, Cultures of Antimilitarism: National Security in Germany and Japan (Baltimore: Johns Hopkins University Press, 1998).

${ }^{114}$ Maull, Hanns W., "Foreign Policy: From 'Civilian Power' to 'Trading State?'” in The Routledge Handbook of German Politics and Culture, ed. Sarah Colvin (New York: Routledge, 2015), 419.
} 
Tellingly, El Grande is set in Medieval Spain rather than Germany during any time period. This design choice creates a literal and metaphorical distance between its players and the implied narrative. This construction of distance, which is not an anomaly of German game design, ${ }^{115}$ is a signifying practice that works on multiple levels. On one, it suggests that any narrative conflict that might present does not happen "here," and on another, it suggests that whatever conflict that might take place does not involve "us." The "not here" and "not us" projection suggests an escapism itinerant to game design but also, when the narrative is based in reality, deflects any acknowledgement of culpability. The "this-happened-long-ago-elsewhere-among-other-people" implication performs an ideological belief through game mechanism. Following Althusser, the belief is realized through ritual practice cyclically prescribed by that belief, or as he puts it, an idea's "existence is inscribed in the actions of practices governed by rituals defined in the last instance by an ideological apparatus." ${ }^{" 16}$ An ideology, in other words, has material constituents that are ritualistically acted upon in a way prescribed by the ideology to deterministically realize that ideology. As a consequence, German game designs not only task players to perform actions to concretize their antimilitaristic positions but those actions are regulated by that stance.

Abstracting conflict from the game design has another effect: it obscures the reality the game simulates. In the case of El Grande, the reoccupation and repopulation of Medieval Spain during the $13^{\text {th }}$ through $15^{\text {th }}$ centuries were characterized by real violence and conflict. This era, part of what is commonly known as the Reconquista, was comprised of several campaigns to recapture terrain from the Moors occupying the

\footnotetext{
${ }^{115}$ As the analysis of Istanbul (2014) in Chapter 3 further supports.

${ }^{116}$ Althusser, 115.
} 
peninsula up until their expulsion in $1492 .{ }^{117}$ Given the time period, this expansion effort would necessarily impact the Jewish population as well. However, these cultures are not mentioned in El Grande. Instead, expansive influence exists for the sake of itself. Under the pretense of the game, these expansive operations are victimless and therefore harmless.

As a performance that realizes an ideology undergirding its own production, $E l$ Grande exemplifies how cultural attitudes toward violence and conflict manifest within game design. A continual focus on mechanism over narrative secures the significance of mechanical performance while simultaneously skewing and obscuring the reality of the events simulated. This favoring of the ludic end of the ludonarrative gradient can yield problematic implications. The reality of its narrative, with whatever violence, exploitation, or oppression that might comprise that reality, is subjected to selectivity and exclusion in the service of mechanism. Culpability and complicity risk being eschewed as a result of this curation. As a result, players are encouraged to enjoy the game for the sake of its mechanical innovations and turn a blind eye to the unsettling reality that may lurk beneath the surface of its narrative.

\subsection{CONCLUSION}

American and European styles of board game design are distinct, especially in their approaches to conflict. Despite this distinction, board games present as discursive artifacts that reveal how people think, feel, and act upon certain ideas within a given time and space. Beyond this, following the archaeological method proposed by Michel

\footnotetext{
${ }^{117}$ Cf. Joseph F. O'Callaghan, Reconquest and Crusade in Medieval Spain (Philadelphia: University of Pennsylvania Press, 2003).
} 
Foucault, these discourses reveal the regulatory conditions that makes these experiences and actions possible — what Foucault called the episteme. Vietnam and the Cold War were a priori contexts to the design of Cosmic Encounter, for instance, and neoliberal economic structures provides a foundation from which Android: Netrunner is allowed to express its attitudes toward corporate greed and public power. From a European design perspective, a prevalent aversion to physical conflict informs antimilitaristic stances held by its locus of production. As metaphorical "portholes" into a slice of humanity at a given place and time, board games reveal the ideologies revered by its players and producers. Additionally, being tasked to perform actions that affirm these ideologies, these ideologies are further concretized through play.

These observations are made possible by two characteristics of modern board game design: board games necessarily abstract elements from the events and objects simulated, and modern board games reconcile mechanical and narrative demands to cohere an intended play experience. Those elements that are abstracted from playwhether fictitious or historical—present as opportunities for further inquiry. We are able to question the selectivity and curation of its narrative as well as highlight what has been avoided, for better or worse. Further, because modern board games reconcile a ludonarrative gradient, games risk forestalling attention and debate regarding any realworld implications or consequences of ideological practice. By analyzing games as discourse, these ideologies and practices reveal themselves. 


\section{CHAPTER III}

\section{UNEARTHING EUROCENTRISM}

We must be insistently aware of how space can be made to hide consequences from us, how relations of power and discipline are inscribed into the apparently innocent spatiality of social life, how human geographies become filled with politics and ideology.

-Edward W. Soja ${ }^{118}$

Maps and geography are prevalent design features in board games, given their convenience of marking boundaries and spatializing goals, and as more games use realworld places as arenas for simulation, questions emerge about the relationship between the social space for play and the material space of play. With the necessary abstractions of board game design, concerns of subjectivity, selectivity, and exclusion operating in a game's production of space come to the fore. Given that geographical representations are socially constructed, the use of geography in games both expresses and emerges from ideological contexts, risking an endorsement of Eurocentrism.

The 2000 Spiel-des-Jahres winner Carcassonne exemplifies this concern. Carcassonne is a tile-laying game wherein players draw and place small tiles featuring different aspects of the landscape as they actively construct the walled city of Carcassonne and its surroundings. The requirement for placing tiles is that features must match the features of contiguous tiles - e.g. grass must connect to grass, roads must

\footnotetext{
${ }^{118}$ Edward W. Soja, Postmodern Geographies: The Reassertion of Space in Critical Social Theory (Brooklyn: Verso, 1989), 6.
} 
connect to roads, etc. Once tiles are place, players have the option to place one of their limited number of player tokens, known as "meeples," on a feature represented on the tile $\mathrm{e}^{119}$ — city, farm, road, or cloister. Once that feature is completed according to the rules of the game, players score their tokens and return them to their supply to be re-placed on a later turn. ${ }^{120}$ The player who has earned the most points at the end of the game is declared the winner.

Carcassonne reveals interesting and underlying assumptions about the use of space and place in board games.

The title of the game is a reference to a real-world place, but players construct that place differently each game. The game, then, supports two functions of space, that of a realistic and material reference and that of imagined or conceptual space. How do we reconstruct an actual place with real boundaries and features differently each time?

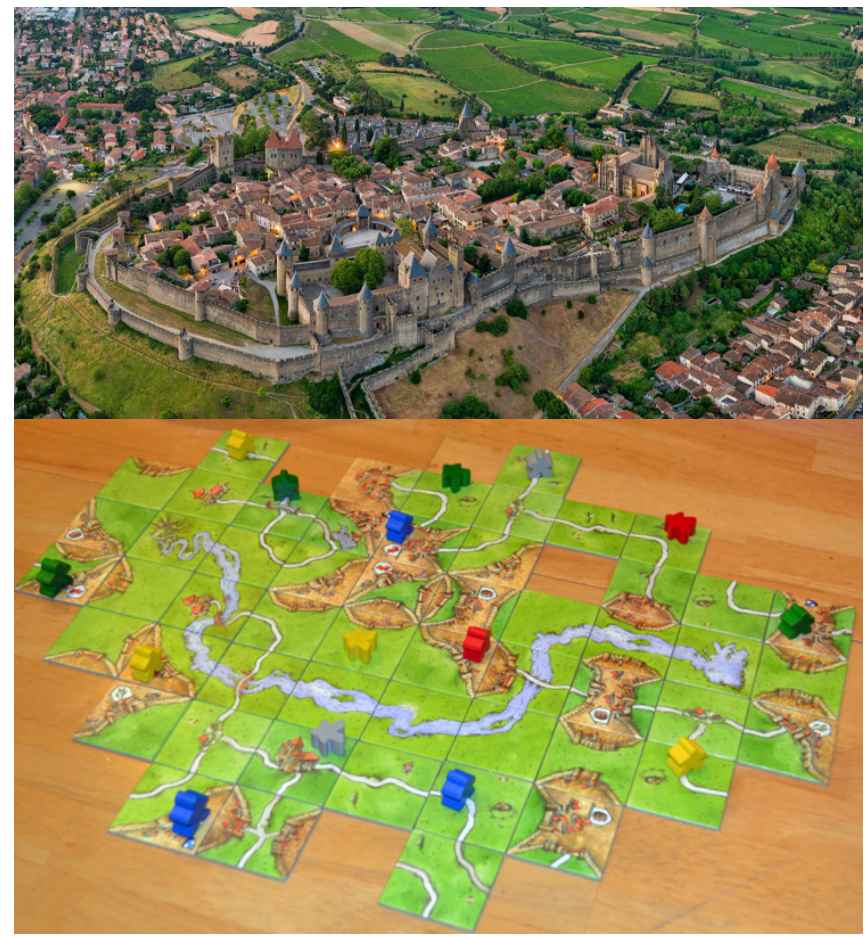

Figure 3.1 Contrast between Carcassonne, France, and the board game Carcassonne.

\footnotetext{
${ }^{119}$ Dawn Dalton, "The Evolution of the Meeple," Geek \& Sundry, August 29, 2017, https://geekandsundry.com/the-evolution-of-the-meeple/. These tokens, though not originally referred to as such, have come to be affectionately referred to as "meeples" after player Alison Hansel referred to Carcassonne's little wooden representations of people through a mashup of "my" and "people." The term has become widespread to describe these and similar tokens used in Eurogames to signify the player's human presence within the play space.

${ }^{120}$ Apart from tokens in farmland, recognized as farmers - these remain until the end of the game, when they are scored.
} 
As a result, Carcassonne becomes something real—with a real history, culture, and appearance — but simultaneously something subject to imagination — it is malleable, destabilized, a blank slate upon which to describe and direct personal interests. This convergence of the real and the imaginary regarding places is what scholar Edward J. Soja has referred to as "Thirdspace." This results in an experiential distance between the object and practice, an assertion even more clarified when we consider games published under the "Carcassonne" label, such as Carcassonne: South Seas (2013) ${ }^{121}$ or Carcassonne: Gold Rush (2014) ${ }^{122}$. Carcassonne, then, loses its status as a real place and becomes a malleable ordering system through which points are eraned. And this understanding of how place and geography are caught between real references and conveniences of play raises questions about how the real-world geography is represented, what subjectivities constrain that representation, and how geography can be used to reinforce ideology.

The three games analyzed here-Istanbul (2014), Jamaica (2007), and Puerto Rico (2002) - work in separate ways to show how geography, conceptually and in praxis, can work dually to stabilize and naturalize the ideologies of the map's producers while deflating, disparaging, or even erasing the importance of the space's inhabitants. Each of these games use representations of distant spaces — in space, time, or both — as a medium through which we reveal a narrative and through which we manipulate the game state. Istanbul, for instance, profiles a culture of people as greedy criminals within a "crowded" destabilization of place; its subjective malleability and abstraction ultimately secures disparaging assumptions of both the place and its people. Jamaica, by contrast, deflates

\footnotetext{
${ }^{121}$ A game which has players trading tropical fruit and fish within the same tile-laying concept.

122 Set in the American "Old West."
} 
the significance of a culture through selective representation and a stagnant nostalgia. And Puerto Rico skews geographical significance under the purview of naturalized colonialism. Geographies in game design, then, become a metaphorical workbench upon which producers and players perform ideologies within a naturalizing and legitimating framework. In short, geography materializes subjective ideologies while naturalizing those ideologies within a supposed inert objectivity.

\subsection{THEORIES AND CONCEPTS}

Space has many and far-reaching implications for game design, and because of the breadth of implications, there are several avenues all equally worth pursuing. Indeed, in games, we speak of reaching spaces, occupying spaces, developing spaces, sharing spaces, and so on. Generally, there is also a space of play-in its materials, mechanisms, choices, its temporal constraints, its social implications, as well as community. But I want to focus on two major aspects of space: that of conceptual distance and boundariesthere is a "hereness" and "thereness" quality within games that proves insightful but also a Manichean binary characterizing what space is "theirs" versus "ours" - and that of social constructions of space.

\subsubsection{The Social Construction of Space: Lefebvre, Soja, Foucault, and de Certeau}

Dealing with the latter first, the social construction of space as I employ it here has roots in the theories put forth by Henri Lefebvre, particularly his work The Production of Space (1974), and expanded in the work of Edward W. Soja. The contribution of Lefebvre's work toward understandings of space and spatiality cannot be 
overstated. The Production of Space works to destabilize conventional presumptions

about space. Among these are assertions that space is inert, pre-social, natural, apolitical.

It is a tool by which knowledge and language frame human activity rather than a

constituent result of social praxis. ${ }^{123}$ Whereas space is presumably given as real and

stable, Lefebvre counters that "physical space has no 'reality' without the energy that is

deployed within it." 124 The prevailing presumptions of space have allowed spaces to be

"read" as objective and neutral artifacts of cultural activity within a given timeframe. ${ }^{125}$

While this is in part the case, it misses the productive capabilities of space. For Lefebvre, space is as much a 'text' as it is a 'language.' 126

The presumed inertness of space-what Lefebvre refers to as the "illusions" of space $^{127}$ — that conceal the productive qualities of space raises questions about how a board game's use of space unintentionally conceals conflicts. When we think of the space represented in board games, it is often a material medium through which human conflicts

\footnotetext{
${ }^{123}$ Henri Lefebvre, The Production of Space (1974, repr. Cambridge, MA: Blackwell, 2000$), 4$.

${ }^{124}$ Lefebvre, Production, 13. As a theorist within the Marxist tradition, words like "production" and "energy" carry the weight of a Marxist economic structuralism.

${ }^{125}$ Lefebvre, Production, 36.

${ }^{126}$ Indeed, Lefebvre recognizes 'space' as a mode of production, and he uses the term with knowledge of its loaded implications. As a Marxist scholar, he is concerned with not only these modes of production but the reproduction of relations to production. Lefebvre's insights into space can be observed as metaphorically 'writing' economic ideology onto the land itself, a notion we can quantitatively observe from urbanism, with the centralization of economic energy within cities and the implicated relationships to that economic locus mapped through green spaces and labyrinthine suburban infrastructure that 'compel' prescribed relationships to labor, wages, and capital. See, for instance, Lefebvre's notion of this contradictory division and unity in city planning, Production, 358-60.

127 Lefebvre, Production, 27-8. Presumptions about the inert and natural qualities about space have been allowed to flourish throughout history and scholarly work, according to Lefebvre, due to two central illusions about space: the illusion of transparency and the realistic illusion. The first of these suggests that space has itinerant qualities that make it measurable, observable-an intelligible "mediator" that reveals mental conceptions and social activities. But this ability to "bring to light" what is significant or relevant connotes its own status as an illusion, for the selection and curation of revelation mandates exclusionary practices and representations. In short, the perceived transparency of space conceals as much as it reveals. The second of these illusions, the realistic illusion, bolsters the assumption that space is natural and pure, untainted and preexistent of subjectivity.
} 
play out. Games like Risk (1959) and Diplomacy (1959) utilize space as a boundary between national powers, and games like The Game of Life (1960) use space as a symbolic progression toward goals. With our focus on our own goals, it is easy to dismiss space as a material convenience to play. This objective materialism, however, masks the ideological uses of space, as well as attitudes toward space, that facilitate and stabilize power dynamics. ${ }^{128}$ When space is considered as a social construct in game play, we are able to include space alongside player action as a means of understanding conflict and access toward goals. ${ }^{129}$

\section{Extending the work of Henri Lefebvre, Edward W. Soja's Postmodern}

Geographies aims to concretize the importance of space in critical geography by echoing the laments of Lefebvre and Michel Foucault that space has been historically subsumed by the privileging of time. Echoing Foucault, ${ }^{130}$ Soja criticizes the passivity of past geographical inquiry, putting forth:

Modern Geography was reduced primarily to the accumulation, classification, and theoretically innocent representation of factual material describing the areal differentiation of the earth's surface [... . Geography thus also treated space as the domain of the dead, the fixed, the undialectical, the immobile - a world of passivity and measurement rather than action and meaning. ${ }^{131}$

\footnotetext{
${ }^{128}$ Cf. Henri Lefebvre, "Reflections on the Politics of Space," trans. Michael J. Enders, Antipode 8 no. 2 (1976): 31. Therein, Lefebvre states: "Space is not a scientific object removed from ideology or politics. It has always been political and strategic. There is an ideology of space. Because space, which seems homogeneous, which appears as a whole in its objectivity, in its pure form, such as we determine it, is a social product."

${ }^{129}$ In this light, the space of The Game of Life, for instance, becomes less inert as we are able to see how the game's space allows an ideological "script" about wealth, family, and education to play out as "natural."

130 Michel Foucault, "Questions on Geography," in Power/Knowledge: Selected Interviews and Other Writings 1972-1977 (1976, repr. New York: Vintage, 1980), 70. As Foucault describes, "Space was treated as the dead, the fixed, the undialectical, the immobile. Time, on the other hand, was richness, fecundity, life, dialectic."

${ }^{131}$ Soja, Postmodern, 37.
} 
Instead, through Lefebvre and Foucault, Soja sees an opportunity for a new way to think about and practice geographical inquiry that remains attentive to sociality and by consequence, social justice through spatiality. For Soja, human geography, how people live within and negotiate material and imaginary conceptions of space, proves to be a "competitive arena [...] for social practices aimed either at the maintenance and reinforcement of existing spatiality or at significant restructuring and / or radical transformation."132 Space, then, allows for a relative autonomy amongst its users to adhere to or compete against prevailing ideological principles that govern space as both a medium and an outcome of social activity.

This sentiment is continued in another of Soja's works, Thirdspace, in which he refigures Lefebvre's spatial triad—spatial practice (the material configurations of space), representations of space (conceptual imaginings of social space), and representational space (how space is lived and experienced) ${ }^{133}$ —as firstspace, secondspace, and thirdspace so as to emphasize experientiality within Lefebvre's framework. ${ }^{134}$ Thirdspace, the experiential aspect of space that negotiates both material and symbolic organizations of

\footnotetext{
${ }^{132}$ Soja, Postmodern, 130.

133 Lefebvre, Production, 33. Lefebvre puts forth the notion of the spatial triad in an attempt to balance scholarly attentions to space. Space, for him, is divided into three interrelated and codependent frameworks: spatial practice, which concerns the material aspects of space, representations of space, which concerns imaginary conceptions of space as it is planned or envisioned, and representational spaces, which concerns how people 'live' within and negotiate spaces. Space, according to Lefebvre, has been couched in quantitative terms of the material and the conceptual with little attention given to space as a social production, and because of these presumptions that objectify and neutralize the dynamics of space, ideologies engendered through and within space have been largely ignored.

${ }^{134}$ Edward W. Soja, Thirdspace: Journeys to Los Angeles and Other Real-and-Imagined Places (Cambridge: Blackwell, 1996), 74-79. Firstspace, in his view, is the materiality of space-the buildings, roads, and other observable structures that organize space. Secondspace, by contrast, is an imaginary organizational framework, which could be figured in terms of conceptual principles such as commerce or symbolic associations to a space. Here, Soja also suggests that symbolic associations to space-e.g. anthems, cultural distinction, etc. - tend to supplant the firstspace materiality so that a space refers as much to its materiality as to its symbolic organization.
} 
space to express a unique experience, ${ }^{135}$ is useful for understanding how board games utilize space because space in games utilize material and conceptual organizations but also include an experiential simulation. What Soja refers to as "thirding," an opportunity to explore the multiplicities concealed within the material-social binary of firstspace and secondspace, ${ }^{136}$ looks at how people mediate the material and social realities of space. This proves useful for inspecting board games because it expands agonistic and antagonistic conflict to include a spatial framework as well. ${ }^{137}$ The prevalent city-builder games like Suburbia (2012) reconcile this framework rather well. While players compete to acquire city-feature tiles - from housing, to factories, to parks, and restaurants - to develop their personal cities, how these different features interact with one another and contribute to the population's contentment is a key element that players need to consider. Generally, how players and producers frame access, inequality, and power is not simply located within negotiations of game materials as inert media; power shapes and "writes" itself into the game's landscape.

Thirdspace perceives how people negotiate spatial order through an experience that combines the material and the imagined. ${ }^{138}$ Michel Foucault, however, puts forth a different notion that simultaneously combines the real (material) and the imagined (mental) space: heterotopias. As he remarks in The Order of Things, heterotopias "are

\footnotetext{
${ }^{135}$ Soja, Thirdspace, 81.

${ }^{136}$ Soja, Thirdspace, 5 . Soja states that "the geographical imagination can be expanded to encompass a multiplicity that have heretofore been considered by the epistemological referees to be incompatible, uncombinable."

${ }^{137}$ Soja, Thirdspace, 5. Soja tends to look at this opportunity optimistically, highlighting how thirdspace opens a multiplicity of experiences. Social justice through spatial justice is one of Soja's key concerns, and thirdspace allows for "a space where issues of race, class, and gender can be addressed simultaneously without privileging one over the other [... . "It can be said though that the opportunity to negotiate material and conceptual frameworks of space can further exacerbate cultural divisions. With the itinerant conflict of board game design, I emphasize this possibility.

${ }^{138}$ Soja uses Los Angeles as an example of this simultaneously real and imagined space.
} 
disturbing" spaces. ${ }^{139}$ They represent space that has been marked off and separated from everyday experience. But in their removal they retain an interconnectedness to all other places. These might include the cemetery, the psychiatric hospital, the nursing home, the prison. They represent a disruption in both space and time. They are out of place while simultaneously located in reality, gesturing toward and juxtaposing the places surrounding it. ${ }^{140} \mathrm{We}$ can see this concept of entangled and contradictory place directly connecting to notions of the abject ${ }^{141}$ or Mary Douglas's assertions about pollution ${ }^{142}$ in that what is expelled from the (social) body retains a symbolic connection to that body, challenging the boundaries that maintain that separation. In a similar vein, heterotopias undergo a totalizing material removal from the everyday, but they retain a conceptual space within the everyday.

These assertions—-from Lefebvre and Soja to Foucault—offer a useful insight into how we play and think about games. On the one hand, we play as roles within a specific landscape, manipulating pieces to reach some prescribed goal with a multiplicity of choices about how those goals can be realized. We can see this attentive focus on lived spatiality in a game like Android: Netrunner, wherein the play space represents a contested cyberspatial network that is governed by both material - e.g. hardware, servers—and conceptual—e.g. greed, individualism, and autonomy—frameworks. ${ }^{143}$ The experiences of both the runner and the corporate entity vie for control and acquisition of

\footnotetext{
139 Foucault, Order, xviii.

140 Michel Foucault and Jay Miskowiec. "Of other spaces." diacritics 16 no. 1 (1986): 22-27.

141 Julia Kristeva, "Approaching Abjection," in Powers of Horror: An Essay on Abjection (New York: Columbia University Press, 1982), 1-31.

142 Mary Douglas, Purity and Danger: An Analysis of Concepts of Pollution and Taboo (1966, repr. New York: Routledge, 1994).

${ }^{143}$ See Chapter II.
} 
information, demonstrating the possible maneuvers players can exploit in order to reach their respective goals. On the other hand, players in many games take the role of an omniscient overseer, who conducts and manipulates the forces of production within the play space. In this sense, games are less attentive to the experiences of those colloquially "on the ground" but to the ideologies that constrain material and conceptual frameworks. When applying these concepts of space, we are able to observe and dismantle ideological performances that are veiled through presumptions of objectivity.

To better understand this conceptual distance between player and experience, I turn to the work of Michel de Certeau, whose The Practice of Everyday Life draws from the work of Michel Foucault and sociologist Pierre Bourdieu to present a view of spatiality that coalesces with Soja's work. Drawing on Foucault's notion of panoptic classification and surveillance ${ }^{144}$ and Bourdieu's notion of habitus - the acquired and differentiating improvisations a body expresses within a given social organization ${ }^{145}$ - to highlight a potential for resistance in imposed ideological practices. Through the dichotomous spatial metaphor of looking down upon a city street and the act of walking the same city streets, de Certeau puts forth the notions of strategies and tactics. Strategies are the practices that "read" the material and social arrangements of a given space-like

\footnotetext{
${ }^{144}$ Particularly, Foucault's work on the panopticon from Discipline \& Punish.

${ }^{145}$ Admittedly, this is a simplification of a profound and complex assertion. In Outline of a Theory of Practice, Bourdieu clarifies that individuals inhabit specific and overlapping sociological "fields" that constrain the possibilities of their expression and through these negotiations they develop social capital that can be deployed as stylistic differentiation. With the "habitus," individuals have the capability to maintain the ordering principles defining the given field or differentiate from those principles. He states, "The habitus, the durably installed generative principle of regulated improvisations, produces practices which tend to reproduce the regularities immanent in the objective conditions of the production of their generative principle, while adjusting to the demands inscribed as objective potentialities in the situation, as defined by the cognitive and motivating structures making up the habitus" (p. 78).
} 
the act of viewing the city from the high floor of a skyscraper. ${ }^{146}$ This is the vantage point of ideology: it is panoptic, assessible, and deterministic. This is the conceptual locus of power that organizes and constrains social activity in a Foucauldian sense, but de Certeau suggests that lived experience - that of walking the streets - allows for a relative sense of autonomy. The walker, he suggests, "actualizes" the possibilities of the spatial order: "he [sic] makes them exist as well as emerge. But he also moves them about and he invents others, since the crossing, the drifting away, or improvisation of walking privilege, transform or abandon spatial elements." "147 These tactics, for de Certeau, demonstrate a possibility for resistance and ideological transformation.

de Certeau's spatial metaphor proves useful for understanding how players position themselves in relationship to the avatars and materials of a game. Indeed, some games

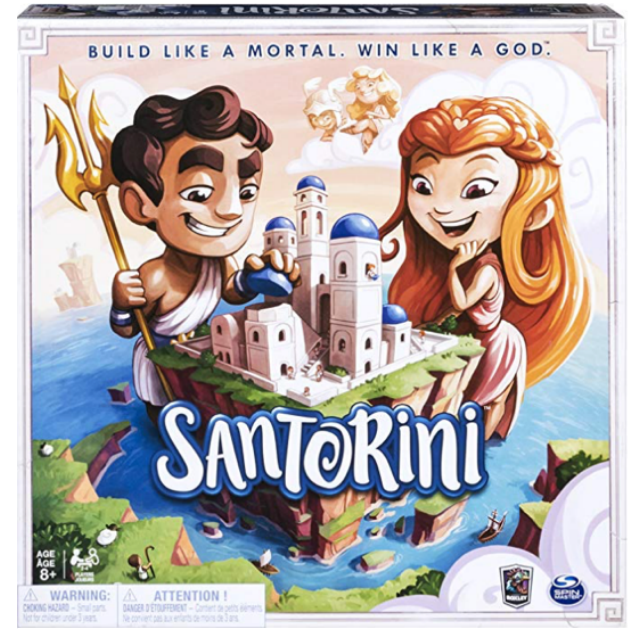

Figure 3.2 Santorini box art, depicting gods looking down upon the construction of the city

literalize this panoptic omniscience of looking down upon the game state. The 2016 game Santorini positions players as mythological gods literally overseeing the construction of an island city. But what is most useful in de Certeau's assertions about spatiality and ideology is that the lived tactics, the site of potential resistance, is largely neglected in board games. The rules and mechanisms of gameplay allow for multiple choices and rewards, but choice is relatively constrained in board games since some the rules

\footnotetext{
${ }^{146}$ Michel de Certeau, The Practice of Everyday Life (1984, repr. Berkeley: University of California Press, 1988), 92.

147 de Certeau, Practice, 98.
} 
predetermine the desired result of the game and some actions are not mechanically available to players. Given the limited opportunities for choice and individualized expression, players are more often than not compelled to maintain whatever social ordering principle is valorized by the game's rules.

\subsubsection{Cartographic Silence: Harley}

This malleable and flexible production of space as a social product connects directly to issues of cartography and the role maps play in board games. Maps are a common staple to board game design, for they provide a prescribed spatial organization to play. Maps ${ }^{148}$ offer a convenient way for game designs to demarcate boundaries amongst players, isolate goals, and provide space for players to traverse in order to achieve those goals. They order and organize the play space in many instances, and they are often taken for granted as inert and "factual" representations of the given region. However, like the production of space generally, maps are a social construction. To clarify, I turn to the work of J.B. Harley.

J. B. Harley's work on critical geography shows the many ways maps are imbued with the subjective biases of the producer. Maps are perceived as unproblematic mediators of geographic information, but Harley demonstrates that maps are made within and informed by social contexts. ${ }^{149}$ For instance, not only do maps work to "reproduce"

\footnotetext{
${ }^{148}$ I am focusing on verisimilar maps of real-world geographies here, but similar issues would arise when considering fictitious or fantastic maps.

149 J. B. Harley, J "Maps, Knowledge, and Power," (1988, repr.) in The New Nature of maps: Essays in the History of Cartography, ed. Paul Laxton (Baltimore: Johns Hopkins University Press, 2002), 53. Harley states: "Maps are never value-free images[... . ] Both in the selectivity of their content and in their signs and styles of representation maps are a way of conceiving, articulating, and structuring the human world which is biased towards, promoted by, and exerts influence upon particular sets of social relations."
} 
an understanding of a geographical space, they also reproduce "territorial imperatives" for the ideological framework from which and for which the map was made. ${ }^{150}$ Of particular interest in Harley's work is his assertion that maps conceal "silences" through its association with accuracy and replication. ${ }^{151}$ What is omitted from a map, necessarily due to scale but in part due to the interests of the map-maker, is an opportunity to reveal the ideological implications hidden within the map's features. Omitted features, such as houses and roads, can thereby create a palliative distance between the map's user and the depicted region, deflating or deflecting any moral or ethical concerns underlying geographical prospects. These "silences" itinerant to maps and the ideological premises they emerge from and constitute prove especially useful for game analyses, for games, like maps, necessarily omit features from the represented geography. Harley's assertions allow us to observe how the "accuracy" of game maps conceal power hierarchies through their "silences."

\subsubsection{Thereness: From Said to the Tourist's Gaze}

Alongside notions of the social production of space and critical cartography are concepts that deal with conceptual distance - that is, how places and cultures are categorically represented as "there" rather than "here." For this, I turn to the work of Edward Said and his notion of Orientalism. In his analysis, Said suggests that the image of the East is filtered by Western thought and practice, and this bias of exoticizing the East in terms of the West skews the image of the Orient and the Oriental. Observations about the Orient were not merely descriptive but constructing, in that the image of the

\footnotetext{
${ }^{150}$ Harley, 54.

${ }^{151}$ Harley, 67.
} 
East, continually defined as exotic, strange, non-Western, was made and reproduced by the West. ${ }^{152}$ Orientalism, then, is a categorical practice that creates differentiation across groups, dually confining the Orient into an image of Otherness while actualizing the boundaries of a normalized Western identity. There is a conceptual "us" and "them," whose distinctions and separations from one another are socially constructed and maintained in service of the empowered, leading Said to question if one can "divide human reality, as indeed human reality seems to be genuinely divided, into clearly different cultures, histories, traditions, societies, even races, and survive the consequences humanly?"153 The categorical practice of Orientalism not only demarcates differentiated cultures and places but creates and sustains a power dynamic favoring Western subjects over Eastern objects.

The objectified foreignness that Said discusses implicates a range of Othering practices, but particularly useful to analyses of board games is how the geographically and culturally Othered are commodified for a consuming "gaze." Games task players to not only manipulate their given environments but to interact within them, to "visit" places and cultures distinct from their own. This raises the notion of the tourist's gaze, as aptly discussed by John Urry and Jonas Larsen. Urry and Larsen put forth the notion of the tourist's gaze to detail that the visitor's desire to "consume" experiences puts the tourist in the privileged position of dictating the quality and presentation of the toured objects. This results in a "spatial fixity" that confines cultural expression into signs and signifying practices that correlate with the visitor's expectations. ${ }^{154}$ Rather than witnessing

\footnotetext{
${ }^{152}$ Edward Said, Orientalism (1978, repr. New York: Vintage, 1994), 3.

${ }^{153}$ Said, 45.

${ }^{154}$ John Urry and Jonas Larsen, The Tourist Gaze 3.0 (Los Angeles: Sage, 2011), 49. They further suggest that "tourists tend to have high expectations of what they should receive since 'going away' is normally
} 
differentiated authenticity, the tourist makes the image of the host, one that is burdened by stereotype and cliché. ${ }^{155}$ Given the economic pressures of tourist destinations and the expectations of the tourist, the visited culture is reduced and presented as an object for tourist consumption, maintaining the visitor's privileged position as curator and consumer of cultural distinction while deflating the agency of the represented.

Tourism connotes a necessary negotiated contact between cultures that is contingent on multiple contextual pressures. This contact and context are largely absent in board game design, for producers and players operate within a relative cultural homogeneity: they select, curate, and determine the rules of cultural representation and contact. Despite this, the tourist's gaze proves useful in understanding how the construction of "place" in board game design participates in implicit mandates similar to those of the tourist. As Urry and Larsen note, "Places emerge as 'tourist places' when they are inscribed in circles of anticipation, performance, and remembrance." 156 And this holds true for board game design and consumption as well. Take, for instance, the representation of Japan. Players often anticipate a specific performance of Japanese culture, replete with samurais, villages, and pagodas. A game not conforming to those expectations would disrupt the anticipated experience of the player. Indeed, the production of Takenoko (2011), an aloof game about a gardener struggling against a hungry panda to farm and grow bamboo, was at least in one instance criticized as having

endowed with significance [. . . . People are looking for the extraordinary and hence will be critical of services appearing to undermine such quality."

155 Urry and Larsen, 17. "[A]s tourists, we see objects and especially buildings in part constituted as signs. They stand for something else. When we gaze as tourists what we see are various signs or tourist clichés. [. . .] Gazing is a set of practices. Individual performances of gazing at a particular sight are framed by cultural styles, circulating images and texts of this and other places, as well as personal experiences and memories."

156 Urry and Larsen, 119. 
"nothing Asian" in the game apart from bamboo and pandas, ${ }^{157}$ a comment that suggests there is a ready-made image of Asia players expect to see in their games. The tourist's gaze allows analyses of board games to inspect and understand how the culturally and geographically Othered are presented as commodifiable objects for consumer pleasure.

In tandem with these here-there and us-them dichotomies produced through objectification and conceptual distance, there exists a sort of Manichean division amongst spaces in board games. Not only are spaces compartmentalized and differentiated on the boards themselves, but the social play environment — wherein groups gather to play—is often in stark contrast to the narrative space. With narratives commonly centering on locales such as the Middle East, the Far East, and other exoticized places, the statistical prevalence that many players surround a table in Europe or America ${ }^{158}$ cannot be overlooked. What Frantz Fanon astutely observed in The Wretched and the Earth that the world of the colonized and the world of the colonists were two separate, markedly different worlds also seems to apply to board games. While this conceptual distance between play environment and narrative space exists for countless games, the importance of this distinction is given more gravity when considering narrative spaces of the colonial era and the ethnically distinct.

When taken together, these theories and concepts strip away the presumed inert qualities conventionally tethered to geography and geographical representation in board games. Underlying these presentations — whether spatial or cartographic — are ideological

\footnotetext{
157 “Looking for Good Asian-Themed Games," boardgamegeek.com, August 9, 2017, https://boardgamegeek.com/thread/1827199/looking-good-asian-themed-games ${ }^{158}$ Cf. Dan Jolin, "The Rise and Rise of Tabletop Gaming," The Guardian, September 25, 2016, https://www.theguardian.com/technology/2016/sep/25/board-games-back-tabletop-gaming-boompandemic-flash-point
} 
principles from which these representations emerge that simultaneously constitute that ideology. Power and inequality is not merely "read" from the geography, but they are in part manufactured through the ordering, differentiation, and use of space.

\subsection{THE ISSUE OF 'THERENESS' IN ISTANBUL (2014)}

How games present geographical distance between the social and material spaces of play has several implications for game design. The vast majority of board games transport their players to other worlds and other times. Players are compelled to escape the banal and everyday to venture into the less known. While American-style games often depict this distance through science-fiction or fantastic foreignness, Eurogames tend to transport players to real-world locales within the past. Most often, the players and producers of the games do not belong to the place being depicted; instead, it is a place that is "real" but juxtapositionally "there" as opposed to "here." This issue of "thereness" can impact the ideology of the players and producers of the game, with people and places being depicted as different, strange, or even backward. This implication solidifies the social space of the player as "normal" as opposed to the narrative space, which is perpetually "different." Given this conceptual distance between the social space and the narrative space, games risk endorsing Eurocentric worldviews at the expense of another culture or place. The 2014 Kennerspiel-des-Jahres-nominated game Istanbul is emblematic of this issue. Therein, Istanbul is depicted as a crowded, exotic, and dangerous place populated by criminals and greedy merchants. Given the German locus of development and the Turkish subject matter, the conceptual "distance" veils an apprehensive cultural contact space that is much closer to home than the game depicts. 


\subsubsection{Istanbul (2014) \\ Istanbul is a grid-}

movement resource

management game in which

players take on the roles of

Turkish merchants in the grand

bazaar trying to acquire a preset

number of rubies. The first to do

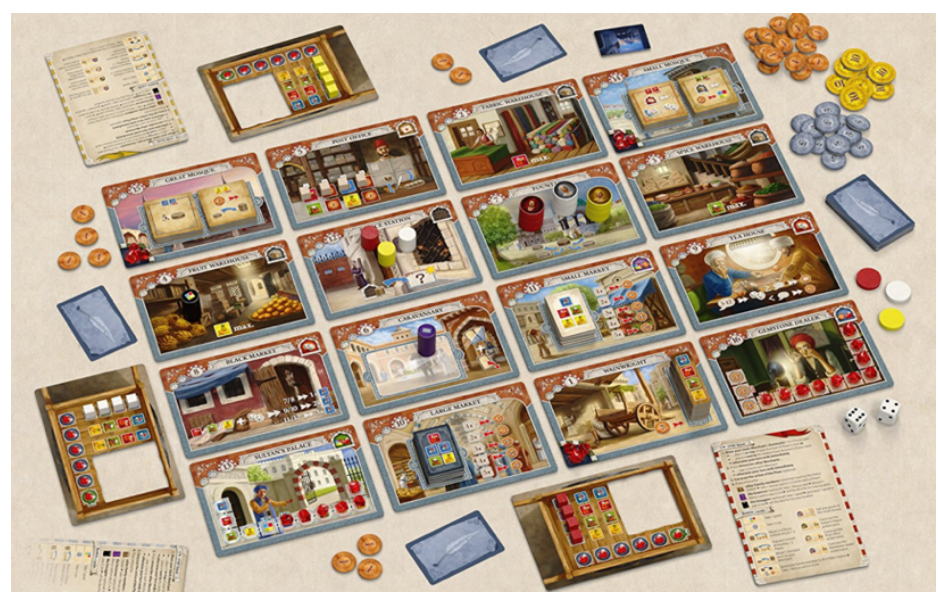

Figure 3.3 Istanbul board setup, depicting the sixteen bazaar locations

so wins the game. Players accomplish this by moving their merchant and group of assistants to sites displayed on the common board, each of which display a specified action that can be performed there. The warehouses, for example, allow players to fill their wheelbarrows with the depicted resource, while tiles like the markets allow players to trade in resources for lira (the game's monetary currency). Other tiles, like the mosques and the caravansary, allow players to acquire "rule-breakers" that they can utilize to bolster their resource gains or manipulate their restricted movements on the board. Completing certain in-game tasks, trading in resources, or cashing in lira are three ways players can acquire rubies. In most cases, the cost to meet these requirements increases as other players meet the goal first, so there is a race element that requires players to be efficient in their movements. For example, trading resources for rubies at the "Sultan's Palace" tile requires the player to trade in each of the goods that are uncovered and visible, but as rubies are removed, the required goods increases for future turns. 
The premise of the game is simple, but it is complicated by a few aspects.

Movement for players is highly restricted: players may only move one to two spaces orthogonally before choosing to activate a tile's action. Additionally, players may only activate a tile if they can drop off or

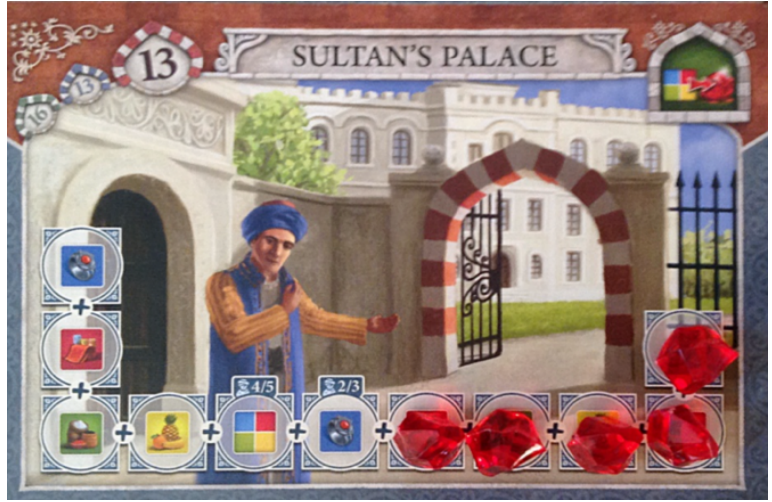

Figure 3.4 The Sultan's Palace tile, depicting the increasing number of resources needed to obtain a ruby (Istanbul).

pick up one of their assistant tokens on the space-player avatars do not themselves activate tiles. ${ }^{159}$ The board itself can become very crowded with other merchants, as well as a patrolling "governor" who can be paid for temporary rule-breakers and a "smuggler" who can be paid to receive a good to stock that player's wheelbarrow. When a player encounters another merchant, they must pay to be able to activate an occupied space. With money being relatively tight and needed for purchasing rubies, the crowded bazaar can frustrate a player's aspirations. Players do, however, have supplemental help in the form of a recidivist family member locked up at the police station. Presumably breaking them out of jail-you do not pay money to release them - they are able to move anywhere on the game board to carry out an action, sidestepping any fees that might arise from encounters. This allows players to maneuver the crowd of other merchants better, but it also allows for another merchant in need of a few lira to report the family member and have them returned to jail. With these obstacles and resources at their disposal, successful players need to calculate their monetary risks from the potential gain in order to be the first to acquire the game-winning number of rubies.

\footnotetext{
${ }^{159}$ Materials gained from tile actions do not stay with the "assistant" but go directly to the player's area, which houses the wheelbarrow that controls how many resources the player can carry.
} 
As a geographical representation, the depiction of Istanbul in the game is rather subjective, manipulating the real-world bazaar into a tight network of sixteen tiles-in fact, the layout can be rearranged to add variety to play— but what the game layout does attempt to capture is the social aspect of maneuvering a crowded area, feeling restricted and closed off from your goals. In this sense, we might think of Istanbul as addressing the real (material) and conceptual simultaneously, what Soja has referred to as thirdspace. Players need to navigate material distance alongside the concept of a commercial locus to be successful. What de Certeau has referred to as strategies and tactics is important here, for players take the bird's eye position of looking down upon the bazaar's material arrangement, they can see how it is ordered and plan their routes accordingly—-this would be akin to what de Certeau called strategies. During play, however, the knowledge gained from such a stance must be adapted to accommodate the crowds - tactics, in other words. But where de Certeau sees an opportunity for ideological resistance and Soja observes an opportunity reshape and restructure dominant ordering principles, the game does not allow for choices to subvert the game's overarching ideology. In short, player avatars are depicted as shrewd, conniving, and greedy, and any choices along the way generally support that description.

Instead of being able to see Istanbul as an opportunity to subvert ideological constraints, we are forced to concede that the implied narrative of the game paints a specific picture of the grand bazaar as a crowded place filled with people who would best be characterized as criminals, partaking in jailbreaks, underhanded bribes-as presumed from encounters with the governor and other merchants—and potentially theft—tellingly, you do not pay for goods when visiting the warehouses while money is required at many 
other locations. And the choices players have do not compete against this picture. Instead, it is more critically beneficial to observe what this game says about a culture when played by cultures who do not identify with the place or characters in the game.

It is important to note that Istanbul is a Eurogame design developed by German designer Rüdiger Dorn predominantly played by European and American gamers. ${ }^{160}$ Additionally, the Turkish people associated with the game's narrative is the dominant minority group residing in Germany. This raises questions about attitudes within Germany about their resident minorities and how this game aligns with those attitudes. The reality for Turkish people living in Germany has been uneasy for decades. Turks face oppressive work environments, such as lower wages, unfair treatment in the workplace, and an unemployment rate that doubles the native German. ${ }^{161}$ Further, Turks living in Germany face harsh and negative stereotypes. Turkish people are often seen as corrupt, greedy, wicked, vulgar, violent, backward, and static. ${ }^{162}$ And when these negative attributes of Turkish individuals are taken into consideration, the lack of positive imagery regarding Turkish people in a game like Istanbul demonstrates a problematic representation.

Instead of offering a space to be inclusive and welcoming of restructured ideologies, the game presents a Manichean division between the social play space of its players and the narrative space. The worlds are distinct and different. Istanbul upholds and actualizes fears and stereotypes surrounding the Turkish population, with players

\footnotetext{
${ }^{160}$ Boardgamegeek.com lists the different versions and language translations of the game, and these include English, European languages, Japanese, and Chinese.

${ }^{161}$ Rob Euwals, Jaco Dagevos, Mérove Gijsberts, and Hans Roodenburg. "Immigration, Integration and the Labour Market: Turkish Immigrants in Germany and the Netherlands." IZA Discussion Papers 2677 (2007).

162 Boris B. Baltes and Cort W. Rudolph, "Examining the Effect of Negative Turkish Stereotypes on Evaluative Workplace Outcomes in Germany," Journal of Managerial Psychology 25 no. 2 (2010): 149.
} 
engaged in criminal activities and underhanded deals to meet their goals. As such, the game suggests a sort of spatial fixity that Urry and Larsen describe in The Tourist Gaze. ${ }^{163}$ As a visited—or toured—place, Istanbul as represented through the game aligns with the anticipations of the tourist. What expectations the visitor brings from personal attitudes, experiences, or circulating images are reduced to commodifiable objects for the pleasure of the visitor. ${ }^{164}$ Instead of compelling a host population to perform according to the expectations of the tourist, gameplay has players themselves doing the performance, foreclosing many opportunities to observe nuances in the depicted population that might compete against problematic attitudes they may harbor.

Tourism involves a contact between visitor and host, but board games are largely unilateral in this contact. As such, the tourism occurring in game play is akin to identity tourism found online, and Lisa Nakamura's work on “cybertypes" proves important. Exploring racial identity on internet platforms, Nakamura has suggested that identity tourism allows the visitor to take on a double role as both host and visitor without the necessary real-world encounters inherent in living the life of the other. ${ }^{165}$ The online roleplaying platforms she examines allows users to "play" with race and ethnicity as a "costume" and find pleasure in the use of race and ethnicity without the encumbrances that may result from real-life encounters. ${ }^{166}$ While her focus has been on digital virtual worlds, her notion of identity tourism can be deployed onto analog gameplay as well. With Istanbul, players are meant to find some level of joy in playing as a Turkish

\footnotetext{
163 Urry and Larsen, 49.

${ }^{164}$ Urry and Larsen, 17.

165 Lisa Nakamura, Cybertypes: Race, Ethnicity, and Identity on the Internet (New York: Routledge, 2002), 56-7.

${ }^{166}$ Nakamura, 47.
} 
merchant. The real-life encounters of that experience are abstracted in favor of a distilled representation of the Turk as greedy, manipulative, and shrewd. Making light of negative representation through play both risks skewing the reality of an experience and finding pleasure in the act of skewing that reality. Indeed, in response to the game, one player playfully lamented that the wooden discs used to represent people in the game lacked the descriptive richness of the game's graphic design and would have preferred "stackable camel figures" instead ${ }^{167}$, an assertion that underscores the negative reality of playing with stereotypes since camels are not native to Istanbul. These negative assumptions about Istanbul and the Turkish population more generally are exacerbated by the fact that the game is produced and consumed within a relatively closed demographic, with no input or agency on the part of the game's subject material.

The player interacting with the game material belongs to the same or similar demographic as the producer who has offered the interaction, forming a sort of echo chamber. In this sense, board games produce a filtered image of Otherness in line with what Said has asserted about Orientalism. Rather than engaging in an authentic experience with a distinct place or population, the experience is prescribed and constrained by the implicit bias of the producer, proliferating rather than competing against narrow assumptions and stereotypes. While these biases may be unintentional or unconscious, the figuration of the Other proves to be an East-as-seen-through-the-West objectification. Istanbul is conceptually "there" as opposed to the "here" of the social play space, dually demarcated as different and foreign while constituting the social play space as "normal." When considering the obstacles that ethnically distinct minority

\footnotetext{
167 “Do You Want the Truth Reviews Istanbul," boardgamegeek.com, July 6, 2015, https://boardgamegeek.com/thread/1367819/do-you-want-truth-reviews-istanbul
} 
groups face in a country like Germany and the itinerant hostilities associated with that contact between minority and majority cultures, Istanbul does less to offer an inclusive ideology through its play as it does to affirm attitudes and assumptions that may be held on the part of the player.

\subsection{GEOGRAPHICAL MISREPRESENTATIONS IN JAMAICA (2007)}

\section{AND PUERTO RICO (2002)}

Real-world geographies are a common trope in board games, and given the inherent subjectivity and social construction of space through geography, it is important to understand how ideologies are expressed within and shaped by geography. Two games_Jamaica (2007) and Puerto Rico (2002) —offer representative insight into how geography both veils and reveals ideology in game design. Through selective representation and exclusion, Jamaica deflates dynamic cultural expression in favor of fixing the space within a closed narrative of valorized piratic activity. Puerto Rico, on the

other hand, allows players to simulate the exploits of Spanish colonizers during the early colonial period. Their presence and authority is "written" into and shapes the land itself while any non-European presence is abstracted from play. In both cases, a Eurocentric worldview is secured, naturalized, and endorsed through geographical misrepresentations. 


\subsubsection{Jamaica (2007)}

The French-designed game Jamaica is a family-style, pirate-themed racing game wherein players attempt to sail around the island of Jamaica and reach the "finish line" at Port Royale with the most points. Players assume the role of a historical pirate during the $17^{\text {th }}$ century. A ship marks a player's presence on the board, and players each have a deck of cards to facilitate their actions as well as a hull board representing their cargo space.

Play progresses through the use of simultaneously selected cards, which depict two actions - a morning action and an evening action—and at the

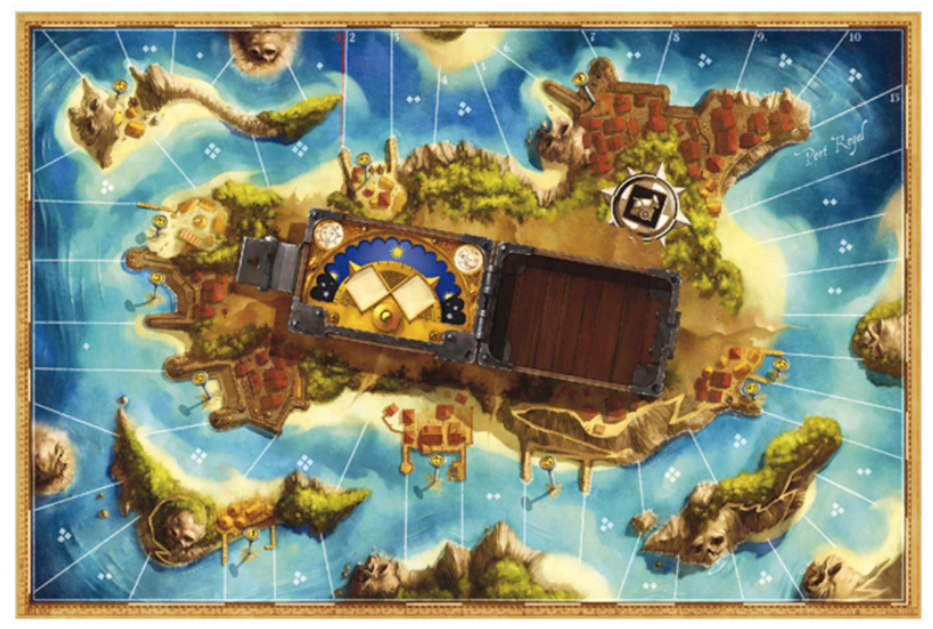

Figure 3.5 Jamaica in the game functions as a hub and material placeholder for player actions.

beginning of each round, two dice are rolled, which determine how many times each morning and evening action must be completed by each players. These actions include moving the ship along sea and port spaces surrounding the island, loading cargo- - food, money (doubloons), or gunpowder - into their limited hull compartments. Sailing may help players reach Port Royale first, but sailing further away from shore costs extra food and sailing along ports costs doubloons. If a "shortage" occurs, players are forced to recede backwards along the race path until they reach a space they can afford to pay. In addition to this, players may seek an advantage by engaging in combat with other pirates to steal from their hull or to give them cursed treasure (negative points). Players may also discover treasure along the race route, which may present as positive points or items that 
allow players to "break" the game's basic rules. At the end of the round in which a player has circled the island and returned to Port Royale, the game ends and players add and subtract points according to their place along the race route, doubloons, and treasures. The player with the most points is the winner.

As a family-style board game aimed to please players of ages as young as eight, the implied narrative of Jamaica is largely cartoonish and innocuous. There is little to be learned about the island of Jamaica itself, and players would discover little of piracy apart from the names of notorious historical pirates of the area. ${ }^{168}$ The island itself has no narrative role in the game, apart from acting as a hub around which a race "track" can be established, and the graphic design of the island on the game board serves as a placeholder for game pieces. The island serves as a formal design convenience rather than an opportunity to engage with a place or culture. Jamaica, through play, is what Lefebvre would call semiologically destitute. ${ }^{169}$ The question arises then why the designers chose to localize the game around the island of Jamaica at all, except for the cultural heritage of the island as a site of piratic activity in centuries past. By doing so, the choice to use a real-world geography as a setting for gameplay raises concerns about the innocuity of the gameplay itself.

As J.B. Harley notes, maps contain "silences" through their exclusion of certain features, and he asserts that the conceptual distance between lived experience and graphical representation promotes a palliative distance through the "remote" qualty of

\footnotetext{
${ }^{168}$ Players can take on the roles of Mary Read, Anne Bonny, John Rackham, Edward Drummond, Samuel Bellamy, and Olivier Levasseur.

169 Lefebvre, Production, 349.
} 
maps. ${ }^{170}$ A similar palliation can be said to occur in the use of maps in board games. In the case of a family game like Jamaica, the map used diminishes the importance of the people and the cultures on the island. It is literally drained of significance in the game. Everything about the people and culture has been erased by an unconscious and "inert" map. Its use is tantamount to equating the people and culture with insignificance and triviality. Any resistance or conflict that may occur on the island is muted, and the only conflict that can be seen to arise occurs homogenously amongst fellow pirates. By using a representation of the island as such, the game compels players to reinforce a fiction that the only thing of significance and worth is the island's historical associations with piracy.

Jamaica, in the game, is literally closed off from the rest of the world. It is not only cut off from the remaining world through the circling of pirates around the island, it is dissociated in time, as well. The game stabilizes the island in the past, as a curiosity of heritage tourism. As Urry and Larsen points out, the mandate to reproduce the past for the consumer's pleasure stifles the dynamism of its present while sterilizing the past. ${ }^{171}$ Indeed, players of Jamaica are encouraged to valorize piratic exploits in a cartoonish and aloof manner that is safely removed from the violence itinerant to the time and place. Further, colonial interests and slavery are ignored. While we would expect some

\footnotetext{
${ }^{170}$ Harley, 59. Harley contends that military operations through the use of maps palliates the guilt of conquest through the remote control of territory via maps. We can say a similar lack of empathy arises regarding cultural representation and the itinerant silences of map design.

${ }^{171}$ Urry and Larsen, 140. "The production of the past conceals the destruction of the present. There is a distinction between authentic history (continuing and therefore dangerous) and heritage (past, dead, and safe). The latter, in short, conceals the social and spatial inequalities, masks a shallow commercialism and consumerism, and may in part at least destroy elements of the buildings or artefacts supposedly being preserved." While they speak of material structures in the tourism industry, the concept of localizing significance within a "safe" and "dead" past diminishes whatever cultural agency occurs within the present.
} 
abstraction of violence and colonial exploitation in a family game, the "silences" written into the land itself perpetuate a narrow and unilateral view of the island itself.

\subsubsection{Puerto Rico (2002)}

Puerto Rico, by German designer Andreas Seyfarth, is a role selection economic game taking place on the island of Puerto Rico during the early colonial period. Three to five players compete to earn the most points by producing goods at plantations, trading and shipping produced goods, and building new structures on the island. As more colonists arrive at the island, players need to find a balance between earning doubloons, producing goods, and scoring points, with goods and doubloons necessary to build, ship, and trade.

Players start the game with a personal board that depicts the island of Puerto Rico overlaid by several "slots" designating where players may build structures and plantations. The game flows over several rounds through the selection of one of several roles - the settler, the mayor, the builder, the craftsman, the trader, the captain, and the prospector. Each role has a unique ability that all players are able to perform and most have a "bonus" ability for the player selecting that role. These roles allow players to construct buildings, deploy colonists, and earn money. Common boards at the center of the play area house the different structures and trading opportunities available to all

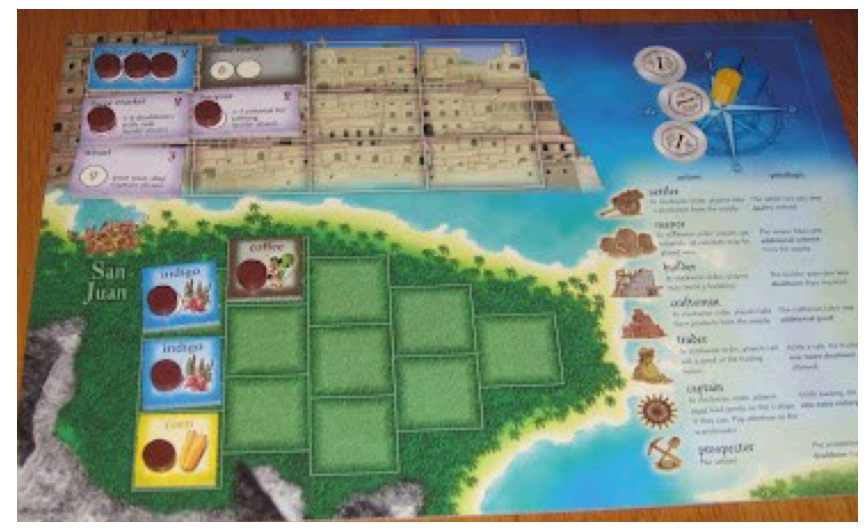

Figure 3.6 Puerto Rico player board, mid-game, showing a green blankness gradually replaced by industry 
players. The ship boards, for example, simulate goods being transported back to the "old country" and players earn points for using the "captain" role to fill the ship with cargo. Building tiles on these common boards are purchased using specified resources, and players constructing them relocate them to their personal island boards. Over the course of the game, the greenspace of the island becomes gradually covered with plantations and industries.

Play proceeds in the manner described, with each player selecting a role, carrying out its action and/or benefit, and other players carrying out the standard action. Players accrue goods and wealth as they produce, process, trade, and ship goods from the colony back to Spain. Once game ending conditions have been met, the round is completed, and players add up the points they have earned over the course of the game and at game end. The player with the most points is declared the winner.

It is troubling that Puerto Rico, like dozens of other popular board games, chooses as its setting a period of colonialism. What proves more troubling is how nuances in design and play reinforce and reward the privileges obtained through colonialism. Many have commented on the game's use of brown tokens for "colonists" when the time and place of the game would historically include slaves. ${ }^{172}$ But in addition to this, the subtle implications of the use of a geographically verisimilar map and the abstracted violence and oppression endorse this period in history as a rewarding venture while simultaneously obscuring culpability.

Beginning with the map, Puerto Rico uses a player board that depicts a verisimilar depiction of the Eastern quarter of the island. San Juan is the only noticeably populated

\footnotetext{
172 Cf. “Why We're Getting Rid of 'Puerto Rico,'” boardgamegeek.com, July 28, 2017, https://boardgamegeek.com/thread/1820171/why-were-getting-rid-puerto-rico
} 
establishment on this portion of the island at the beginning of the game. The remainder of the island is depicted as an expanse of green emptiness. This emptiness proves telling. As J. B. Harley has noted, omissions of landmarks and establishments can be politically motivated by the makers of the map, suggesting that producers of these maps can be biased toward their own interests and sense of self-worth. ${ }^{173}$ The island in Puerto Rico contains no indigenous Taíno features, such as villages or manmade structures of any kind. Significance of any indigenous presence is completely erased from the design. This green blankness raises concerns about what is being endorsed through play.

The green expanse on the player's personal game board accentuates what might be considered valuable for the player who possesses it. The natural resources, such as wood, preexist a colonial presence on the island as valued objects. These are depicted on the map. However, Taíno culture has been removed; it is rendered obsolete, insignificant, and valueless by the map's design. What is reinforced by the map in the game's design as meaningful and significant is reduced to natural resources and the potential for industrial growth. The game abstracts any presence that is not a European presence, creating what Soja terms as a "territorial allegiance" to a centralized ideology. ${ }^{174}$ The geography of Puerto Rico, in this instance, expresses a colonial ideology as much as colonialism shapes the land itself. This "allegiance" through abstraction allows the implied narrative to proceed without the grim reality of violence and oppression that accompanies colonialism. As the game narrative is presented, it would be easy to assume that nothing but the natural resources available on the island were harmed by a colonial presence,

\footnotetext{
173 Harley, 59.

${ }^{174}$ Soja, Postmodern Geographies, 35.
} 
which dually deflates the significance of the Taíno while naturalizing and neutralizing the threat of colonialism.

The blankness of the map adds to this justification. The island is without meaning apart from its natural significance. Rather, meaning and significance are added by the exploits of colonialism. The dominant culture controls the narrative, and the geographic space is thus presented as "empty" or even "virgin" prior to the introduction of European colonists. By deflating or omitting any indigenous cultural signposts from the geography, it is easier to see the space as an invitation for European development rather than a moral obstacle, what Harley likens to the "self-fulfilling prophecy" of geography and power. ${ }^{175}$ European maps, he suggests, have shown a "one-sided view of ethnic encounters" that supported their own "territorial appropriation" by the silences encoded into the maps themselves. ${ }^{176}$ This proves true in the play of Puerto Rico. Before play begins, the map of the island is void of human presence. As the game progresses, plantations are established and buildings are constructed, and players can see the objects of productive human involvement only by their own role on the island. They become the sole meaning-makers on the island, bringing significance to the geography, and the reward system of the game endorses this mentality.

What the geography in a game like Puerto Rico informs us as players is that power and value resides within the dominant ideology of colonialism. The land itself frames and justifies that presence, with significance given to natural resources and industrial development over indigenous cultural expression. Through the ruleset, which outlines the goals and rewards for the game, and the simultaneous abstraction of dissent

\footnotetext{
175 Harley, 68.

176 Harley, 67.
} 
or exploitation, the design skews the reality of the colonial era to favor the ideological interests of the colonizing power structure. Using a representation of the land, players "write" colonial power and inequality into the geography while the mechanisms and goals focus the narrative on economic development rather than exploitation and violence. This risks endorsing views that colonialism is relatively harmless - no humans are visibly harmed - that it was economically justified, and that it was a "natural" result of an encountered "empty" land. When interpreted as such, Puerto Rico and similar colonialthemed games, distorts history so as not to appear threatening to the status quo of many of its white European players while simultaneously deflecting the narrative away from unsavory topics such as slavery, exploitation, and oppression. Players instead get to enjoy the benefits of historical colonial power and presence without needing to reconcile that power alongside what constitutes it.

\subsection{CONCLUSION}

Due to the conventions of available play space in game design, board game designers necessarily abstract out certain elements of play and/or story to sustain the game's enjoyability from beginning to end. One cannot retell a specific historical event down to the finest detail in a game or, of course, the game would be as long as the event itself. This proves true for the represented geography as well. Selection and exclusion determine what is simultaneously significant and insignificant about a place. What is silenced in geography is telling of how space is socially constructed to support a certain ideological perspective. In the case of the games detailed here, a Eurocentric worldview 
emerges as valorized or normalized at the expense of the geographically or culturally distinct.

This necessary incompleteness within the represented geography ultimately hides narrative and mechanical elements that might be unpalatable to the player's taste. In the case of games dealing with colonialism, for example, the violence and oppression itinerant to such an enterprise is buried within gaps in the narrative and mechanism of play. When looking at board game designs that center on experiences of the foreign or the distant, anything unpleasant about that encounter or contact are often deflected to the gaps in board game design. This makes board game design a dangerous site of propagated prejudice. The narratives of oppression and violence can be sterilized of their gritty realism and operate from within the silent gaps of the design without any necessary consciousness on the part of the player. The geography, while facilitating these narrative and mechanical gaps, further assuages conscious reflection due to presumptions that geographical representations are "inert" and therefore apolitical.

Generally, these design gaps allow a distorted and incomplete worldview to emerge unchallenged. Taking this into consideration for games that utilize distant geography and foreignness as a site of available play, distorted worldviews that reinforce invisible structures of Eurocentric dominance over ethnically distinct can be harmful to real-world attitudes toward other cultures. These games, through their use of geography and unilateral narratives champion Eurocentric worldviews by diminishing or damaging the cultural values of others. Whatever superiority they may feel or practice about themselves or inferiority of others felt or practiced are largely reinforced through game play. Because these disparities often undergird the game from within gaps in narrative, 
mechanism, and geography, and because players and producers acknowledge the necessity of these gaps, few players notice what destructive values are being rewarded through their play. 


\section{CHAPTER IV}

\section{UNEARTHING RACISM}

Color, for anyone who uses it, or is used by it, is a most complex, calculated and dangerous phenomenon. —James Baldwin ${ }^{177}$

Racial differentiation has the capacity to enrich gameplay, but with representations of people of color, concerns arise. More pointedly, the board game analyses presented in this chapter look beyond the question of whether or not racial diversity exists to probe how racial relations function in board games. ${ }^{178}$ We live in an age where it is not difficult to play a game that includes characters and bodies ${ }^{179}$ from different racial categories, and there are negligible examples of racial prejudice playing a significant role in the design of major board games. However, the aims of the industry at large to be more racially conscious and inclusive in board game design raises significant questions: how, for one, is the gravity of race and prejudice handled in board game design; does the representation of non-white bodies in board games rectify racial issues; and how does the consumer feedback loop encourage or constrain non-white

\footnotetext{
177 James Baldwin, "Color," in The Price of the Ticket: Collected Nonfiction, 1948-1985 (New York: St. Martin's Press, 1985), 322.

${ }^{178}$ While the analyses here focus on black minorities, there is no intention of suggesting that other racial demographics are excepted from problematic treatment nor is there a suggestion that whiteness is not a racial category with real-world significance, as Chapter $\mathrm{V}$ inspects more closely.

${ }^{179}$ I make a distinction here between bodies and characters. Regarding board game design, I use character when representation is given some narrative context-we are offered information regarding motivations and aspirations in some way-whereas bodies suggest a closed system of visual representation.
} 
representation in board games? Despite the inclusion of non-white bodies and characters in many modern board games, this diversity does little toward deflating racial prejudices and undermining harmful stereotypes. As the analyses presented here show, race and representations of race remain difficult topics for both the producers and consumers of modern board games.

Take the acclaimed cooperative game Pandemic (2009) as an example. This globetrotting game about tampering disease outbreaks while racing to find the cure includes seven roles from which players may choose as their in-game character. ${ }^{180}$ Each role comes with a unique ability that may be used throughout gameplay to aid the players' chances of winning against the game. ${ }^{181}$ One role, the operations expert, is particularly striking. A black male is represented in the role, wearing a safety vest and holding a walkie-talkie. His unbuttoned shirt and rolled sleeves suggest a stressful or labor-intensive day. The operations expert has the unique ability of being able to fly to any city from an established research station by discarding any card in hand—other players can only fly between research

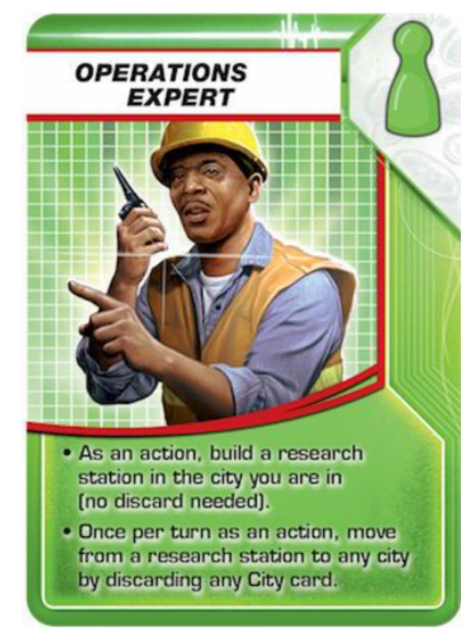

Figure 4.1 Operations Expert attire associates the role with the working class (Pandemic). stations using this action. Additionally, the operations expert can build a research station in their occupied city without discarding a card —other roles require players to discard a

\footnotetext{
${ }^{180}$ I am using the revised printing of the game, which includes seven roles in the base game. The original printing of the game included five roles, and the role in question-the operations expert-was represented by a white male in the original.

${ }^{181}$ All players, regardless of their roles, have the same basic abilities-drive between cities, fly between cities, build a research station, treat disease, share knowledge, and discover a cure. Many of these abilities require the player to discard one or more cards. For instance, a direct flight action allows a player to fly to the city depicted on the discarded card while a charter flight requires the player to be in the city depicted on the discarded card to fly to any city on the game's map.
} 
matching city card to build. Among the other available roles - i.e. the contingency planner, the dispatcher, the medic, the quarantine specialist, the researcher, and the scientist - the operations expert is a valuable role to have in the game. ${ }^{182}$

To some extent, Pandemic shows a board game industry that is successfully diversifying representation in board games and making the experience more inclusive to diverse players. There are multiple non-white roles available in the game, and gender representation is nearly evenly split amongst males and females. And each role exhibits its own value for gameplay purposes, so no role appears particularly disadvantaged in relation to others. In an industry that historically has and continues to overlook diverse representation in board game design, the designers behind the production of Pandemic should be commended for their aim to promote diversity. However, this inclusion does little besides offer token representation of non-white and non-male bodies as a largely conciliatory effort to assuage concerns of underrepresentation. At best, racial and gender representations in the game are interchangeable and make no effort to create a sympathetic connection to the role's gender or racial identity. No narrative space is offered for players to gain an understanding of their role's character as white, black, Asian, female, or so on. Instead, the diverse representation is at best a symbolic gesture toward inclusivity. At worst, the roles available still depend on racial and stereotypical assumptions. For one, the Asian role works at a computer. The operations expert, too, is associated with the working class, with his hard hat and protective vest, rather than with more presumably erudite roles such as the researcher, who is depicted making

\footnotetext{
182 Only one role per player is used in the game, so in a game of four players, the game's maximum player count, only four roles are used.
} 
observations through a microscope, or the scientist, who biochemically manufactures a cure to the disease outbreak.

There is no simple and direct answer as to how well Pandemic and games like it negotiate a complex topic such as racial representation within board game design. Whichever way the particular representation of non-white bodies is observed in Pandemic, what can be discerned is that racial representation remains a complex and difficult terrain for board game designers and players. Observing representations of nonwhite bodies in Pandemic raises the question of how board game design creates a space for players to negotiate issues such as race, how the representation of non-white bodies are constructed by the producers, and how those representations might continue to depict negative ideologies about racial difference. In what follows, analyses of four board game designs_-Small World (2009), Eldritch Horror (2013), Freedom: The Underground Railroad (2012), and Five Tribes (2014) — show that race as a board game concept and racial representation remain problematic in modern board game designs. By governing the contexts through which race, play, and identification are understood, the largely white and male producers and players of modern board games perpetuate, presumably without ill intent, harmful stereotypes concerning non-white bodies while also avoiding meaningful confrontations with issues of race, racism and representation.

\subsection{THEORIES AND CONCEPTS}

Board games are simulations of events both fictitious and factual, but at best, they are incomplete simulations. As the space of play must be negotiated amongst factors such as player enjoyment, acceptable game length, and ease of play, many facets of the game's 
narrative and mechanism must be abstracted to meet the marketable conventions of the industry. ${ }^{183}$ Similar obstacles arise with issues of representation. As incomplete simulations, designers and players are compelled to constrain racially marked bodies and characters within incomplete information. Players add meaning to images and performable actions with what little information is provided within the game. Because of this constraint on representation, I wanted to incorporate theories and concepts that addressed issues concerning the body as a constructed entity that is shaped and conditioned by social and cultural forces rather than as an ontological given.

\subsubsection{Constructed Docility and the Gaze: Foucault, Butler, and Fanon}

One of the characteristics we see operating within games is that racially marked individuals are caught in a paradoxical role of being heroic protagonists while simultaneously neutralized from assertive power. Their bodies are inscribed as docile, and this observation is informed by notions put forth by Michel Foucault. Foucault's work on bodily inscription, wherein meaning and subjectivity are added onto bodies from institutional forces exterior to the body - it "is the inscribed surface of events" "184 as he puts it - allows for inspections of representations and characters regarding the exhibited constraint placed upon them by outside forces. A dominant gaze, with its ideological determinations, surveils and molds the marginalized body to be in accord with those

\footnotetext{
${ }^{183}$ Cf. Matt Forbeck, "Metaphor vs. Mechanics," in The Kobold Guide to Board Game Design, ed. Mike Selinker (Kirkland, WA: Open Design, 2011), 19-23. Forbeck argues that game mechanisms and narrativewhich he calls metaphor-need to mesh together well in a game design, and attributes of one or the other should be cut from the design for a more pleasing gameplay experience.

${ }^{184}$ Michel Foucault, "Nietzsche, Genealogy, History," in The Foucault Reader, ed. Paul Rabinow (New York: Pantheon, 1983), 83.
} 
ideological preferences. In this manner, we can see that the body is a construction from varied and invisible forces. The body speaks of and speaks from ideological premises.

What Foucault offers analyses of games is a tool by which we can dismantle the ontology of the body to see it as a medium for ideology. This recognition shows that the inclusive practices on the part of players and producers are superficial at best. The operations expert from Pandemic, in this view, is a token gesture toward inclusion that masks a deeper ideological premise. His being as a valuable asset to the global crisis is simultaneously undermined by the confines of his representation. The working-class trappings associated with infrastructural laborers inscribes his body as subordinate to the presumed erudition of his research counterparts. Characters like him are constructed to reside in an uneasy tension between action and submission.

Following Foucault is Judith Butler's notion of performativity, a notion that adds to the social constitution of the body to further suggest that identity is maintained through actions and the capacity—or lack thereof- to act. ${ }^{185}$ These concepts prove useful to an analysis of racial representations in board game design given how the industry is largely populated by those belonging to a majority racial demographic. As such, meaning, significance, and the (in)capacity to act are envisioned and controlled by a feedback loop of mostly white producers and white players. What results is a mediated imagining of raced experience. Focusing on the externalized construction of meaning helps reveal the issues of race and representation of race in board game design.

\footnotetext{
185 Judith Butler, Gender Trouble (New York: Routledge, 1990). While Butler focuses her notion of performativity on effects within gender and sexuality. Her assertion that the body is a contested space for ideological significance and constrain is applicable to other marginalized by a dominant order.
} 
Itinerant to Butler's notion of performativity is a spatialization of identity performance. What one identifies as is demarcated from what one is not, and this connects to what E. Patrick Johnson asserts in his study of black authenticity. In Appropriating Blackness, Johnson follows Butler to argue that performances of black authenticity are continually negotiated and circumscribed. ${ }^{186}$ What demarcates any notion of black authenticity — which defaults as male, heterosexual, and lower socioeconomic status - manifests through signifying practices and gestures toward excluded frameworks. ${ }^{187}$ What results is a performance that constructs signifiers for itself by spatializing it from what is excluded along a gradient. ${ }^{188}$ Blackness both interprets and produces the boundaries of blackness and deploys it through signifiers of belonging and exclusion. For Johnson, this can be deployed as a progressive act as well as a counterproductive act that delimits possible manifestations. ${ }^{189}$ What results are hypervisible signifiers that establish symbolic relationships between actions and skin color, but these signifying markers of "blackness" risk distilling racial identification down to commodified generalizations of black authenticity that delimit and exclude black experience. Despite his focus on black performance and agency, which is largely absent in game design, Johnson's work highlights the mediation of authenticity, something that would be of concern not only to black performers but the producers of represented

\footnotetext{
${ }^{186}$ E. Patrick Johnson, Appropriating Blackness: Performance and the Politics of Authenticity (Durham: Duke University Press, 2003), 3.

187 Johnson, 5. One example Johnson offers is the performance of "talking black," wherein authenticity is performed by spatializing an agreeable manner of speech among male heterosexual blacks-a black vernacular-from what it is not-talking "white" or according to rules of Standard English.

188 Johnson, 22. For instance, when embodying blackness, performers are measured as "more black" and others as "less black." The performance of blackness for Johnson is continually contingent and surveilled by social frameworks that implicate and constrain its own authenticity, and as such, the construction of blackness is continually maintained and circumscribed according to these rules.

189 Johnson, 12.
} 
blackness. Through Johnson we can see how white imaginings of black experience are constrained by mediated expectations that are stabilized through signifying practices.

What has been suggested throughout these assertions is that meaning for racially marked bodies is attributed from without rather than from within. Black bodies have a history of being mediated by whites and excluded from the politics of their own representation, connecting to assertions Frantz Fanon discussed in his 1952 work Black Skin, White Masks. Fanon argues that his experience as a black man is reduced to that of an object continually surveilled, shaped, and made docile by the white gaze. For Fanon, the black body is constructed not from the experience of the person but from the signifiers that body gestures toward. ${ }^{190}$ It stands as a document of the race's history and of the race generally. ${ }^{191}$ Controlled and shaped by the white gaze, the black body is made docile and made to feel a sense of guilt for its objective appearance. ${ }^{192}$ The black body, he argues, is assimilated into the dominant culture if that body is made docile to the expectations of the white gaze. A telling moment in Black Skin, White Masks describes a white person's caution to not make the black man angry, ${ }^{193}$ and we can directly connect this to the dangerous potentiality and neutralization of black empowerment in games. Black experience is constrained and shaped by a feedback loop that continually checks and rechecks its own submission to the dominant expectation. What results is a walking contradiction — a person whose lived experience is determined from without and void of

\footnotetext{
${ }^{190}$ Frantz Fanon, "The Lived Experience of the Black Man," in Black Skin, White Masks, 1952, reprint (New York: Grove Press, 2008), 90.

191 Fanon, "Lived," 92.

${ }^{192}$ Fanon, "Lived," 93. In Fanon's anecdotes, he recounts encounters with whites where they proclaim that his race has no bearing on him as a person, but the same whites cannot stop pointing out his racial difference.

${ }^{193}$ Fanon, “Lived," 93.
} 
any unsettling assertive qualities. The black body, in other words, is scripted to act and behave according to ordering principles placed upon it by white bodies in order to be accepted — or at least tolerated—by those same white bodies.

\subsubsection{Semiotic Fixity: Yancy and Hall}

The notion of the gaze and docility raises questions about the resulting representation. While there are a variety of racially marked characters in games with wide-ranging traits, representations of characters of color are relatively stabilized within a closed system of representation. This fixity works more to affirm assumptions about those races than to allow for dynamic expression. Take, for instance, the inclusion of the many Asian characters in games. Despite their prevalence, their representation is largely confined narrowly to mediated assumptions. They are technological adept (Pandemic, 2009) or martial artists (Ghost Stories, 2008; Yamatai, 2017, Rising Sun, 2018). They are continually associated with the exotic and mysterious (Madame Ching, 2014; Hanamikoji, 2013), or Zen (Tokaido, 2012; Onitama, 2014). Despite the variety of representation, Asian characters - and racially distinct characters generally - are enclosed within a boundary of expression that is constructed from the outside, narrow, and an affirmation of dominant culture's assumptions.

Black characters are similarly represented by pre-informed assumptions, and George Yancy's assertion about what he terms the "elevator effect"194 clarify this fixity. In that essay, Yancy suggests a fixed meaning of danger or criminality or any number of negative connotations is inscribed onto black bodies when encountered by white bodies.

\footnotetext{
194 George Yancy, Black Bodies, White Gazes: The Continuing Significance of Race (New York: Rowman \& Littlefield, 2008), 4.
} 
Caught in the view of a white body as he describes, Yancy details feeling detached and externalized so that he feels he is seen as an object rather than a subject of experience. His existence as a black body sufficiently contains a narrative of his existence. As he puts it, "The meaning of my Blackness is not intrinsic to my natural pigment, but has become a value-laden "given," an object presumed untouched and unmediated by various contingent discursive practices, history, time, and context." 195 The negativity placed upon black bodies in this encounter is perceived not only a priori, without meaningful interaction, but as natural and essential. The material black body is, in short, semiotically fixed. Yancy argues that the black body, by its existence within a given context, encapsulates a repertoire of negative associations that are externally enforced and sustained.

This repertoire he acknowledges helps us to understand how material trappings and signifying practices encapsulated in the representations of people of color operate within a closed system of assumptions that generally and largely reveal and affirm prejudices. While Yancy's argument necessitates a physical encounter between different races, this assertion that black bodies carry meaning as a presence alone rather than a dynamic interaction has some impact on how we might look at minority representations in games. In her discussion of diversity and inclusion, board game review Mandi Hutchinson, who identifies as non-white, suggests black bodies in game design carry meaning based on their inclusion alone. During a convention wherein a board game prototype was being displayed, Hutchinson recalls that a white male passerby remarked that all the characters in the prototype were black. She admits to being taken aback that

\footnotetext{
195 Yancy, p. 3, italics original.
} 
this feature stood out as the most noteworthy when so many games portray exclusively white characters. ${ }^{196}$ It shows that black bodies in games are not normalized and continue to exist as extraordinary and remarkable for their existence. Following Yancy's notion of the "elevator effect," racially marked bodies are signifiers in and of themselves while white bodies are normalized and unmarked.

Representations of black bodies, in this sense, are always symbolic: they stand for something. Confined by representation, racially marked bodies require viewers to connect and interconnect meanings associated by that representation. Stuart Hall's "The Spectacle of the "Other"' examines this intertextuality itinerant to the body. As a signifier, the body directs meaning away from itself to the array of meanings superadded from generalities, assumptions, and histories. Viewer interpretations of difference compound alongside other signifiers of difference in what Hall terms a "spectacle of otherness."197 Representational meaning, then, is not isolated to the subject matter but overlaid by an interplay of meanings.

The represented image of the black body, for Hall, "speaks,"198 meaning less that he or she speaks as an individual but more for the panorama of assumptions and possibilities pre-associated with the black body. And regarding representation, meaning is constrained by the producers of the image, which in terms of the board game industry is predominantly white. Hall offers what he terms a "regime of representation"199 to

\footnotetext{
${ }^{196}$ The Dice Tower, "Back Talk 16: Inclusive Gaming” YouTube video, November 21, 2016, 19:57, https://www.youtube.com/watch?v=hO9bEIR8IZc

197 Stuart Hall, "The Spectacle of the 'Other,' in Representation: Cultural Representations and Signifying Practices, ed. Stuart Hall (Thousand Oaks: Sage, 1997), 231-2. Hall notes how images of athletes, catching a peak moment of physicality and action, "carries" interpretations of virility and sexual desire which are similarly interpreted through physicality.

198 Hall, "Spectacle," 230.

199 Hall, "Spectacle," 232.
} 
demonstrate how meaning shifts according to the will or need of the dominant order producing the images of blackness. Within a feedback loop of representation, the image is produced, and its consumption regulates further representations of similar images so that an agreeable framework for meanings associated with a particular image is stabilized within a particular regime.

Hall probes the question of representation further and asserts that what results from the control over representation by the dominant culture is a complex system of naturalized stereotypes about black people that are caught between binary oppositions. Semiotically, the black body is dually paradoxical. Not only are they, for example, stereotyped as infantilized, they are simultaneously interpreted as lustful and sex crazed. ${ }^{200}$ In the same manner, black bodies came to signify what was primitive and savage while white bodies came to signify civilization and decorum. What proves telling in this opposition is that being civilized suggests learning and negotiation while being primitive is natural, beyond remedy, unchanging. ${ }^{201}$ When we consider the common relationships made between black bodies and nature in games, this notion suggests these symbolic associations function to subordinate or dismiss the racially distinct while normalizing the dominant culture. Representational signifiers, then, catch people of color in a complex triangulation between two disparaging poles of a binary and an inauthentic passive ambiguity between. ${ }^{202}$ Within a mediated consumer network, such as the board game industry, a feedback loop of selection, production, acceptance, and consumption stabilize the boundaries of this representation. What it means to be black, to live as black,

\footnotetext{
200 Hall, "Spectacle," 243.

201 Hall, "Spectacle," 245.

202 Hall, "Spectacle," 253. Hall highlights performances by Sidney Poitier as exemplifying this sterilized existence deemed as acceptable and nonthreatening for white audiences.
} 
and what a black person might desire, is not produced by blackness in the case of board games but by a feedback loop that reconciles mediated assumptions rather than individualized experiences.

\subsubsection{Pollution and Liminality: Douglas and The Black Image in the White Mind}

Modern board games are rarely overtly or intentionally racist. As such, we do not often see representations of people of color as occupying one pole of a dually disparaging binary. Instead, we see designers and publishers rationalizing their particular use of racially distinct cultures. ${ }^{203}$ What results in game design, rather, is a representation of people of color that resides at the border of identification. People of color are simultaneously and paradoxically selfsame and other, passive and assertive, empowered and neutralized. To best comprehend this blurring of boundaries, I turn to the work of Mary Douglas. In her work Purity and Danger she has shown that cultures create boundaries to demarcate what belongs within that cultural framework from that which does not. She forwards a notion of interstitiality to suggest that what most threatens the cultural order is that which does not obey the boundaries of belonging and otherness, that which exists in ambiguity. ${ }^{204}$ What is thoroughly conceptualized as othered and different for the controlling powers is also deemed as necessarily excluded. What blurs the cultural boundaries, existing as polluting and interstitial, is marked as "matter out of place" and persists as a threat to the boundaries created by the controlling order. ${ }^{205}$

\footnotetext{
${ }^{203}$ For instance, Mombasa (2015), discussed in further detail in Chapter V, takes steps within the rulebook to explain how the game intends to treat the racism that undergirds its narrative. We see similar clarifications in games like Freedom: The Underground Railroad (2012) and Concordia (2013). ${ }^{204}$ Mary Douglas, Purity and Danger: An Analysis of the Concepts of Pollution and Taboo, 1966, repr. (New York: Routledge, 1994), 103.

205 Douglas, 41.
} 
Not only does this suggest that black bodies, by their prevalent exclusion, present as potential pollutants and "matter out of place" for the largely white board game industry, it also allows an inspection of how the magic circle of play is demarcated from the reality from which play attempts to escape. As mentioned, play cannot completely divorce from the reality it escapes, so thinking in terms of Douglas, the magic circle is a space like the cultural boundaries she describes. The magic circle's boundaries are continually policed, and Douglas's assertions allow inspections of how racial experiences are selectively included or excluded from game design.

Douglas's assertions also suggest that the interstitial is conceptually paradoxical - it both belongs as much as it is expelled. This brings in the notion of liminality put forth by Entman and Rojecki. In The Black Image in the White Mind, they contest assumptions that the prevalence of representation for people of color has improved racial relations. Drawing from Mary Douglas, they suggest that individualized expression exists on a graded spectrum between what might be interpreted as ideal or normal and what is seen as abnormal and counter-ideal. In between these poles is liminality, and the individual expression between possesses both positive and negative traits. $^{206}$ While liminality is seen as "exceptional" when pertaining to white expression, it is the dominant and contradictory image of black expression for white audiences. ${ }^{207}$ Black representation is paradoxically caught between acceptance and rejection and thereby exhibit contradiction. Selfsame and other, lionized and demonized—black representation signifies the unsettled attitudes and assumptions regarding black bodies by

\footnotetext{
${ }^{206}$ Robert M. Entman and Andrew Rojecki, The Black Image in the White Mind: Media and Race in America (Chicago: University of Chicago Press, 2000), 52.

207 Entman and Rojecki, 53.
} 
white audiences. And when we take this into consideration as we inspect board game designs, the paradoxical representations of black characters as both heroic and passive, empowered and neutralized, emphasizes the lack of resolution between belonging and exclusion regarding people of color in games.

\subsubsection{Commodified Otherness: hooks and Nakamura}

Conventional constraints on narrative space in games tend to confine representation to reductive distillations even when opportunities exist for dynamic representation. This reliance on stereotype invites bell hooks' notion of cultural appropriation, or what hooks terms as 'eating the other.' In hooks' view, dominant culture has a desire to not only dominate the 'other' but to be transformed by contact with the 'other.' ${ }^{208}$ For the dominant power, the 'other' is representative of experience, while white experience is associated with banality and inexperience. In actions that manifest sexual desire and longing, dominant culture consumes the 'other,' taking the experience in a manner that signifies experiential contact but significantly maintains the hierarchical status quo. ${ }^{209}$ According to hooks, consumer culture offers an avenue for dominant culture to fulfill that desire by offering forays into 'otherness' that do not threaten their domination. Cultural appropriation of markers of ethnicity and racial difference as well as exploitations of otherness in consumer culture offer dominant culture the pleasure and experience that they desire. As hooks makes clear, these symbolic acts of appropriation that simultaneously maintain the status quo while deflating the meaning and significance

\footnotetext{
208 bell hooks, "Eating the Other: Desire and Resistance," in Black Looks: Race and Representation, 1992, repr. (New York: Routledge, 2015), 25.

209 hooks, "Eating," 22.
} 
of the 'other' function as a substitution for the literal physical domination over otherness dominant culture has enforced for centuries.

This desire to experience, consume, and appropriate otherness connects with ideas of identity tourism that Lisa Nakamura has explored. How race and markers of racial difference are used and exploited for the pleasure of the consumer suggests a tourism experience akin to what Nakamura finds in cyberspatial frameworks. ${ }^{210}$ While the majority of board games are analog and socialized within a physical space, the notions Nakamura puts forth are useful for understanding how players may play with racial identification. Combining hooks" "eating the other" with identity tourism allows me to explore how race in games dually operates to enrich the consumable experience while affirming the boundaries of the status quo. Race both enriches the enjoyment for the players without being threatening and conjures feelings of guilt and culpability that players would rather keep out of play. What results is a process of racial representation that constrains the significance and context of race and identity while simultaneously offering race as an agreeable play space.

\subsection{PLAYING AS / WITH RACE IN SMALL WORLD AND ELDRITCH HORROR}

Modern board games offer players a unique position to play as and play with different races. Race is a prevalent mechanism in asymmetric games that allows players to mold their strategies to subtle differences between players. ${ }^{211}$ These differences could manifest from various causes such as an occupation, but difference often manifests

\footnotetext{
210 Nakamura, Cybertypes.

211 Often, the term "faction" presents as a preferred and less volatile label for describing these differences amongst players, but the premise remains the same.
} 
through racial difference. Two example games-Small World (2007) and Eldritch Horror (2013) — demonstrate how playing as and playing with race potentially reduces racial difference to just being "part of the fun." Games like Small World "make light" of racial difference, suggest that racial difference is central to what demarcates us from one another, and that racial difference adds interest to an otherwise homogenous conflict. In different ways, games like Eldritch Horror utilize stereotypical representations of minorities to enrich the game's narrative while their white counterparts are remarkably different in both mechanical possibilities and narrative associations. When considered as symptomatic of a broader impulse within the industry, these two games show how minorities are regularly delegitimized through stereotypical representation and how racial identification is a personally activated concern that should not be treated seriously within gameplay.

\subsubsection{Small World (2007)}

Small World is an asymmetric area control game wherein players take on the role of a differentiated fantasy race to occupy and secure terrains on a relatively small and crowded map. As the rulebook describes the game:

Space is getting tight in Small World. There are just too many races living off your land - land your ancestors bequeathed to you in hopes you would build an empire with which you could dominate the world. [. . .] Picking a fantasy Race and Special Power combination, you must use their unique racial traits and skills to conquer surrounding Regions and amass Victory coins - often at the expense of weaker neighbors. ${ }^{212}$

212 "Object of the Game," in Small World (2007), des. Phillippe Kayaertz, Days of Wonder, Inc. 
Over the course of the game, players

choose from a selection of races-

including sorcerers, halflings,

skeletons, humans, and amazons

(which are curiously distinct from

humans) - each possessing a unique

skill that is randomly matched with

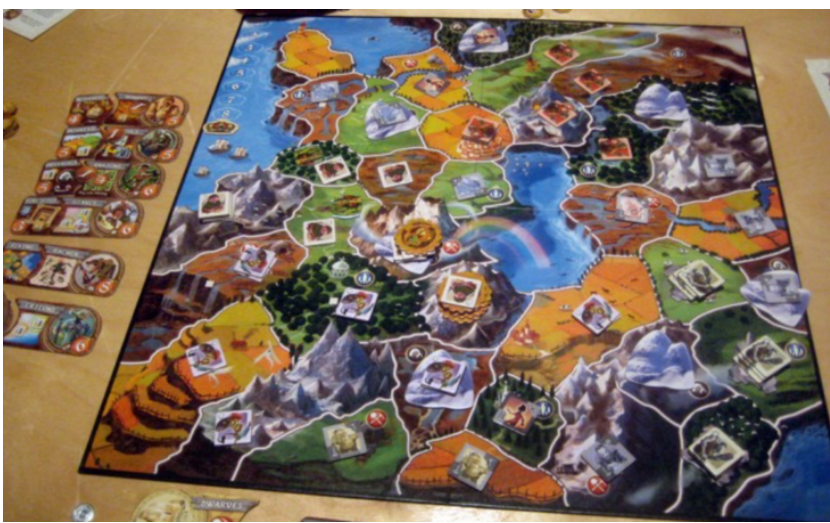

Figure 4.2 Small World setup, featuring the crowded terrain regions and the selection of available races.

an ability that further modifies the race's traits. With these chosen races, players deploy units across borders to take over and occupy contiguous regions, each region requiring a specified number of units depending on occupants, defenses, or terrain type. For each region they control at the end of a round, players earn a coin — which doubles as a victory point - and racial skills and abilities augment the ability to move, occupy, or earn coins. For example, the "Humans" as a default skill earn an additional coin when occupying farm regions. When randomly paired with the "Commando" ability, they may conquer a region using one less unit than normally required, or if paired with the "Flying" ability, they may move to conquer any region rather than following adjacency rules. The randomized blend of abilities and racial traits compel players to adjust their strategies and tactics to best utilize the given modifiers and add variation between game sessions.

Players must bid to take a race/ability pairing. During setup and throughout play, a display of races and abilities are arranged within view of all players. Players choose their initial pairing from this arrangement, taking the first pair for free or paying a coin to skip pairings to obtain what might be considered a stronger pairing. Players take the specified number of units and use those unit tokens to claim territories and conquer new 
regions. Throughout the preset number of rounds, players build up their attacking units when conquering regions or reinforce occupied territories to raise their defense against encroaching opponents. As player regions are conquered, unit tokens are discarded from the game and the players become weakened as their forces are depleted. Instead of conquering regions on a turn, players may choose to "put their race in decline" in order to choose another race from the available pairings. Races "in decline" still earn money for occupying regions but they cannot reinforce or conquer regions, but players will deploy their new race and earn money for all races they control on the board at a given time. Play continues in this manner, with players conquering regions and reinforcing defenses, until a specified number of rounds are completed. The player who has earned the most money and spent wisely when bidding for racial skills will win the game.

Small World is emblematic of a wide selection of modern board games that use race to describe and employ unique player attributes. Despite its aloof fantasy setting, the game raises concerns about what it means to play as and play with racial identities. ${ }^{213}$ One concern is that racial identity is equated with power. The mechanisms of play task players to occupy territories, for which they are rewarded for sustaining. Choosing a raceability pairing and exploiting that power is the central interest of the game. The remainder of the game equates to "just flipping burgers" and moving things around without any opportunity to plan, as one player lamented. ${ }^{214}$ The computation of

\footnotetext{
${ }^{213}$ There are other games not previously mentioned here that utilize real-world races, nationalities, and ethnicities as ability boosters in gameplay. Imperial Settlers (2014) is a prime example, allowing players to choose from such groups (known in the game as "factions) as the Japanese, the Romans, or the Egyptians, each providing players with a different ability. Small World was chosen as the exemplar for this point in the discussion due to its relative ease of play and its playful malleability of racial connotations.

214 "I Don't Really 'Get' Small World," Boardgamegeek.com November 1, 2014, https://boardgamegeek.com/thread/1262434/i-dont-really-get-small-world
} 
randomized pairings exceeds two hundred possibilities, ${ }^{215}$ encouraging players to replay as a different race. While the game mechanics remain the same from game to game, how players exploit their racial traits changes, making racial differentiation a focal point of the game's design. By putting such focus on racial identity and power, Small World endorses a worldview that suggests racial identity is central to what distinguishes us from one another. And players are encouraged to maximize the unequal benefits that arise from racial inequality.

While the case could be made that the use of different racial traits in the game subverts reducing race to essential traits by endorsing a fluidity between racial categories and highlighting racial inequality, this position is undermined by the narrowness through which players are allowed to express their identity. For one, racial traits are "locked in" during the game's setup, and players may not take what attributes they wish as part of their identity. For instance, if a player controls the bivouacking ghouls, that player is not allowed to retain the bivouacking ability when choosing another race. The traits, instead, are stabilized within the game session. Further, players are confined in the skill-ability pairing to express what racial traits they possess. This limits and reduces racial characteristics to something that can be exploited for personal gain. What concerned Lisa Nakamura when she examined the role of race amidst online platforms connects to what occurs with race in board games. In her discussion of identity tourism in Cybertypes, she demonstrates that race is activated as a costume or masquerade that is completely reversible. ${ }^{216}$ Race becomes a plaything, a commodified subjectivity, for the enjoyment of the identity tourist. In Small World, players choose, use, and switch between races.

\footnotetext{
${ }^{215}$ Expansions to the game increase this computation substantially.

${ }^{216}$ Nakamura, Cybertypes, 47.
} 
Race is treated as something unenduring and selectively activated, and it never rises to the level of serious conversation. Though board games lack the anonymity that Nakamura discusses as characteristic of virtual interactivity, ${ }^{217}$ Small World and the many racially enriched games like it conflate race with entertainment, an enjoyable space wherein differentiation is a source of antagonistic pleasure.

Small World not only encourages players to "play as" a racial group but also encourages players to "play with" race. As a family-friendly game, the game does not take itself too seriously, and the violence and destruction undergirding the implied narrative is cartoonish and playful. This playfulness carries over into how players negotiate racial identity. Players choose, use, and switch between races. Race is treated as something unenduring and selectively activated. It never befalls players or hinders a player's access to goals, and players are able to bypass unfavorable races - during bidding - to secure one that is more advantageous. This aloof playfulness undermines the gravity and seriousness of race as it emerges in real-world interactions. Any weakness or obstructed access a player may feel regarding their racial traits is only temporary and largely results from a player's choices.

Playing with and playing as a race, then, complicates racial politics as they present in board games generally. Racial politics might be assumed to extend the perimeter of the so-called "Magic Circle" of gameplay wherein players negotiate the boundaries of everyday life as distinct from elements of play. ${ }^{218}$ A glossary review of

\footnotetext{
${ }^{217}$ This is exacerbated when considering virtual board game platforms, such as app implementations. 218 Jesper Juul, "The Magic Circle and the Puzzle Piece," in Conference Proceedings of the Philosophy of Computer Games 2008, ed. Stephan Günzel, Michael Liebe and Dieter Mersch, Potsdam: University Press 2008,60 . He states: "The magic circle is a description of the salient differences be- tween a game and its surrounding context. It does not imply that a game is completely distinguished from the context in which it is played."
} 
online discussions of race in games demonstrates that many players would rather racial politics remain outside the play space entirely. ${ }^{219}$ Indeed, enflamed discussions of race are sometimes relocated to a fringe platform on Boardgamegeek.com for "Religion, Sex, and Politics." While many of these threads include harmful attitudes about race, the potential marginalization of racial discussions to these fringe boards secures an assumption that racial politics and play do not mix. Instead of progressing a serious discussion of race and identification, the majority of board game designs that use some aspect of race as a key feature rely on distillations of race as a mechanism of play for enjoyment while simultaneously divorcing that representation from the gravity of racial identification.

\subsubsection{Eldritch Horror (2013)}

Eldritch Horror is a globetrotting cooperative game set within the H.P. Lovecraftinspired Cthulhu mythos. Therein, players take on the role of an investigator who works with others to help tamper otherworldly monsters, close portals to other dimensions, and discover clues surrounding the rise of a monstrous deity. Using acquired items, assets, and spells alongside personal skills, players traverse the globe to stop the threat before it "awakens." While the lengthy American-style game consists of many nuances and contingencies regarding the mechanism of play, the general goal is to discover clues to three successive mysteries concerning the monstrous deity before a "doom" track reaches zero and the monster awakens. If they successfully manage to do so, they win the game collectively. However, if they fail to defeat the deity or all fall victim to debilitating

\footnotetext{
${ }^{219}$ Cf. "The Political Insensitivity of Archipelago," boardgamegeek.com, December 6, 2012, https://boardgamegeek.com/thread/894504/political-insensitivity-archipelago
} 
injury or madness, they lose the game. This overview is admittedly glossed and simplified, but what is pertinent to the argument made here is how racially marked investigators are represented in the game and how that representation exemplifies the (mis)use of race in board games more generally. ${ }^{220}$

There are several playable investigators from which players may choose, and the choices are diverse, with women and people of color constituting the ranks despite being outnumbered by white male counterparts. Two investigators of color-Jim Culver and Akachi Onyele ${ }^{221}$ — exemplify how the inclusive diversity is undermined by a recurrent reliance on stereotypical representation. While they offer strategic advantages for players, they are markedly unequal to their white counterparts and marked by associations to "native" and "mystical" qualities. These reductive representations function to commodify the racial Other as a consumable object for the player's pleasure, which has ramifications both inside and outside of gameplay.

To cooperatively combat the rising otherworldly threats, players choose from an assortment of investigators and take the player boards, tokens, and assets specific to that character. The personal player boards track a player's statistics and includes a backstory for the character as well as a unique ability. Over the course of the game, players are required to pass skill tests to access powerful artifacts, relics, spells, and clues. Each

\footnotetext{
${ }^{220} \mathrm{I}$ am aware of the racism exhibited by the source material for this game, and while that may prove to be another avenue toward understanding the role of race in the game, I have chosen to focus on characters created not by Lovecraft but by the game's publishers. This, I feel, shows how the accusations of racism cannot be relocated from the present onto dated material or views.

${ }^{221}$ As examples, the arguments made about these characters are not exclusive to these characters, and the game's racist underpinnings can be observed within many of the title's minority characters. We can, in fact, see racism operating in depictions of Asian and other African-American characters, and we can observe sexism in many of the game's female characters, as well. I do not want to lessen the importance of these concerns, but exploring these in successive detail would overburden the arguments made here. For brevity, I have chosen to focus instead on these two characters as representative examples.
} 
character has varied ranks for each of these skills, which include observation, influence, research, physical, and mental skills. ${ }^{222}$ Tests will require one or more of these skills to be used, and the number associated with a character's skill corresponds to the number of dice - and hence the chances of rolling a success - that player will roll to resolve the test. These statistics, along with the character's backstory and unique abilities, demonstrate marked differences between minority characters and their white counterparts.

One of the minority characters players may choose is Jim Culver. Culver is a jazz trumpeter from the deep south who has a supernatural connection with the dead. His skill sets are average and evenly distributed, neither exceeding nor suffering in any category. Players who choose Jim Culver will be most successful by avoiding physical and

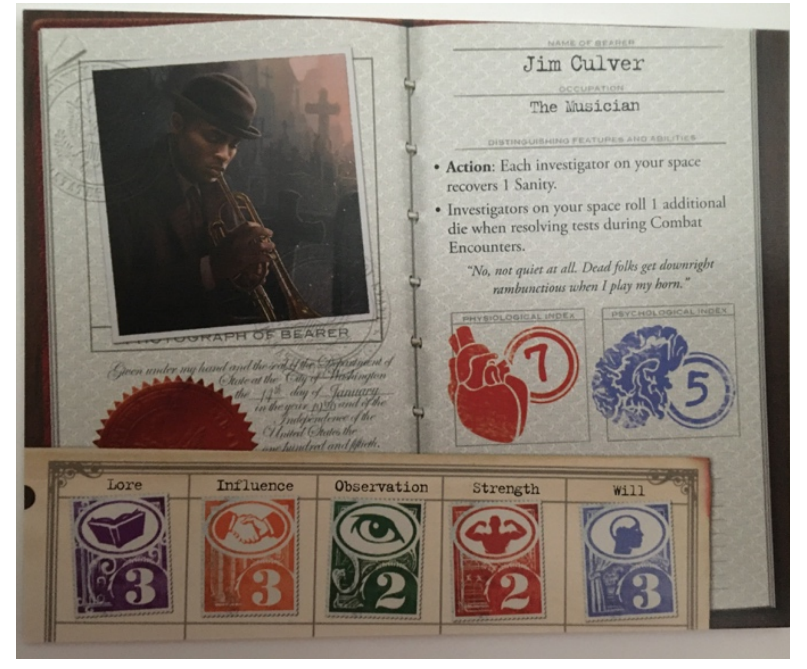

Figure $4.3 \mathrm{Jim}$ Culver's role is associated with jazz and magic, and his unique actions offer support for other players (Eldritch Horror).

psychological threats in favor of using his abilities to interpret ancient lore and spells and sway other people's emotions. He is most advantageous as a support character alongside characters who possess directly combative skills. His unique abilities-allowing others to recover lost sanity or boosting how many dice other investigators can roll during combat - require players to share a space on the game board to activate. As such, Culver presents as a helpful companion—or even "sidekick" — to other investigators.

\footnotetext{
222 These are dubbed observation, lore, influence, strength, and will in the game's parlance.
} 


\begin{abstract}
Akachi Onyele from Nigeria
is described as a shaman who has learned supernatural means of protection by an ability to traverse into the spiritual realm. Akachi has seven points of mental resistance, but her physical resistance dips to five, meaning she can withstand mental stresses well while her ability
\end{abstract}

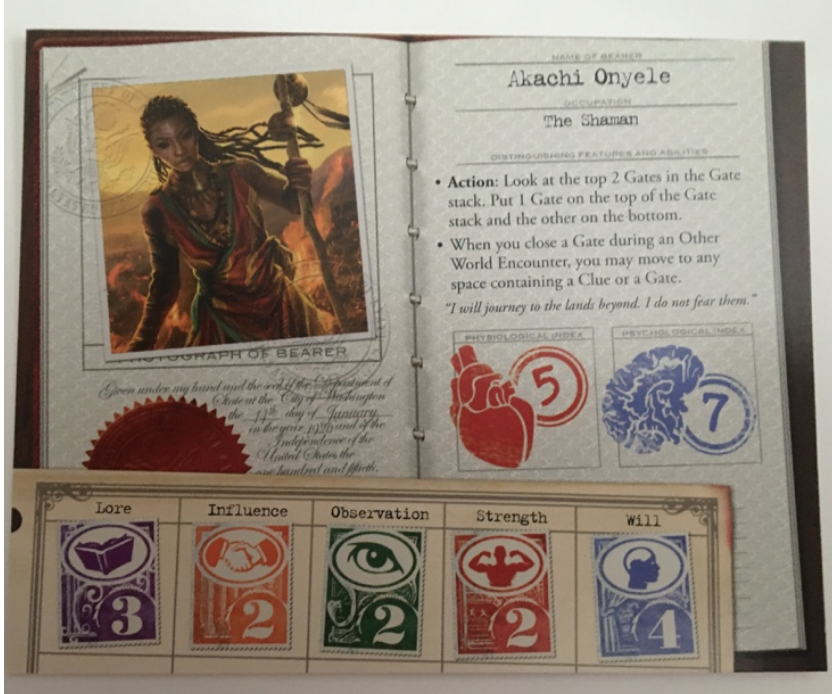

Figure 4.4 Akachi Onyele is exoticized as a mystical African shaman with a spiritual connection to the supernatural realm (Eldritch Horror).

to persevere in physical confrontations is somewhat limited. With a will skillset of four, she can muster courage and overcome frightening obstacles as she encounters them, but her ability to influence, observe, or physically fight is severely limited by each skill having a value of two. Players using Akachi will gain the best advantage by using her spell casting abilities using her lore attribute and by withstanding mental damage in psychologically damaging conflicts.

Within the supernatural contexts of the game, these occupations and backstories may not appear unusual. Each of these characters has a unique skill set that allows the controlling player a different experience of the game. However, the constraint placed on black characters restricts their roles to stereotypical associations to music, magic, and nature. This limited and narrow presumption of black characters is further exemplified by the variety of occupations and backstories available for white characters. Players can take on roles of politicians, archaeologists, astronomers, professors, cops, soldiers, chefs, and so forth. The variety of prestigious occupations and skills available for white players 
conflicts with the limitations placed on black characters. Black characters are disproportionately entertainers and share a kinship with the supernatural. As presented, the gamut of characters implicates that white characters are predominantly in culturally significant and empowered roles in comparison to their black counterparts. Take, for instance, the role of Akachi Onvele, who is not only constrained to associations of the supernatural but also the natural. Heralding from the imagined exoticism of Africa, her representation becomes entangled with associations with nature. As Stuart Hall has shown, representational associations of black bodies with nature help stabilize and naturalize prejudicial assumptions of being associated with wildness, the primitive, the dark, the mysterious, and the dangerous. ${ }^{223}$ Further, nature is beyond learning, history, and education; it is natural rather than civilized. That presumed, the association of black bodies with nature stabilizes the pejorative associations as static and unchangeable.

Beyond displaying limited opportunity for black characters in the game, the continual parallels between blackness and magic denaturalizes their abilities as heroic contenders. Characters like the cop or the sailor — both white characters - imply their skills derive from learning and training. Magic abilities, by constrast, suggest that the heroic potential of black characters is neither natural nor gained through rigorous training. Rather, their skill comes from without. It is gifted or cursed upon them. ${ }^{224}$ Magic "explains away" black empowerment, relocating power from self-determination to external sources..$^{225}$

\footnotetext{
223 Hall, "Spectacle," 239.

${ }^{224}$ As the narrative backstories of Culver and Onyele demonstrate.

225 Cf. Ben Carrington, Race, Sport, and Politics: The Sporting Black Diaspora (Thousand Oaks: Sage, 2010), 2. This explanation of skill from without compares to racial stereotypes in sports that endorse views that black athletes are "gifted" with innate talents rather than becoming skilled through a rigorous physical
} 
In addition to neutralizing black empowerment, these representations associate characters of color to harmful stereotypes, such as the "magical negro" stereotype that has proliferated in Western mass media for decades, particularly in film. This magically imbued character surfaces to offer aid to white characters facing a dilemma. ${ }^{226} \mathrm{Jim}$ Culver's ability to aid players sharing his board space exemplifies this. He presents as a supportive rather than assertive character, helping others more so than personally resolving conflicts. While Eldritch Horror does not limit the magical abilities of black characters to solely servicing white characters' conflicts, constraining the characters' abilities to magic recalls such stereotypes.

Associating black characters with incomprehensible magic and the supernatural also contributes to the unpredictability of black empowerment; their power disrupts logical associations of power with physical strength or weaponry. As a result, black characters are paradoxically heroic and dangerous. As Entman and Rojecki have noted in their The Black Image in the White Mind, the black body occupies a space of liminality within the white gaze. It is neither completely accepted nor completely rejected. ${ }^{227}$ For the white viewer, the black body is never fully conceptualized as selfsame or equivalent but as a body in flux. On the one hand, the image of the black body is accepted but, echoing Yancy, retains the potential for danger and pollution. ${ }^{228}$ We can see this

and intellectual plan. Ben Carrington suggests that the image of the black athlete has a double meaning as a role model and debased object, simultaneously "despised and lionized."

${ }^{226}$ Susan Gonzalez, "Director Spike Lee Slams 'Same Old' Black Stereotypes in Today's Films," Yale Bulletin \& Calendar, March 2, 2001, http://archives.news.yale.edu/v29.n21/story3.html. This "magical negro" trope, as seen in such films as The Green Mile (1999) and The Legend of Bagger Vance (2000) in one instance empowers black characters but consistently directs the efforts and achievements of black characters toward the satisfaction or support for white characters. As director Spike Lee suggested, the "magical negro" trope continues the legacy of harmful stereotypes like the "noble savage" and the "happy slave" in that the use of magic and power is to support and save white characters.

227 Entman and Rojecki, 46.

228 Entman and Rojecki, 52. 
operating with the reliance on the supernatural and the primitive for representations of black characters in Eldritch Horror, but this is exacerbated and clarified by the fact that we rarely see protagonist characters of color wielding weapons in board games while armed white characters are prevalent. This remains true with Eldritch Horror. While white characters such as "Skids" O’Toole, Jenny Barnes, and Zoey Samaras can be seen wielding one or more weapons in their representative images, black characters hold instruments (Jim Culver) or a staff (Akachi Onvele). ${ }^{229}$ As Fanon and Hall suggest, representations of blackness are subjected to the dominant constraint of the white gaze. These characters are constructed to appear safer and less threatening to the status quo through their use of magic and their lack of weaponry. Even though all characters are working together in Eldritch Horror, the belittling representations of black characters suggest an ideologically determined limit on their access to empowerment. Consequently, the image of black bodies produced by and for whites suffers racial prejudice without overt racism.

Maintaining this potential that black bodies are potentially dangerous, we can see how bell hooks' notion of cultural appropriation operates games. In Eldritch Horror, black characters are offered as distinct experiences from the realities of white experience. By playing as white characters, players may enjoy opportunities to roleplay as a politician or an astronomer or a chef, but with black characters, players can experience magic, seedy jazz nightclubs, the bayou of Louisiana, or Africa. These representative experiences are hyperbolic but promise players an experience that is distinct. In the same

\footnotetext{
${ }^{229}$ Marie Lambeau (likely a reference to Marie Laveau), another black character in the game, is a blues singer who may have inherited her grandmother's sensibilities for witchcraft. She is depicted holding a microphone.
} 
ways that hooks explored, players are encouraged to consume the experience of the other without a threat to their status quo. ${ }^{230}$ Through their foray into the dangerous, the unknown, and the markedly Other, players gain a transformative experience that relocates that experience as a white experience while deflating and cultural or racial attachment to the significance of that experience.

Conversely, taking the role of minorities in games can yield false equivalencies amongst different racial groups and promote assumptions that obstacles affecting minorities through systemic racism are similar to obstacles endured by the dominant group. Through a roleplaying tourism akin to Nakamura's description of identity tourism, ${ }^{231}$ players risk conflating the incomplete experience of their role with their relatively less-hindered personal experience. In so doing, they diffuse white experience as synonymous to human experience and minority experience as "not as bad off" as presumed.

In Eldritch Horror and similar games, narrative space for the development of black characters operates to sustain rather than protest negative assumptions about race. While players and producers of the games might have no ill intent in enjoying or producing these representations and while they may find these representations as progressive within the contextual history of board game design, these representations are ultimately constrained by a feedback loop that consumes and regulates those representations according to a white consumer gaze. With the black characters in Eldritch Horror, players are offered representations of blackness that are constrained by

\footnotetext{
230 hooks, "Eating," 22.

${ }^{231}$ Nakamura, Cybertypes, 56-57. "Players who represent as members of a minority may get the impression that minorities "don't have it all that bad," since they are unlikely to find themselves discriminated against in concrete, material ways."
} 
stereotypes. The associations with magic, nature, danger, and exotic places are all deployed in Eldritch Horror, and roleplaying as these characters offers a racial contact experience that can be 'toured' without any physical or ideological threat to their identity.

\subsection{SANITIZING THE PRESENT IN}

\section{FREEDOM: THE UNDERGROUND RAILROAD AND FIVE TRIBES}

Explicitly negative representations of black characters are largely anomalies in the modern board game industry. Instead, there appears to be a proclivity in modern game design to avoid unsettling topics altogether. There is an obvious tension in the community about candid discussions of race and racism, and it is common for discussions about racial representation to spiral out of control into polarized political entrenchments. ${ }^{232}$ This potential for animosity among consumers has arguably compelled designers to focus attentions away from hot-button issues by compartmentalizing unsettling events within the presumed innocuity of the past and by deflating the gravity and significance of these issues. Two games in particular, Freedom: The Underground Railroad (2012) and Five Tribes (2014), demonstrate the pressure for an industry to avoid what the consumer finds unsettling. By compartmentalizing slavery to the past, as in the case of Freedom: The Underground Railroad, or by deflecting the gravitas of human suffering, as in the case of Five Tribes, the producers and players have shown a desire to remove culpability and complicity from the present-day status quo, consequently endorsing a guilt-free play space that does not acknowledge the lingering seriousness of these issues.

\footnotetext{
${ }^{232}$ Cf. “Puerto Rico: Isn't This Game a Little Racist?” boardgamegeek.com, February 22, 2013, https://boardgamegeek.com/thread/935394/isnt-game-little-racist One only needs to review the complaints of racism and the skirted theme of slavery in a game such as Puerto Rico to see how a frank conversation about race quickly unravels into polarity.
} 


\subsubsection{Freedom: The Underground Railroad (2012)}

Few games confront the issues of racism in gameplay explicitly. One of the most prevalent designs to do so is Freedom: The Underground Railroad, a cooperative game wherein players attempt to guide escaping slaves north toward Canada through a dangerous network of slave catchers. While navigating the physical danger of escaping slavery, the players also attempt to raise funds to fight for the abolition of slavery. Players win the game if they manage to move a prerequisite number of slaves to freedom and if they have used their funds to purchase the required number of support tokens before the end of eight rounds. Players lose the game if the "Slaves Lost" track is filled to its preset limit and another is to be added, or they run out of time-i.e. players do not win the game by the end of the eighth round. As a cooperative game, no one wins or loses the game alone. Further, all antagonism toward the abolitionist cause are intrinsic to the game design and not played by any player at the table.

The game treats the issue of slavery with gravity and historical accuracy. Historical facts are included on game materials such as cards and within the rulebook, and the rulebook contains ancillary material about the history of American slavery and the important figures behind the abolitionist cause. While much of the violence is abstracted in the game, and enslaved persons are represented on the board as wooden

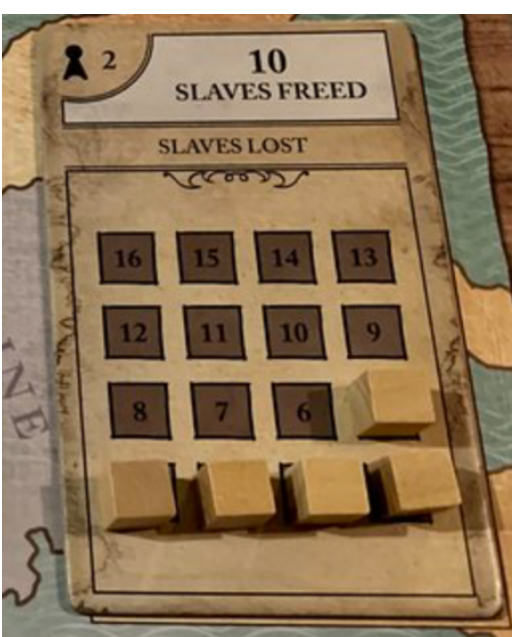

Figure $4.5 \mathrm{~A}$ tile tracks the number of slaves recaptured or killed (Freedom: The Underground Railroad). 
cubes, a common board game token, players and reviewers have noted the somber feelings that come each time a cube is removed from play to the "Slaves Lost" card. ${ }^{233234}$ Generally, the board game community has commended the game for its content but have also suggested that it may be a theme that is too uncomfortable for players to enjoy. ${ }^{235}$

What becomes an issue for a game like Freedom is how the tragic institution of slavery is somehow permanently located as the past or as an "ugly chapter" in American history. ${ }^{236}$ The rulebook of Freedom includes historical information regarding slavery, noting the formal end of slavery came with the ratification of the 13th Amendment. ${ }^{237}$ With this presentation, slavery and racism appear as compartmentalized and stagnant horrors of the past with little impact on the present. To play Freedom is to play within a historical moment rather to play with the present in mind. As Alcoff has made clear, a key struggle for those identifying as white face in the present is a reconciliation of viewing themselves as racially marked, and beneficiaries of privilege contained within that marker, and the complicity with the institutions that have procured those privileges by oppressing others. ${ }^{238}$ There prevails a desire among many whites to declare themselves "as individuals separable from history and structure." 239 When board game designs compartmentalize oppression as something confined to the past, the same designs encourage players to see themselves as separate from that past, both in psychological

\footnotetext{
${ }^{233}$ Cf. The Game Boy Geek, "Freedom: The Underground Railroad - With the Game Boy Geek," YouTube video, August 27, 2013, 16:40, https://www.youtube.com/watch?v=bmyniDbKXDs

${ }^{234}$ Cf. The Dice Tower, "Freedom: The Underground Railroad - with Tom Vasel," YouTube video, December 12, 2013, 11:34, https://www.youtube.com/watch?v=BC-f7GZlwnk

235 Cf. "A Black Player on Freedom," Boardgamegeek.com, April 14, 2014, https://boardgamegeek.com/thread/1155831/black-player-freedom

236 The Dice Tower, "Freedom."

${ }^{237}$ Freedom: The Underground Railroad, des. Brian Mayer, Academy Games, 2012.

${ }^{238}$ Linda Martín Alcoff, The Future of Whiteness (Malden, MA: Polity, 2015), 163.

${ }^{239}$ Alcoff, 141.
} 
complicity as well as material gain. Games that avoid, sanitize, or compartmentalize issues of racism offer players not only an opportunity to reap the rewards of exploitation but to see that exploitation as detached from their physical present.

While a game such as Freedom: The Underground Railroad should be commended for its choice of narrative content, the larger dilemma about the game is that so few games deal with the issue of slavery, a game like Freedom feels at odds with the notion of the magic circle. In simple terms, slavery is not a subject that can be imagined as a welcome narrative within a play space that wants to divorce gameplay from the banalities of reality. However, as has been shown, the magic circle can never completely separate its play space from the reality of its players, and players and game producers select attributes of reality to emphasize as a system of choice and rewards - such as violence or economy.

\subsubsection{Five Tribes (2014)}

Selectivity and exclusivity of what real-world contexts are deemed appropriate for game play has never appeared so pronounced as the controversy surrounding the design of Five Tribes (2014). The issues of and solutions to representations of slavery in Five Tribes demonstrate that there is little desire within the board game community to remove issues of oppression in games but more a desire to obscure how board games connect to issues of race and racism. The problematic result is that playing race and discussing race becomes a conscious and political act on the part of the player and not an impetus of the game design itself. In other words, players are viewed as choosing to make race an issue within a game rather than responding to racial issues in the design. 
When Five Tribes was

announced to be released at

GenCon 2014, player expectations

were high. The publisher, Days of

Wonder, had a reputation for

releasing quality game designs with

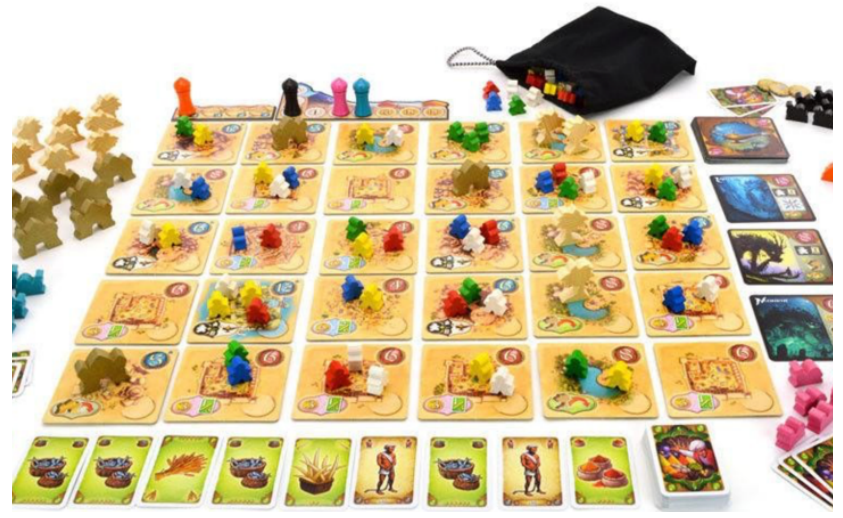

Figure 4.6 Five Tribes setup, featuring the location tiles, available djinns, and the slaves available at the market.

widespread appeal: one of their

titles, Ticket to Ride, is one of the bestselling modern board games. Bruno Cathala, the designer of Five Tribes, also had received celebrity status among game designers for being involved in such games as Shadows over Camelot (2005), Mr. Jack (2006), and Jamaica $(2007)^{240}$. Adding to this, Five Tribes was marketed as a more complex game for gaming connoisseurs than games previously released within the Days of Wonder catalogue. The hype surrounding the game predictably invited criticism from within the community, as often happens when buzz is generated about forthcoming releases. For Five Tribes, this criticism came in the form of how slavery functions as a mechanism of play.

Five Tribes is a grid-movement action selection game set within the fictional world of One-Thousand-and-One Nights that uses a mechanism borrowed from Mancala to facilitate play. The game's thirty landscape tiles are setup as a five-by-six grid, and those tiles are seeded with five different colored meeples ${ }^{241}$ representing the five tribes of the game's namesake. Each tribe has a different ability, from allowing players to score

\footnotetext{
240 See Chapter III, where Jamaica is discussed in detail.

${ }^{241}$ See Chapter III. The "meeple" terminology combines the words "my" and "people" and are a common token used in modern games.
} 
points for majorities, purchasing resources from the market, building structures, as well as assassinating other meeples. Players, on their turn, pick up all meeples from a tile and, moving orthogonally and not doubling back to the initial tile, place meeples one at a time on adjacent tiles, creating a "path." The last tile where a meeple is placed in this manner determines specific abilities that are triggered. The color meeple placed there is removed from the tile along with matching-colored meeples, and the ability corresponding to that tribe is triggered according to its color. If the tile is cleared of meeples in this manner, the player possesses ownership of the tile and marks it with a camel token in that player's color. Each tile has a special ability—from boosting points for occupying the tile to summoning the powers of the djinn—and that ability is triggered upon placement. Successful players negotiate the costs and benefits of these overlapping abilities to gain an advantage over players. Players earn points for sets of resources, occupying tiles, commanding djinns, money on hand, and other criteria. The game ends when a player has taken possession of a prescribed number of tiles or no legal move remains, and the player with the most points wins.

While there are more aspects to the game play that are not necessary to this argument, what makes the game controversial is in its use of slavery. Slavery cards are available in the market alongside material goods and can be acquired by tile or meeple actions. Slaves are "discarded"-sacrificed, perhaps—-when players summon a djinn, but they are also discarded from the game to boost meeple actions. For example, triggering the blue meeple's ability allows a player to score points for the number of blue-labelled landscape tiles surrounding the final movement. These points are multiplied by the number of meeples collected from the tile. If a player discards slave cards, each card adds 
one to the multiplier. On a tile surrounded by four blue-labelled tiles and picking up two blue meeples would score eight points while discarding a slave card in addition to this would yield twelve points. While slave cards can be used to boost point scoring opportunities during gameplay, the cards themselves have no point value at the game's end.

The inclusion of the slave cards adds another layer of strategy and tactics to an already complex game. Upon its release, players complained about the inclusion of the cards to the publisher Days of Wonder, stating that the inclusion of the cards was insensitive and connoted trading in human suffering. ${ }^{242}$ Days of Wonder responded twice to the controversy. The first of which claimed that the source material for the game made several references to slaves and calling them anything different, such as servants as a player had suggested, would have distorted the source material. ${ }^{243}$ After this did not quell the controversial distaste for the game component, Days of Wonder responded again, stating that given the harming effects of a concept such as slavery and how that prevented players from enjoying the game, they made the decision to revise the game. ${ }^{244}$ Days of Wonder replaced the cards depicting enslaved persons with cards depicting fakirs

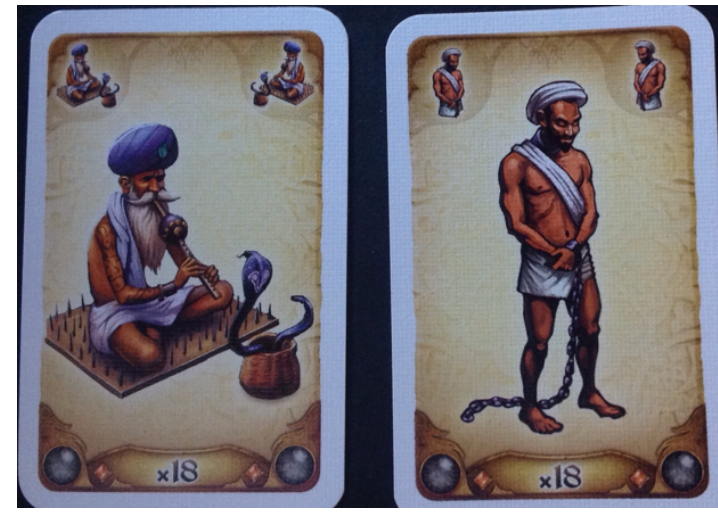

Figure 4.7 Fakirs replaced the slave cards in subsequent printings of Five Tribes on subsequent releases of Five Tribes and

\footnotetext{
${ }^{242}$ Eric Martin, "Five Tribes Revised: Slaves Are Out, Fakirs In," boardgamegeek.com, March 25, 2015, https://boardgamegeek.com/blogpost/40219/five-tribes-revised-slaves-are-out-fakirs

${ }^{243}$ Martin.

${ }^{244}$ Martin.
} 
offered replacement cards to owners. The use of the card remains the same, however.

Only the artwork and the name of the card itself have been changed. The change largely quieted the online criticisms of the game.

What is striking about this decision is two-fold: the card changed only in title and artwork but not in function, and the change apparently satisfied the public distaste for the original design. Changing the card in title and art only does nothing to address harm placed upon human beings. Called fakirs or enslaved persons, the act of "spending" human bodies to call upon the powers of djinns or to boost the abilities of a tribe still presents with ethical problems. Further, the appearance that the name change did satisfy the gaming community demonstrates that the core problem with the representation of enslaved persons in the game was not the human suffering implicated by such a choice but the nomenclature. As can be seen by criticisms of such games as Five Tribes, 7 Wonders: Cities (2012), and the Lords of Waterdeep expansion Scoundrels of Skullport (2013), the mention of slavery can cause game players to avoid a game, but they are comfortable with playing the same game if the word has been removed or substituted. ${ }^{245}$ The controversy is not in the action but in the language, and that shows an overt and explicit avoidance of discussions of race through an erasure of the language.

As a result, slavery is largely a taboo subject amongst board game designs. Few games confront the issue head-on, ${ }^{246}$ but these are met with mixed reviews because

\footnotetext{
${ }^{245}$ Cf. "What Games Depict Slaves/Slavery?" boardgamegeek.com, June 8, 2015, https://boardgamegeek.com/thread/1382715/what-games-depict-slavesslavery/page/1

${ }^{246}$ Freedom: The Underground Railroad is an anomaly amongst modern board game titles for its direct address of slavery, but war simulation games, in efforts to be as authentic as possible, address the issue when it arises. These lengthier wargames commendably address as many variables and contingencies as possible in their designs. Modern board games, however, often abstract these details to constrain play time and simplify mechanisms.
} 
"slavery is not a game" 247 or "slavery kills a game." 248 While the impulse to suggest that violent and tragic events may not align with the enjoyment sought through the play of games, the feedback loop of the gaming community appears to constrain publishers to avoid tragic concepts such as slavery, in some way contributing to the erasure of the language of slavery from games like Puerto Rico, Archipelago (2012), ${ }^{249}$ and Francis Drake (2013) while the institution continues to operate in the narrative subtext.

The feedback that has resulted in numerous games avoiding concepts such as slavery and racism have not slowed production of games set within oppressive narratives. Exploration and colonialism continue to be popular themes within board games, especially Eurogames, but the removal of uncomfortable topics only works to sanitize the institution and whitewash the actual history. Players can enjoy numerous games such as civilization builders and games about colonialism without the white guilt that comes with confronting the oppression of minority groups within these settings. The sanitation of game language, while it may increase playability and sales, ultimately distorts the reality of privilege and oppression.

As Fanon, Hall, and Johnson have made clear, the construction of "blackness" is a complex negotiation between cultural groups and individuals with the panorama of contexts that are super-added onto the black body. These include individual experiences such as family, education, and community but also expand to include the broad experiences of the larger cultural group. Fanon, externalizing the image of his self from

\footnotetext{
247 "A Black Player on Freedom."

248 “Why We're Getting Ride of 'Puerto Rico,'” boardgamegeek.com, July 29, 2017, https://boardgamegeek.com/thread/1820171/why-were-getting-rid-puerto-rico/page/2

249 The colonized in Archipelago are called separatists and rebels, and they are a non-playable feature of the game that can result in all players losing the game.
} 
the view of the white gaze, suggests this: "I was responsible not only for my body but also for my race and my ancestors. I cast an objective gaze over myself, discovered my blackness, my ethnic features; deafened by cannibalism, backwardness, fetishism, racial stigmas, slave traders [...]" $]^{250}$ This is apparently the issue that many white producers fail to realize when constructing images of black bodies. The construction of the black body is never individualized and independent from the generalized attitudes inscribed upon it by the history of its race. To understand the lived experience of black people, these producers would benefit from understanding that the context and history of exploitation comprises that identity. Rather than learning about racism and historical oppression, they

often live it. When board game producers and consumers choose to compartmentalize the history of black experience as something past, done, and neutral to the present, such as the case of Freedom, or sanitize the language of slavery as in Five Tribes, producers and consumers misunderstand the lived experience of black people.

\subsection{CONCLUSION}

The inclusion of racial difference in games proves to be difficult terrain for its players and producers, but at best, it is paradoxical. Racial differentiation can enrich the game experience, allowing players to "play as" someone who is racially different. This however risks distilling experience to stereotypes for the pleasure of an identity tourist. Given this image of the racially distinct is both produced and filtered by a dominant majority culture, players seldom simulate the realities of racial difference but participate

\footnotetext{
${ }^{250}$ Fanon, “Lived," 92.
} 
in an imagining of racial difference. ${ }^{251}$ What results in board game design is a selective context for black bodies. And the largely white demographic of producers and players determine what contexts are included. In Small World, we see rigid and essential traits marked by racial difference in aloof play, and in Eldritch Horror, we see a continual reliance on familiar stereotypes and subordination. In neither do we see a serious attempt to engage with the realities of racial difference or a platform from which serious discussions are likely to emerge.

Representations of black people are generally welcome in board game design, so long as that representation is not a threat to the superiority of its white players and producers. There is an implicit push within board game design to construct an image of racial distinction that is included but denied the contexts that shape that identity. Games such as Freedom: The Underground Railroad may confront issues like slavery but abstract white antagonism - no one plays as a slave catcher — and compartmentalizes the issue as inert history. Such attempts to treat slavery as a contained image from the past with no bearing on the present sanitizes the present while allowing white players to enjoy the game without culpability. Further, choices like the revision of Five Tribes also show another glaring truth about board game design: the issue of race and racism has little to do with the experience of black people and has everything to do with assuaging white guilt. In the end, the representations of black people in board games is not, and has rarely been, about diversity and the welcomed inclusion of people of color; instead, it is about a selective representation that does not threaten the established white cultural order.

\footnotetext{
${ }^{251}$ Nakamura, Cybertypes, 57. She states: "The problem with believing direct experience "as" the other will give access to knowledge about it, its marrow, is that this enterprise devalues actual conversations with it." Italics original.
} 


\section{CHAPTER V \\ UNEARTHING WHITE DOMINANCE}

Whiteness is everywhere in U.S. culture, but it is very hard to see [....] As the unmarked category against which difference is constructed, whiteness never has to speak its name, never has to acknowledge its role as an organizing principle in social and cultural relations.

—George Lipsitz ${ }^{252}$

The dominant demographic of players and producers ultimately raises questions about how board games portray white characters. More pointedly, from what ideological premises do representations of whiteness emerge and constitute? For the vast majority of modern games, whiteness presents as a default; it is centralized, normalized, and made common sensical. Most board games do not call attention to the white race of the characters being played, and when they do, as in games like Eldritch Horror, they are given the trappings of erudition, physical prowess, or influential power. However, the design choice to make a character white or to default implied characters to white is not seen as a politicizing decision: it is simply "matter of fact. This common sensical prevalence risks universalizing white experience as human experience, a risk that sets up false equivalencies of racial experience but does so while simultaneously appearing to exempt whiteness from racial politics. The resulting apolitical invisibility of whiteness

\footnotetext{
${ }^{252}$ George Lipsitz, The Possessive Investment in Whiteness: How White People Profit from Identity Politics (Philadelphia: Temple University Press, 2006), 1.
} 
ultimately functions to secure the role of white bodies as normal, central, and universal while simultaneously distinguishing nonwhites as constrained and markedly visible.

Board games have had difficulty negotiating racial disequilibria. A recent game design titled Scramble for Africa — pulled by its publisher, GMT, prior to its releasedemonstrates this unease. A European style game that largely avoids physical conflict in its rewards system, Scramble for Africa was set to simulate six European powers exploring the unknown interior of the African continent. In his article on the game and the trend of troubling simulations in board game designs, New York Times contributor Kevin Draper calls attention to the fact that the limits of representation in board game designs are subjective and flawed, noting the ability of players to don problematic historical roles such as Nazis and the Confederacy. ${ }^{253}$ According to Draper, the game was pulled after its theme was contested on forum posts on boardgamegeek.com. Scramble for Africa was deemed to treat the severity of the historical period too lightly because it largely abstracted the violence out of the game. ${ }^{254}$

What the aborted publication of Scramble for Africa highlights is the unease white players demonstrate regarding their complicity in racialized domination and violence, however. Largely abstracted violence is not the same as ignored violence, and from the descriptions of the game available, ${ }^{255}$ the conflict in Africa was not ignored. While diminished in its severity, conflicts between colonial powers and indigenous populations

\footnotetext{
${ }^{253}$ Kevin Draper, "Should Board Gamers Play the Roles of Racists, Slavers, and Nazis?" New York Times, August 1, 2019, https://www.nytimes.com/2019/08/01/style/board-games-cancel-culture.html 254 Jon Bolding, "A Cancelled Board Game Revealed How Colonialism Inspires and Haunts Games," vice.com, April 12, 2019, https://www.vice.com/en_us/article/vb9gd9/a-cancelled-board-game-revealedhow-colonialism-inspires-and-haunts-games 255 The listing for the game has been pulled from Boardgamegeek's database, and all forum posts regarding the topic have been relocated to a collective entry labelled "Unpublished Prototype."
} 
presented as events and playable actions. I am not suggesting the game design faithfully simulated historical events, but it is telling how games that completely abstract the violence associated with their events are published and even praised (recall Puerto Rico) and games that portray the harsh realities of racial conflict are avoided as unsettling (recall Freedom: The Underground Railroad). The preference among designers and players appears to be one that eschews the reality of oppressive violence completely. The modern board game is not a contested space striving toward a racial politics that promotes equality; by contrast, it is clear which racial demographic reigns unchecked.

When designs eschew the necessary violence that has historically come with white domination, the implicit narrative of white supremacy can be sustained and even endorsed unchecked. As long as whiteness is presented as innocuous, centralized, and normalized through nonconfrontational narratives, the exploitation and oppression of others that operates as a present absence beneath these narratives too can be seen as innocuous, central, and normal. Only when interracial and ethnic conflict are presented as elements of the game design does whiteness become marked, visible, and problematic. This directly connects with what Linda Martín Alcoff suggested as a white double consciousness that makes racialized whiteness visible through acknowledged shame and guilt for being complicit in and beneficiaries of oppression. ${ }^{256}$ In games, complicity raises awareness and critiques of white power while abstracting confrontation bolsters it.

Here, four games demonstrate problems implicated by a centralized whiteness. Through the Ages (2015) default experience to white characters, largely omitting minorities from narratives that would assuredly impact them. These risk universalizing

\footnotetext{
${ }^{256}$ Alcoff, Whiteness, 140, 163.
} 
white experience as human experience. By contrast, the reward systems in games often point to the deeds of white players, even in scenarios of racial disequilibria. This is what we see with games like Mombasa (2015). By attempting to steer the narrative toward economic confrontation rather than a racial disequilibrium, the game skews historical fact while simultaneously endorsing white expansion, power, and domination. Selectively choosing the perspective through which history should be simulated and retold risks sanitizing white actions within history and naturalizing the oppression of the people. Lastly, two games, Concordia (2013) and Bora Bora (2013) represent as two sides of a metaphorical coin. Concordia promotes expansion, power, and economic prowess while ignoring racial and ethnic contact. Whiteness is rendered as default, universally welcome, and constituent of a broader historical heritage. Bora Bora similarly simulates expansion and resource management, but on a much smaller scale. In contrast to Concordia, the indigenous subject matter of Bora Bora is visibly marked and presented as stationary, exotic, and closed off from the world and history. The disparate treatments of their subjects highlight how players and producers are to see themselves as beneficiaries of historical dominance but not complicit to that dominance. When considered together, these five games clarify and sustain racial boundaries that enshrine the domination of whiteness while obscuring the consciousness of that domination.

\subsection{THEORIES AND CONCEPTS}

The concerns of this chapter center less on what whites think or say about themselves - either in self-reflective philosophies on racial relations or commonplace utterances of identity politics - and more on what white people and characters in board 
games do as well as how they are presented — even preferred-as the default center of board game design. That stated, I wanted to prioritize specific theories and concepts within philosophies of race - and more specifically whiteness - that examine the presence, comportment, and phenomenology of white bodies. These are highly visual analyses of behavior that connects with how we might analyze a board game. We, as players, can see representations of characters and can manipulate their actions on the board, so concepts that focus on the privileges gained through whiteness in action and presence best address how silently and presumably innocently white bodies become centralized, normalized, and invisibly political in board game design.

\subsubsection{Spatialized Whiteness: Mills and Fanon}

Given that expansive presence is a key feature of white performance in game design, negotiating theoretical concepts that address how space is occupied, how mixedraced spaces are negotiated, and the privileges that come with whiteness in said spaces proves useful in inspecting this feature. One way this presents is through geographical space. For this I turn to Charles W. Mills. In his work, The Racial Contract, Mills examines white privilege and how whites are beneficiaries of oppressive actions, in part, through a spatial analysis of white colonial domination in history. The "moralization of space" ${ }^{257}$ Mills asserts applies as much to the expansive occupation of space by whites as it does to the diminished significance of prospective appropriations of space. ${ }^{258}$ Spaces occupied by the racially and ethnically distinct are figured as exotic, primitive, or visibly

\footnotetext{
${ }^{257}$ Charles W. Mills, The Racial Contract (1997, repr. Ithaca: Cornell University Press, 1999), 46-47. He details that foreign spaces are perceived as wild, untamed, and uncivilized in need of intervention while European space may require some modification, it is already a "tamer" affair.

${ }^{258}$ As detailed in Chapter III.
} 
othered while white expansion is unmarked and normalized. In game design, white expansion is common sensical, uncontested, and racially unmarked.

In line with this notion of white colonial presence, Frantz Fanon's The Wretched of the Earth also informs this work. Particularly, Fanon's assertion that colonization extends beyond the acquisition of land and resources and the exploitation of its people to colonize the mindset of the oppressed is significant here. Fanon and Mills agree that this is in part sustained through spatialized practice. Prospective space is "empty" or "primitive" and in need of civilized intervention, ${ }^{259}$ but this Manichean division persists when the space is occupied. The boundaries of whiteness are clarified by the subordination of minority space. ${ }^{260}$ Extracted from this is the notion that what "marks" white space and presence is not intrinsic to white practices but clarified by the visible difference in minority spaces. As a tool for inquiry in a medium like game design, the naturalization of spatialized power is revealed through inspections of what it is not.

While these assertions easily apply to games with colonial themes and narratives such as Puerto Rico (2002) discussed in Chapter III, these assertions of spatialized whiteness can be expanded to include a wide swath of designs. Take, for instance, Dominion (2009), a deckbuilding game that tasks players to expand their territory by acquiring new services and sources of income as a means to acquiring more land. The player's role defaults as implicitly white, and player actions secure the services of "kingdom" cards, which depict different events, locations, and occupations. These, unlike

\footnotetext{
259 Mills, 49.

${ }^{260}$ Frantz Fanon, The Wretched of the Earth (1963, repr. New York: Grove Press, 2004): 3-5. Fanon describes the marked differences between white spaces and colonized spaces. Where one sees lighted paths, paved roads, and surplus food within white spaces starkly contrasts with the crowded and famished spaces of the colonized.
} 
the player's role, are marked by distinctions in gender, class, race, and ethnicity. These services are gradually enveloped amidst a broader expansion. As they are brought under control, they are rendered as subordinate while the player continues further toward more territorial (and thereby lucrative) gains. Games such as Dominion do not explicitly reference racial, gender, or economic inequalities at the center of the design, and it is easy to ignore them given their lack of attention. But highlighting how these spaces constitute the boundaries of disequilibria reveals the ideological premises underlying the narrative.

\subsubsection{Phenomenology of Whiteness: Fanon and Yancy}

Beyond his notions of how the colonizer codes and controls the body and mind of the oppressed, Fanon has also put forth concepts of phenomenological experience that informs this essay. In his "Lived Experience of the Black Man," Fanon scrutinizes how bodily comportment and the capacity to act within space is governed and policed by the white gaze. His movements, he suggests, are given weight and significance by the superadded contextualization of his body in relation to his racial ancestry. ${ }^{261}$ The empowered white gaze dissects and decides meaning and significance of the racialized Other, for Fanon, as he succinctly declares that he is "fixed" and thereby implicating that his capacity to signify as a black body is constrained and policed by the dominant whites who view him. ${ }^{262}$ Fanon's physicality and comportment is visible and spectacle for the white gaze.

Fanon's suggestion underscores the work of later theorists like George Yancy. In his Black Bodies, White Gazes, Yancy suggests that black bodies are constructed by pre-

\footnotetext{
${ }^{261}$ Fanon, “Lived," 92.

262 Fanon, "Lived," 95.
} 
inscribed visions of blackness as curated by white gazes. His skin color associates him with negativity, criminality, danger, evil, and hypersexuality, he claims, but he asserts that this judgment of his character based solely on skin color predates his "existential emergence." 263 But what Yancy makes clear is that this prejudgment need not be expressed or felt by a racist or bigot. Rather, it operates in the everyday experiences of mixed company. ${ }^{264}$ Yancy makes explicit that his body is constrained by white visions of normalcy and acceptability, but implicit in this argument is the freedom and spatialization of white presence. Where his behavior and actions are limited by imposed constraint, whites enjoy a freedom of expansive presence and, because whiteness is unmarked, invisibility. Taking Fanon and Yancy's ideas together, we are able to see the binary of this contact space. On one side there is constraint and particularization; on the other, there is freedom and invisibility.

I am able to use these ideas of markedness and invisibility, constraint and freedom to analyze how players occupy, take up, and expand into spaces in board game design. The markers of spatialized power in Dominion would simultaneously suggest expressive freedom for the white roles in the game. Where the occupations and locations brought under control clarify the spatialized white power in the game, their stationary qualities also reveal the freedom of movement on the part of the player. While expansion and occupying space is integral to countless game designs, using Fanon and Yancy helps show how this physicality and comportment can be understood, in part, through race and racialization.

\footnotetext{
263 Yancy, 3.

${ }^{264}$ Yancy, 35-36. Yancy suggests that his behaviors and actions are scrutinized by whites operating under the "banner of good intentions" who "offer advice" that he reshape those behaviors and actions to be more socially agreeable.
} 


\subsubsection{Invisibility of Whiteness: Yancy, Dyer, Hall, and Foucault}

Underscoring these inspections of game design is the notion of visibility, or the lack thereof. Nonwhite figures in game design are perpetually envisioned as distinct and remarkable. Their manner of dress, actions, and behaviors are highlighted and inscribed with superadded attitudes placed upon those representations. ${ }^{265}$ This continual practice of distinguishing and underlining difference normalizes what is not remarkable and perceived as normal—white experience, in other words. The marked difference George Yancy laments offers a means of dismantling this invisibility within game designs. For Yancy, to be marked as particular was synonymous with nonbelonging to a white vision of normalcy. ${ }^{266}$ In board game design, the conscious efforts on the part of producers and designers to make settings and peoples different and exotic as a form of visual and experiential pleasure is central to the means by which these designs make Otherness visible. They become commodified objects of difference to be consumed, or "eaten" in terms of bell hooks ${ }^{267}$ for the pleasure of the player. Consequently, they clarify what is otherwise and invisibly bound as "normal" through this distinction.

White players, bodies, and characters in games are not presented as noteworthy or particularized. They "just are." White bodies and characters operate as a default that requires no explanation or situating moves that link their presence to any given context.

\footnotetext{
${ }^{265}$ Connecting with the "spectacle of 'Otherness'" as put forth by Stuart Hall. The white gaze of the viewer fixes the objectified other as an embodiment of presumptive stereotypes and prejudices.

${ }^{266}$ Yancy, 35-37. In his discussion of his choices to write in African-American vernacular elucidated his difference from white colleagues, who would suggest he avoid such language to be taken seriously in his field. Within a subtle interchange, the boundaries between abnormality and normalcy are clarified. 267 hooks, “Eating," 25.
} 
"They are at home" wherever they are, as Yancy makes clear. ${ }^{268}$ The modern board game is largely the domain of whites, so there is little reason for white players to rationalize their presence or function. This lends to the notion of invisibility of whiteness, and Richard Dyer's work informs this notion. He argues that the prevalence of white occupation in mediated spaces normalizes their presence and renders it invisible. Whiteness is, in Dyer's words, "everything and nothing." 269 The paradoxical relationship between white identity and racialized white bodies is important to how board games represent white bodies and characters, for they are present but simultaneously absent. In other words, white bodies and characters exist and operate unremarkably. This common estrangement from white skin and racial politics allows dominant ideologies to flourish. As Dyer has put forth, "Whites must be seen to be white, yet whiteness as race resides in invisible properties and whiteness as power is maintained by being unseen." 270

Where white bodies and characters in games exist and operate unremarkably, nonwhite entities are already marked as spectacle, in terms of Stuart Hall, and Michel Foucault's attention to visibility is useful here. In his Discipline and Punish, he uses the structure of the panopticon as a metaphor for the policing of bodies. That structure, with its blacked-out central tower overseeing the inmates of the prison population, nebulizes the possibility of being seen and being policed so as to make ever-present surveillance a means to self-regulate bodies toward docility. "Visibility is a trap," he succinctly notes. ${ }^{271}$ Foucault's assertion ties directly to Stuart Hall's notion of the "spectacle of the Other,"

\footnotetext{
268 Yancy, 40.

${ }^{269}$ Richard Dyer, "White," in The Matter of Images: Essays on Representation (1993, repr. New York: Routledge, 2002), 127.

270 Richard Dyer, White (1997, repr. New York: Routledge, 2008), 45.

${ }^{271}$ Michel Foucault, Discipline and Punish: The Birth of the Prison (1975, repr. New York: Vintage, 1995), 200.
} 
wherein the representation of Otherness in media is fixed in its visibility, caught between binaries of damaging stereotypes that prejudge the nonwhite body. ${ }^{272}$ The passive submission intersecting these binaries is evidence of this policed docility. The gaze of the metaphorical central tower constrains the possibilities of representation for the benefit of the dominant ideology — in this case, whiteness. At either end of the binary, the representations of nonwhite bodies are subject to debasement. They are, for example, seen as ugly or as excessively attractive, sterilized or hypersexualized, repelling as different or compelling as exotic. Neither position on the binary benefits the nonwhite subject, but ultimately benefits the dominant ideology that simultaneously unmarks itself while marking Others. Using Hall, through Foucault, allows me to demonstrate how marked "strangeness" of Otherness in board game design further secures white dominance as an unmarked and unremarkable force in identity politics.

\subsubsection{Racialized and Politicized Whiteness: Mills and Alcoff}

This invisibility allows whiteness to operate in game design as an absent presence. Even when abstracted or removed from material play, the structuring principles that allow for whiteness to order, mandate, and control persist within the periphery of narratives ${ }^{273}$ or within the social play environment. ${ }^{274}$ As an absent presence, white bodies and characters in board game design have the privileged position of being exempt from scrutiny under identity politics while simultaneously operating as a political

\footnotetext{
272 Hall, 'Spectacle," 229.

273 Puerto Rico (2002), for example. The "old country" has no material presence in the game but orders and mandates the economic mechanisms of the game.

274 Istanbul (2014), for example. The subject matter includes no white characters, but the players and producers are predominantly white, shaping the game's presentation of difference.
} 
framework that constrains the representations of others. Mills affirms the point that nonwhite bodies are by default political, but whiteness is not seen as political. He argues that "the most important political system of recent global history - the system of domination by which white people have historically rules over and, in certain important ways, continue to rule over nonwhite people - is not seen as a political system at all. It is just taken from granted; it is the background against which other systems, which we are to see as political, are highlighted." ${ }^{275}$ In board game design, raising issues of gender, race, or ethnicity politicizes the game space where politicization is largely unwelcome, but the irony is that the absent presence of whiteness in board game design is engaging in identity politics. Indeed, conscious efforts to remove confrontational experiences from the white narrative of board games, as we have seen with Puerto Rico (2002), does less to remove the political structuring principle of whiteness than it does to exacerbate it. Not only is there a sanitation of the history of exploitation, there appears to be a desired dissociation between historical white supremacy and white privilege today.

Regardless of the intent of players or producers, games that predominantly depict white bodies and characters in nonconfrontational revisions of history should be analyzed through the lens of identity politics. Here, Linda Martín Alcoff's notion of double consciousness becomes useful. In The Future of Whiteness, Alcoff details the necessary solution to the dismantling of white supremacy begins with a conscious effort to make whiteness visible. ${ }^{276}$ Such a visibility draws attention to current modes of dominance and privilege in light of a historical past that explicitly maintained dominance through force and oppression. This notion of double consciousness allows me to elucidate how games

\footnotetext{
275 Mills, 1-2; emphasis original.

${ }^{276}$ Alcoff, 138.
} 
attempt to dislodge present day white experience from the unsettling histories of white supremacy. Highlighting the linear history of white supremacy in game narrative to present day privilege marks white identity as visible and political, and seeing white bodies and characters in games as political agents reveals the concealed ideology of white supremacy.

Collectively, these theoretical concepts show how the board game communitywhether intentionally or not—endorses, or at least turns a blind eye upon, a system of white dominance and superiority. Largely, this dominance operates invisibly. Further, the universalization of white experience as human experience maintains the reproduction of these images without any self-reflection or culpability. As it stands, whiteness, as an invisible construct that polices the modes of representation and signification in board games, risks exacerbating the normalization of white dominance both in and out of play spaces. The following games_-Through the Ages, Mombasa, Concordia, and Bora Bora - all work to elucidate how whiteness is centralized, unmarked, and unchecked in its dominance of the industry as a whole.

\subsection{CURIOUS OMISSIONS IN THROUGH THE AGES (2007)}

Negative portrayals of minorities and culturally distinct groups is troubling for the board game industry, but problems of representation go beyond the negativity that might be portrayed. In many cases, black bodies are not presented at all, despite the surrounding narrative implied by the game clearly impacting minorities. Colonial-themed games are 
often guilty of these omissions. ${ }^{277}$ The absence of minorities threads through other themes as well, particularly those in which players simulate the building of a civilization.

\subsubsection{Through the Ages: A New Story of Civilization (2015)}

Through the Ages: A New Story of Civilization (2015) 278 is a civilization-style game that omits black experiences from presence and importance while the narrative clearly impacts people across racial and ethnic lines. A civilization-style game is a complex type of Eurogame that simulates the progression of a culture throughout time, usually marked in the various games as ages. As boardgamegeek.com describes the family of board games,

Civilization games often have players developing and managing a society of people. The aim of each player is usually to employ citizens in ways that are beneficial to society, [sic] and have them progress throughout the game so that their civilization gains superiority over others. ${ }^{279}$

Although the mechanics of civilization games vary from game to game, many center on players advancing their society through technological, cultural, military, diplomatic, and architectural enhancements. Using a technology tree system, specific advances and features are unavailable unless prerequisite conditions have been met. As players progress, they typically score points for advancing these criteria.

\footnotetext{
277 As we have seen with Puerto Rico (20020. Additionally, the 2007 game Age of Empires III: The Age of Discovery, for example, simulates the age of colonial exploration and expansion but fails to include slavery as a strong component to colonial power. The slave trade is omitted from the narrative of the game, preferring instead to focus on the deeds of explorers and colonists who trade goods like silver, sugar, and tobacco, and build colonies to support their economy.

278 Henceforth shortened to Through the Ages for brevity.

279 "Civilization," (wiki) boardgamegeek.com (n.d.), https://boardgamegeek.com/boardgamecategory/1015/civilization
} 
In Through the Ages, players progress their civilizations through time from antiquity through the internet age. The complexities of the game need not be explained here, but to offer a concise understanding of the game, players use a variety of cards to control a society and strive against other players to accumulate the most culture points. They do so by establishing and developing facets of social life: developing agricultural techniques, building a military presence, establishing a form of government, and establishing venues for the arts and culture. By carefully negotiating the costs versus the benefits of development, players compete across several tracks that measure player progress in areas of science, military strength, and overall culture.

One of the ways players gain an advantage in the game is by securing and following a leader. Each leader has a special ability that adds a benefit to performing a specific action, whether that action boosts military strength, culture, philosophy, or civil actions. Leaders help players focus their strategies and tactics to best compete in various facets of the game. Each age has several historical leaders that can be drafted alongside developmental advances. As the ages progress, leaders become antiquated and leave play, encouraging players to draft a new leader from the current age. Given their unique abilities that cannot be adopted by competing players, leaders offer players a unique strategy to best develop their society and focus their attention on the game's various mechanisms. The leadership available in the game, however, is very whitewashed. Leaders are predominantly

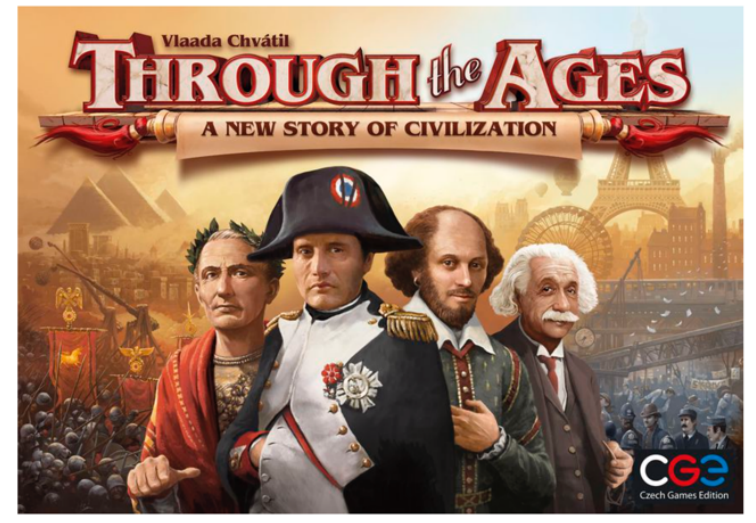

Figure 5.1 The white male leadership on the box art for Through the Ages 
male and European. Of the twenty-four

leaders available in the base game,

including such historical figures as

Alexander the Great, Isaac Newton, and

Winston Churchill, only one is female-

Joan of Arc — and three would be identified

as non-white-Hammurabi, Genghis Khan,

and Mahatma Gandhi. Notably, the three

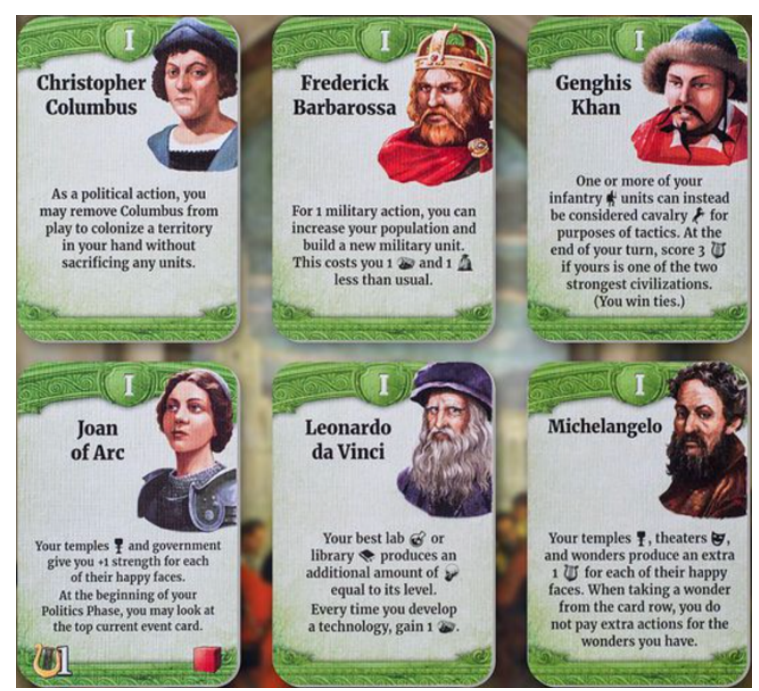

Figure 5.2 Leaders in Through the Ages are whitewashed and dominantly male

men share a fair-skinned complexion as that

of the white leaders in the game. It is in this area-the use of leaders- that Through the Ages and similar civilization-style games run into problems regarding race.

While much of recorded Western history has championed the deeds of white Europeans, Through the Ages perpetuates this problematic worldview by ignoring the significance of non-white people. ${ }^{280}$ Even as play progresses into ages II and III, when black voices gain prevalence in historical record via abolitionist efforts against slavery, scientific discoveries, and civil rights activism, the design of the game ultimately curates "historical importance" through its selection of leaders and simultaneously deflates the importance of black figures through their absences. Narratively, there is nothing in the game obstructing the inclusion of such figures as Harriet Tubman, Oscar Micheaux, Martin Luther King Jr., George Washington Carver, and many others that have played significant roles in the development of culture and society. Presuming the "good

\footnotetext{
${ }^{280}$ An expansion for the game, released in 2020, addresses this lack of diversity by offering more nonwhite and nonmale leaders, but players are required to spend more to "fix" this issue in the base game.
} 
intentions" of the game's producers, the prevalent spotlight on white agency throughout history is synonymous with what Dyer calls the universalization of whiteness. "Other people are raced, we [white people] are just people," he asserts. ${ }^{281}$ Whiteness is so prevalent that it is rendered invisible — the racializing adjectives are dropped — by its common sensical inclusion. The implication here is that the predominant representation of whites as leaders speaks to human experience rather than white experience. By avoiding inclusive representation, the game secures whiteness as the unmarked standard. However, these curious absences have further implications. Considering how leadership in the game offers direction to player interaction and strategy, the absence of black figures speaks volumes. What these curious absences imply is that black figures have little to no role in the development of society, and worldbuilding is predominantly a white male's task. ${ }^{282}$

Exacerbating the problem of this absence is that the various artwork available on the game's many cards further depict the actions, achievements, and plights of fairskinned people. The game design skirts racial tension and conflict at every level. While enslavement is a small feature within the game, the artwork on the card "Aggression: Enslave" depicts the shackled enslavement of fair-skinned people. Colonial exploitation is another feature in the game, but the object of that exploitation, according to the cards' artwork, is land; each colonial territory is represented by land rather than by people. In

\footnotetext{
281 Dyer, White, 1.

${ }^{282}$ While I have focused on civilization-style games, we can see these omissions operating in other games where players build or rebuild a society. The post-apocalyptic genre, notably the game $51^{\text {st }}$ State: Master Set (2016) exemplifies this. Therein, players negotiate actions and locations to scavenge for resources. Notably, there are few likenesses in the game's art that would be inarguably minorities. Rather, there are multiple representations that signify oppression, from the prevalence of slave trading on cards to the displayed confederate flag on the card "Gun Shop." The implication with this game, alongside Through the Ages, is that minorities have little to no role in the rebuilding of society.
} 
the game overall, there are scant representations of black bodies and none in empowered positions.

Civilization games ultimately perpetuate the myth that the major events of history are decided through the deeds of "great men." ${ }^{283}$ While these games are attentive to the micro-level work of labor as an important constituent to a thriving society, the lack of people of color in positions of power proves telling. As these games would suggest, positions of power to control the material and social organizations of a society are filled by white males. The dominant whiteness in the game is worsened by whitewashing. Events abstract the oppression and violence inflicted upon racially marked others and instead depict the victims as fair skinned. The selection and curation of history as the result of "great men" impacting a largely white population undermines the historical reality. The implication of these omissions is that people of color have little agency or role in the progress of a given society.

\subsection{THE DICHOTOMY BETWEEN EXPLOITATION AND ECONOMY IN}

MOMBASA (2015)

As we have seen, unsettling issues of racialized confrontations are generally taboo in game design. By and large, game designs avoid or abstract racialized conflicts. In Eurogames, we see an emphasis instead on economic conflicts. When a game's system of rewards and goals point to the achievements of white entrepreneurs while abstracting a reality of racial contact, the design extracts economic gains from a broader contextual framework that would include racial disequilibria and oppression. As a result, producers

\footnotetext{
${ }^{283}$ As put forth by Thomas Carlyle (1840).
} 
and consumers, albeit unintentionally, endorse principles of white superiority by highlighting material gain over oppression and thereby obscuring white complicity to that oppression. Mombasa (2015) offers an example of this endorsement.

\subsubsection{Mombasa (2015)}

Mombasa is a complex stock manipulation game set during the exploits of chartered companies in Africa. Players attempt to earn more money than their competitors by investing in four chartered companies, spreading the influence of those companies throughout Africa, taking part in the diamond mining trade, and increasing their investment potential through bookkeeping acumen. At the end of the game, investment assets are liquidated and the player with the most money wins.

Displayed between players is the main board for the game. This depicts the continent of Africa divided into several regions. Four chartered companies-Mombasa, Saint-Louis, Cape Town, and Cairo — are depicted at the periphery of the continent and seeded with trading post tokens representing plans to expand the company's influence inland. As these trading posts are relocated to the board, the value in the company increases for all investing players. Surrounding the square board are four tracks that represent investments players may make with each of the four companies. As players progress these tracks, they earn shares in the company that are ultimately multiplied by its value.

While complex, the game is largely driven by card play and hand management. Cards allow players to explore the continent for trading post locations, invest in the diamond trade, trade goods for improved actions, and progress along the 
share tracks - each card action

offering money-making potential.

Players begin the game with an

identical deck of cards, and each

improves their deck over time by

purchasing more powerful cards. A

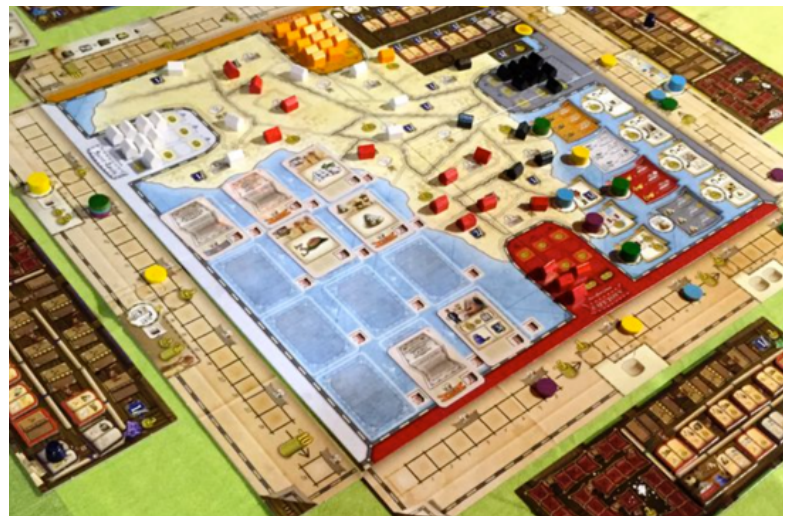

Figure 5.3 European enterprises spreads inland across a personal player board tracks their blank Africa in Mombasa

"knowledge" of the continent and their investment level in the diamond trade. These, along with shares in the companies, are translated to money at the end of the game. Play progresses over a series of rounds with players playing card actions and manipulating the stock values of the four companies accordingly. In the end, players hope to have secured more stake in the lucrative companies than their competitors.

As a game about "[t]rade rivalry in the age of chartered companies," ${ }^{284}$ Mombasa exhibits several problematic issues with racial representation. Among them is the separation of economy from the exploitation of labor. The designer of the game, Alexander Pfister, acknowledges the disparity. In the rulebook, this disclaimer appears:

Chartered companies were associations formed for the purpose of exploration, trade and colonization, which links them inextricably to a very dark chapter ${ }^{285}$ in human history: global colonialism. [...] Although Mombasa is loosely set within this time frame, it is not a historical simulation. It is a strategy game with an economic focus that roughly refers to historical categories and places them in a fictional setting. The exploitation of the African continent and its people is not explicitly depicted within the game play. ${ }^{286}$

\footnotetext{
284 “Rulebook," in Mombasa, des. Alexander Pfister (Pegasus Spiel, 2015).

285 As a "dark chapter," we see a return to the suggestion that history is compartmentalized and hermetically sealed from affecting the present.

286 "Game and History," in Mombasa.
} 
The producers of the game acknowledge that the narrative of the game is associated with distasteful human actions, but they attempt to sidestep the racial subtext of the game by focusing on the economic mechanisms of play rather than the racial narrative itself. This proposed dichotomy between economy and exploitation presents a deliberately narrow worldview that presumes exploitation can be extracted from economic disequilibria generally. However, as Mills has made clear, a consent to economic disequilibria mandates a consent - implicit or otherwise — toward racial inequality. ${ }^{287}$ The two are inexorably combined and cannot be divorced as simply as the game would suggest.

This focus toward mechanism away from narrative carries with it a visual deflation of racial conflict. In Mombasa, African bodies are generally absent. They; along with their towns, villages, and other cultural markers; are absent from the map of Africa itself. They present, at best, as ancillary décor adorning cards and the cover art. The remainder of the game is drained of an African presence and focuses instead on the exploits of white Europeans. The story of Africa during this time is told through European traders, implicating that the experiences of whites are universalized as human experiences. Dyer's assertion that whites function as a universal stand-in for human experience $^{288}$ elucidates the problem of this depiction. The simultaneous valorization of white exploits and abstraction of people of color by dissociating the economic reality

\footnotetext{
${ }^{287}$ Mills, 32-33. He clarifies that "the economic dimension of the Racial Contract is the most salient [...] since the Racial Contract is calculatedly aimed at economic exploitation. The whole point of establishing a moral hierarchy and juridically partitioning the polity according to races is to secure and legitimate the privileging of those individuals designated as white/persons and the exploitation of those individuals designated as nonwhite/subpersons."

${ }^{288}$ Dyer, White, 3. "[W]e have not reached a situation in which white people and white cultural agendas are no longer in the ascendant. The media, politics, education are still in the hands of white people, still speak for whites while claiming - and sometimes sincerely aiming - to speak for humanity."
} 
from the racial disparity undergirding

it bolsters assumptions that white

success functions separately and

distinctly from white supremacy.

In one area we do see African

bodies presented in the game is upon

the cover art, but this, too, exhibits

problematic representations of the

racially distinct. The cover art,

depicting a European entrepreneur

within the shade of a tent while African

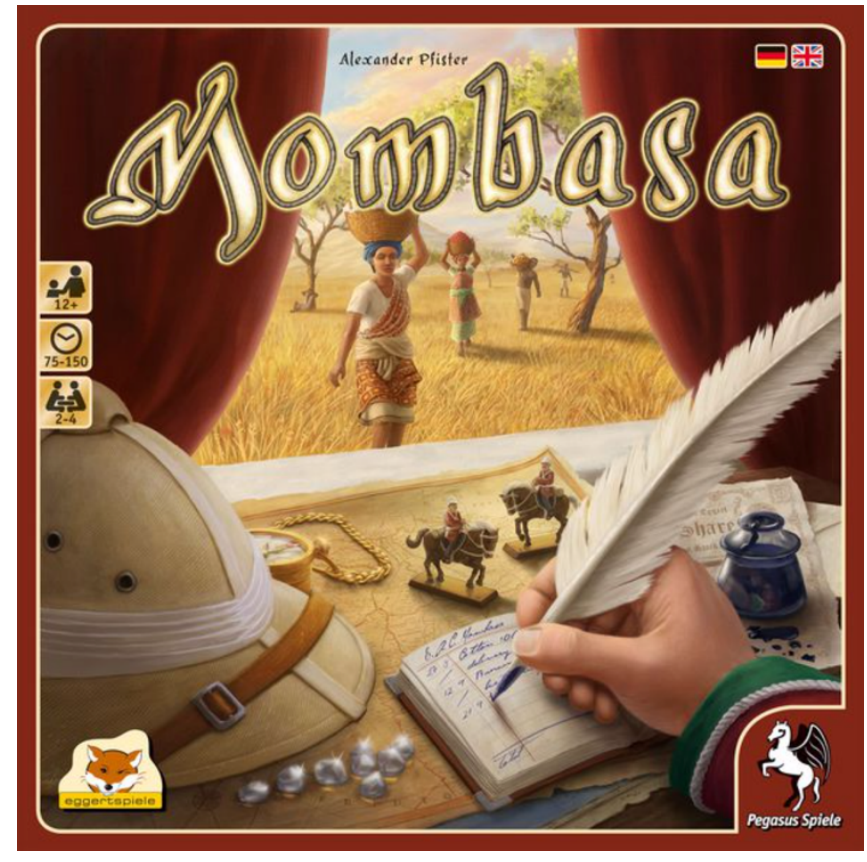

Figure 5.4 Mombasa's box art depicts a Manichean separation of labor and power

bodies labor in the sun, presents a Manichean spatialization between the races, as Fanon has clarified. ${ }^{289}$ The worlds presented are separate and distinct. The trappings of the European — the diamonds, compass, ledger, and ornate paperweights—are in direct opposition to the world of African labor outside, which is sunbaked and descriptive of toil and fatigue. On the cover art, we take the perspective of the European entrepreneur while the African people are marginalized in the distance. Iris Marion Young has asserted five interrelated categories demonstrating oppression, of which "marginalization" is one. Therein, she argues that oppressed groups suffer diminished use-value by their social exclusion. ${ }^{290}$ The Manichean separation of the European from the Africans exemplifies

\footnotetext{
${ }^{289}$ Fanon, Wretched, 4. "The colonist's sector is a sated, sluggish sector, its belly is permanently full of good things."

${ }^{290}$ Iris Marion Young, "The Five Faces of Oppression," in Oppression, Privilege, and Resistance: Theoretical Perspectives on Racism, Sexism, and Heterosexism, ed. Lisa Heldke and Peg O'Connor (New York: McGraw Hill, 2004), 50. Assuredly, all five "faces" of oppression Young identifies-powerlessness, violence, marginalization, exploitation, and cultural imperialism-operate both implicitly and explicitly in this game.
} 
this. The cover art makes explicit the political hierarchy that privileges whites over others.

Mombasa, and modern board games in general, take whiteness as the innocuous status quo. The presence of white bodies is never a politicizing act on the part of the designer. As Charles Mills profoundly declares in The Racial Contract, white privilege is taken so much for granted by its perpetrators that they do not see it as political at all..$^{291}$ By contrast, the choice to diversify representation within a medium, as bell hooks has made clear, politicizes that medium. ${ }^{292}$ Whiteness is the default structuring principle in many modern board games, but that whiteness is not seen as a political action. Rather, white superiority and dominance over others is normalized and assumed to such an extent that its complicity in domination is rendered invisible. We can see this in published protests over the game's racial insensitivities. Player's urge others that "it's just a game" or that players "are overly sensitive" or that they "see no moral connection with a board game and the historical coat hanger it swings from." ${ }^{293}$ Implied by these complaints is the position that race in games is not the problem; those who choose to inject racial discourse into gameplay are the problem. It is this very apolitical assumption about whiteness that allows the system to perpetuate itself.

In video game studies, critic Clint Hocking put forth the notion of ludonarrative dissonance. He asserts that games offer mechanical and narrative choices that are at odds

Given the other theoretical perspectives that constitute the analysis of Mombasa, elaborating on all five would risk redundancy.

291 Mills, 1.

292 bell hooks, Reel to Real: Race, Sex, and Class at the Movies (New York, Routledge, 1996), 69.

${ }^{293}$ Cf. "The Corrosive, Passive Bigotry of Mombasa's Failed Thematic Perspective," May 2016, https://boardgamegeek.com/thread/1582537/corrosive-passive-bigotry-mombasas-failedthematic/page/1. The original post has been deleted, but the comments remain. 
or even paradoxical with one another. These moments in game design, he suggests, disrupt the immersive experience of game by baring the devices of game design. ${ }^{294}$ I want to expand on this notion to suggest there exists a ludonarrative dissociation in games. By this I mean the player's enjoyment of a game tends toward the ludic or narrative ends of the ludonarrative gradient, consequently diminishing the importance of the opposing end. As noted, modern board games use mechanisms and narrative cooperatively to present an enjoyable game experience. However, with ludonarrative dissociation, one of these experiences may be rendered is inconsequential to that enjoyment. What we see in Mombasa is this ludonarrative dissociation at work. The mechanical emphasis deflects attention away from the narrative, thereby making the narrative inconsequential, as even the rulebook appears to endorse. This raises the question of why the designers have chosen a sensitive narrative if the focus of the enjoyment is on the economic manipulations, when countless other scenarios could facilitate the same mechanical experience. As presented, Mombasa tasks players to ignore the harsh realities of the historical narrative while emphasizing the monetary boons of that reality.

Economic boons rewarding players thereby suggest significance, and the abstraction of people of color renders them insignificant. The ludonarrative dissociation obscures this suggestion. In Mombasa, meaning does not preexist a white presence. Meaning is only added after whites encounter the space. Before players expand inland by building trading posts, Africa is beige, bland, and most of all empty. ${ }^{295}$ Through Mills'

\footnotetext{
${ }^{294}$ Clint Hocking, "Ludonarrative Dissonance in Bioshock," ClickNothing, October 7, 2007, https://clicknothing.typepad.com/click_nothing/2007/10/ludonarrative-d.html. He looks specifically at the video game Bioshock to suggest that the Ayn-Randian objectivism of the gameplay is at odds with the politics of self-interest in its mechanisms. This creates an aesthetic divide that cannot be reconciled and ultimately frustrates a player's thorough enjoyment of a game.

295 In a similar manner in which the land depicted in Puerto Rico is void of human presence.
} 
argument, it is a land "morally open for seizure" for it is depicted as an "empty and unoccupied, void, wasteland" that some may go so far as to call "virgin" territory. ${ }^{296}$ If this moralization of space is considered alongside recognitions that game depicts a "dark chapter" of human history, there is a tendency to view the overt domination of Africa as something hermetic to the past and ineffective to the present. However, as Mills has pointed out, the overt domination of the colonial era has been written "out of formal existence" by naturalizing this domination as status quo. ${ }^{297}$ Those who are most likely to reap the benefits of this contract are the least likely to question it. Far from questioning the circumstances of these privileges, the racial contract in part functions and is maintained by misinterpretations of the world that are continually validated by "white epistemic authority." ${ }^{298}$ In other words, the privileges of today are the direct result of the exploitations of past and present, and compartmentalizing the unsettling histories obscures this lineage while exculpating its beneficiaries. In Mombasa, we see not only a deliberate misrepresentation of the world and cultural authority, we see a game that encourages players to blindly and unquestionably reap the rewards of a normalized white supremacy.

In video game studies, Anna Everett and Craig Watkins have suggested that play spaces can serve as "racialized pedagogical zones" that inscribe attitudes and assumptions about race and racial Otherness. ${ }^{299}$ Exacerbated by media representations

\footnotetext{
296 Mills, 49.

297 Mills, 73.

298 Mills, 18.

${ }^{299}$ Anna Everett and S. Craig Watkins. "The Power of Play: The Portrayal and Performance of Race in Video Games." in The Ecology of Games: Connecting Youth, Games, and Learning, ed. Katie Salen (2008), 142. While they focus on the violent and racist depictions of black bodies in games like Grand Theft Auto, their premise that the narrative discourse on race in video games is adopted and intensified from dominant racial discourse in the media is applicable to board games.
} 
and popular perpetuations of stereotypes, games, for them, offer fertile territory for players to learn from and simulate racial disparities. When representation is narrow and/or prejudicial, players are tasked to participate in broader system that oppresses minorities. Mombasa is not creating a racial perspective for colonialization but is adopting it from dominant worldviews. And the problematic worldviews of white supremacy through colonialism is intensified by a deflation or absence of resistance. The abstraction of black bodies in the game ultimately offers a pedagogical space for players to see the world as a white-dominated space structured to benefit whites while eschewing culpability of that domination.

The fundamental problem of a game like Mombasa is that it endorses white superiority and dominance without intending to do so. For the designer and many of the game's players, white dominance is natural and normal. The economic successes are selectively closed as white enterprises while the exploitation of people of color is selectively abstracted from view. The intent to divorce economic forces from exploitative forces distorts the racialized political structures that engender those successes. As a potential pedagogical space, Mombasa upholds whiteness as the normal and invisible political system that should be endorsed, valued, and rewarded. Mombasa is clear as to what stories are "worth" telling in games.

\subsection{INVISIBLE POWER AND VISIBLE CONSTRAINT IN}

CONCORDIA (2013) AND BORA BORA (2013)

Up to this point we have seen examples of how white identity operates as the dominant ideology in game spaces where ethnic and/or racial boundaries contact one 
another. In game designs where the playable characters and bodies are homogenously white, the issue of whiteness is made less visible and by consequence more problematic. Whiteness, in these games, operates as a universalizing default which explains human experience rather than a racialized white experience. They are, in terms of Yancy and Dyer, invisible and unseen whereby representations of Otherness would become spectacle and visible. The presumable aim of board game designs that are homogenously white is not to make a political statement for or against white supremacy but to avoid identity politics altogether.

By not including diverse representation or playable "named" characters at all, it may be understood that these games present as apolitical play spaces where identity politics should be left outside the magic circle. However, as Mills has made clear, whiteness is the dominant political structuring principle of recent global history. ${ }^{300}$ Two games_Concordia (2013) and Bora Bora (2013) — are emblematic of the industry's implicit desire to avoid racialized white identity politics while stabilizing the representations of Otherness in stagnant and harmful ways. These games exist as two sides of a metaphorical coin. Concordia presents, albeit invisibly and unremarkably, as a play space for unchecked white expansion and white dominance-and rewards that mentality-while "plugging into" a linear history that is rife with white dominance. By contrast, Bora Bora presents as an example of how representations of Otherness are fixed and decontextualized. Through this game, Otherness is presented with objectivity as opposed to subjectivity, wherein the implicit characters of the game are dissociated from their own heritage and histories. As such, they present as "spectacles" for the pleasure of

\footnotetext{
${ }^{300}$ Mills, 1.
} 
the player. While the characters implied in Bora Bora's design are particularized and marked at the beginning, the characters and bodies in Concordia resist similar marking. Deliberately making the whiteness of Concordia visible elucidates how white supremacy is sustained through the invisibility of whiteness, and Bora Bora secures that assertion by revealing the converse side of that claim.

\subsubsection{Concordia (2013)}

Concordia (2013) is a complex hand-management and resource management game that is set in the time of the Roman empire. Described as a "peaceful strategy of economic development, ${ }^{, 301}$ players strive to earn the most points by expanding their empire, establishing trading posts, and currying favor with the gods. They earn these points by playing "personality" cards from their hand. Each personality allows the player to perform actions from gaining new card and building trading posts to trading resources and earning money. Once played, cards cannot be returned to hand until another card action draws them back as a turn. Successful players modify their hand of cards with more powerful abilities to increase their point potential while decreasing the number of skipped turns spent recollecting cards.

A common board between players depicts the land that is present-day Italy surrounded by portions of Europe, Africa, and the Middle East. ${ }^{302}$ Beginning with their colonists in Rome, players expand along land and sea routes to nearby cities. Once established in these cities, players are able to reap the trade benefits of their influence,

\footnotetext{
301 “Description," in Concordia, des. Mac Gerdts (PD Games, 2013).

302 The board is double-sided with a distinctly different map on the opposing side. Expansion maps have also been released to enrich play. The mechanisms and scoring via curried favor with the Roman gods remain in all iterations of the game.
} 
earning goods that can be traded for money or other goods as the game progresses. Over several rounds of play, personality cards facilitate moving, trading, building, and profiting. Personality cards are also affiliated with a specified Roman

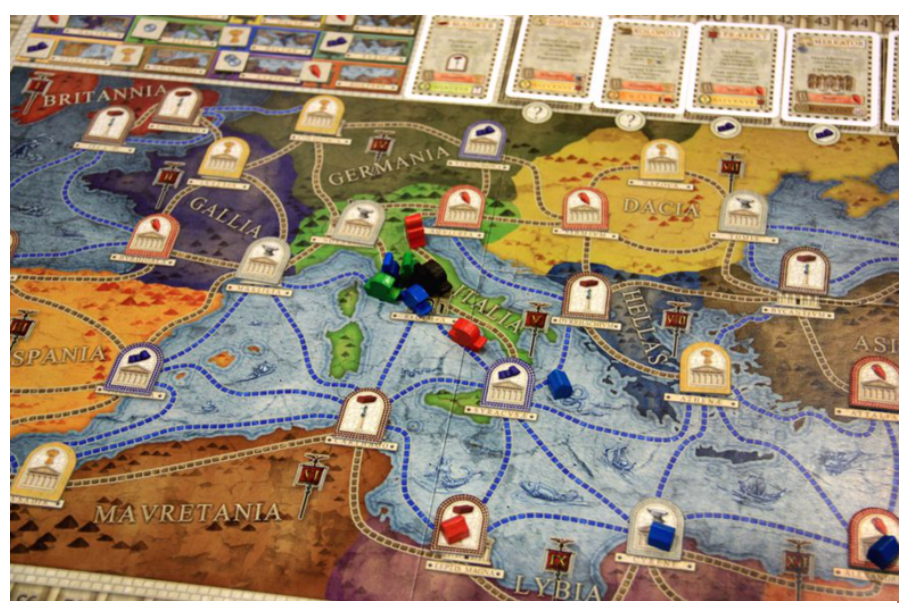

Figure 5.5 White expansive power is unchecked and unremarkable in Concordia

god such as Mars, Jupiter, or Minerva. Regions on the board are distinguished by color and number, and spreading influence into more distinct regions increases a player's point potential. At the game's end, players score points according to how they have curried favor with the gods. For instance, the god Saturn rewards points for the number of regions a player occupies; that number is multiplied by the number of Saturn-affiliated cards the player possesses for a point total in that category. By contrast, Minerva rewards points for producing a specified type of good, so players score for the number of trade cities producing that good in which they have built a trading post and multiply that number by the number of Minerva cards for a total of points. The player who has earned the most points through the gods is declared the winner.

The premise behind Concordia is that players should expand their presence across the map and reap the benefits associated with that expansion. The game's reward system is based on the player's ability to expand and grow. Consequently, by taking on the role of a character who is by default white, ${ }^{303}$ the game encourages an expansive white

\footnotetext{
${ }^{303}$ All graphic images of people in the game's artwork are white.
} 
presence despite players travelling to and through places that are predominantly nonwhite. This expansion is uncontested and presented without any suggestions within the implied narrative of obstacles that may stand in the player's way. The manner in which white characters and bodies are allowed to freely negotiate spaces signifies their own authority as the dominant ideology. White privilege, as Yancy has clarified, has allowed for unconstrained mobility and manipulation without ever reflecting on the white body as a racialized subject. ${ }^{304}$ Whereby depictions of Otherness may be constrained and policed by a white gaze, white actions are conversely unconstrained and in accord with what is "normal." As Tim Wise has put it, "[w]hiteness [. . ] is about never being really out of place, about having access and, more to the point, the sense that wherever you are, you belong, and you won't encounter much resistance to your presence." 305 There is an itinerant belongingness to whiteness that largely goes unnoticed in board games, and Concordia affirms this suspicion in that no expansive action or geographical presence is met with hostility or even scrutiny. White expansion and presence just is. It is normal. Consequently, we can highlight the absurdity of this invisibility by entertaining the thought of how players would react to embodying an expansive presence in a game themed around the Civil Rights Movement or insurrections during the age of slavery. ${ }^{306}$ Concordia is representative of the type of rewards system in board game design that encourages and rewards expansive measures, but it is far from an isolated example. Games such as Navegador (2010), also designed by Mac Gerdts, Dominion (2009), Vasco Da Gama (2009), The Voyages of Marco Polo (2015) and many others simulate a

\footnotetext{
304 Yancy, 40.

305 Tim Wise, White Like Me: Reflections on Race from a Privileged Son (Brooklyn, NY: Soft Skull Press, 2005), 44.

${ }^{306}$ To my knowledge, no ranked board games with these themes exist, which is telling in and of itself.
} 
European expansive presence that is neither checked or questioned. ${ }^{307}$ In board game design, the dominant narrative implied by its mechanisms and systems of rewards is that a white European presence is normal, encouraged, and equated with power.

\subsubsection{Bora Bora (2013)}

The assertion made through Concordia is not intended to suggest that there are no games that depict non-white presence or expansion. Tzolk'in: The Mayan Calendar (2012), Qin (2012), and Yellow and Yangtze (2018) number among these. However, a key difference between games of this ilk and games like Concordia is how stationary nonwhite culture is in board game design. Nonwhite cultures and locales are stagnant in time, caught in an exoticized white vision of otherness and divorced from any diachronic dynamism. They are caught in the trap of visibility, to use Foucault's words. ${ }^{308}$

Consequently, they are fixed as a "spectacle of the Other" that permanently stabilizes the people and culture within stereotypical visions of the exotic and foreign. ${ }^{309}$ Constrained as such, the depicted people and cultures are denied access to history and significance in favor of being "eaten" as a commodification of Otherness for the hedonistic pleasures of dominant consumer culture..$^{310}$

Bora Bora (2013) designed by Stefan Feld presents as a good example of this stagnant objectification. Set on the islands of Bora Bora, players compete to earn the most points by building huts on the islands, discovering fishing grounds, making jewelry,

\footnotetext{
307 Games that do contest white expansion and exploitation, such as Francis Drake (2013), Archipelago (2012), and Spirit Island (2017) are few and far between.

308 Foucault, Discipline, 200.

${ }^{309}$ Hall, 'Spectacle,' 229.

310 hooks, "Eating," 25.
} 
and worshipping gods. ${ }^{311}$ There is no attempt by the game's design or designer to show how this culture changes over time or participates within history. The game's narrative, character, and setting are caught in a nebulous past populated by people in revealing grass skirts and tattooed bodies, using wooden tools. ${ }^{312}$ As the rulebook describes the game: "Stake your fortunes in the mysterious island world of Bora Bora. Journey across islands, building huts where the resilient men and women of your tribes can settle, discovering fishing grounds and collecting shells. Send priests to the temples and gather offerings to curry favor with the gods." 313 The description situates the game in the world of the exotic and foreign. Like most

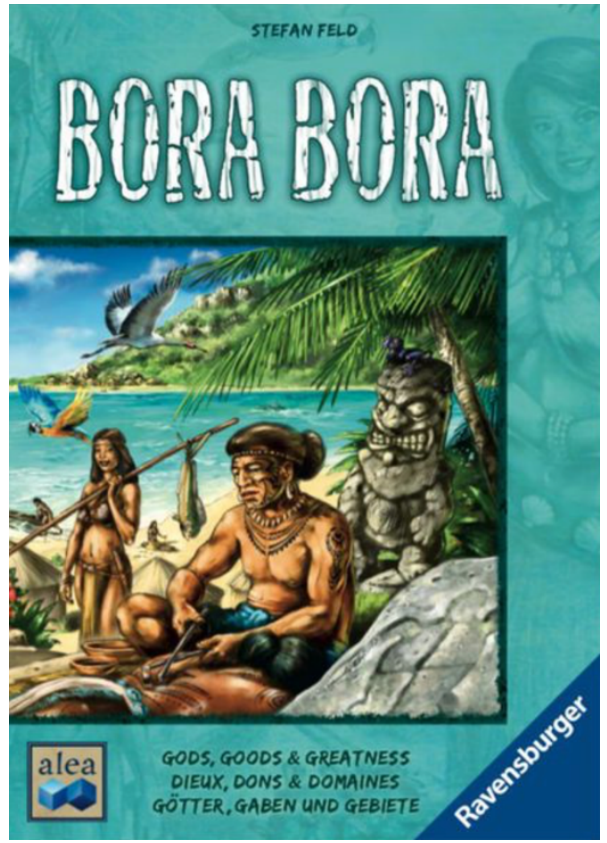

Figure 5.5 The hypervisible exoticism of Bora Bora

European game designs, there is no physical conflict in the game, but tellingly, there is also no contact with anyone beyond the island populations themselves. As a character in the game, you negotiate with and contact other people in the tribe but with no other cultures. The culture of the game's narrative is isolated and removed from the rest of the world. Players leaving the game experience would know no more about how this

\footnotetext{
${ }^{311}$ Apart from the problematic representation of culture, it should be noted that Bora Bora roots its central mechanisms in taking actions that are labeled as "man actions" and "woman actions." In the game, gender roles are strictly defined and separate. While both are viable paths toward victory, the gendering of actions remains problematic.

${ }^{312}$ The cover art of the game depicts a man tattooing another while a woman stands behind the two, smiling and carrying a fish on a wooded hanger. Her narrow grass skirt extends from below her navel to between her legs and is only wide enough to cover her genitalia. A grimacing stone tiki statue is also behind the man, with tropical birds flying among them.

313 "Game Idea," in Bora Bora, designed by Stefan Feld (Ravensburger Spielverlag, 2013).
} 
population or culture relates to other places and peoples or be better equipped to locate Bora Bora on a map. ${ }^{314}$

While players are encouraged to expand and grow in Bora Bora and similar games such as Qin, Tzolk'in, and Yellow \& Yangtze, it is telling that the expansive measures in all these designs are restricted in time and place to the exoticized locales of their setting. Restrained in this manner, the expansive presence of these cultures and populations are rendered harmless to the dominant ideology of the games' consumer market. They are adrift, divorced from any context. As a result, the cultures depicted are denied a place in history or in the making of meaning. They are objectified as exoticized Other. They exist solely to be consumed by the dominant ideology and its voyeuristic pleasure. From a game design perspective, there is no narrative reason for the producers to necessarily use Bora Bora as a setting, excepting that it is a convenient setting wherein players may simulate travel, settlement, the procurement of food, the use of resources to manufacture wares, and worship. These all present in the game's design as different avenues that may be pursued toward points, and there is little effort to better understand the setting through its people, its history, or its culture. As a case in point, there is no way to track Latin American culture through the narratives of board games. Their representation, such as is the case in games such as Tikal (1999), Mexica (2002), and Teotihuacan (2018) are confined to an exoticized past rather than as a component of a broader heritage. They are, in terms of Stuart Hall, "spectacles" of Otherness in their design.

\footnotetext{
314 Incidentally, it should be noted that the geographical representation of Bora Bora in the game is not accurate or verisimilar.
} 
By contrast, games such as Concordia are not adrift from their contexts. The game is "plugged in" to a white cultural heritage that connects prehistory to the modern day. If a player were wishing to explore the simulated experience of white AngloEuropean history, they have a robust timeline within board games. Games such as Stone Age and Tigris \& Euphrates allow for prehistorical simulation, while antiquity and classical periods are simulated in games such as 7 Wonders (2011), Trajan (2011), Tribune (2007), and of course Concordia among many others. The middle ages are thoroughly canvassed in game design from Arthurian simulations, such as Shadows over Camelot (2005) and The King is Dead (2015), to life in medieval cities, such as Carcassonne (2000), Dominion (2009), A Castle for All Seasons (2008), and Caylus (2005). Games like Fresco (2010) and Lorenzo il Magnifico (2016) attempt to encapsulate the Renaissance era, and so forth to the present day. As such, game designs centering on an unmarked and unremarkable whiteness participate in the universalization and normalization of white dominance.

When scrutinized together, Concordia and Bora Bora reveal a mentality implicit to board game design that racialized identities belong in a specified and "proper" place. With Bora Bora, the implication is that representations of Otherness are "in place" when objectified as foreign curiosities and consumed for the pleasure of whites. Additionally, to be in its rightful place also implies that the cultures and people presented therein should be contained and threat-less to white dominance. They may exist as "trapped spectacles" without history or intrinsic significance - significance is projected from the outside — so long as that visibility does not threaten the ordering principles sustained by whiteness. By the same measure, Concordia implies that white bodies and characters are 
never "out of place." They belong wherever they may present themselves. Their attachment to historical context and signification implicitly justifies their own authority to expand, possess, and take up space. With games like Concordia, there only two spatial categories - the spaces of white presence and the spaces of "not yet" white presence.

\subsection{CONCLUSION}

The aim of this chapter has been to highlight the ways in which board game designs centralize white power through representative prevalence and through the absence of representational diversity. This could be seen through analyses of Through the Ages. So centralized, white dominance becomes normalized and taken for granted, to the point that racial and ethnic confrontations can be abstracted or avoided altogether. In Mombasa, as detailed here, the confrontational history of white expansion in Africa is selectively and consciously removed. Instead, the game focuses on economic mechanisms of play without recognition that these monetary benefits have historically come at the cost of oppressive measures against nonwhites. However, it takes some effort to reveal this implicit exploitation in the game's design. As the game would suggest, players can reap the benefits of exploitation and material gain — and are encouraged to do so-without acknowledged complicity in the necessary exploitation associated with those gains. This selective dissociation of material — and consequently political and empowering — gains from the cultural and racial confrontations that facilitates those gains helps to sustain present day white privilege. The boons of superiority appear as happenstance, "normal," and isolated from history. Through games, players are free to 
enjoy endorsements of white privilege and dominance while simultaneously working to separate the benefits of whiteness from an unsettling history.

Centralization and normalization work implicitly to remove the criticisms and scrutiny of white domination. As the impulse of many modern — especially Europeangame designs to avoid physical confrontation, this avoidance does less to debase white supremacy as it does to bolster it. Without policing or checked criticism, simulations of white dominance are allowed to be produced and reproduced without opposition. Much like the games depicting white expansion, the opposition is removed, and the actions of white bodies and characters are further secured as "normal." This has real-world implications for the game's players both within and outside of play spaces. Taken as presented, one playing a game like Concordia could easily assume that white domination was an amicable - perhaps even encouraged — enterprise that could be construed normal or natural. By extension, the "fixing" of Otherness as objects of exoticized appeal does less to diversify the industry — as one could easily presume — and does more to stabilize nonwhites as in their "rightful place" as commodified objects void of history and significance, existing for the sole purpose of pleasing the white gaze. 


\section{CHAPTER VI}

\section{CONCLUSION}

Far from being frivolous, games have always had distinct cultural purposes. [...] We might think of games as charming historical artifacts, but they are also telling reflections

of social values and mores. -Eli Brown ${ }^{315}$

There are innocuous games. There are inclusive designs. Despite this, there are many designs that sustain white privilege relatively unchecked. The system of rewards and goals continually point toward the feats of white men while neglecting others. Tasking players to perform this dominance in many popular games risks shaping the community boundaries to perpetuate that same dominance amongst players. The board game community has yet to realize the assertion that designs should reflect "all aspects of society" so as to "expand our cultural awareness" of others. ${ }^{316}$ In order to be more inclusive, players and producers need to be conscious about what designs and player actions are actually tasking us to do—-both explicitly and implicitly—and conscious about why subversions of this dominance are important for the future of inclusive play.

Attempts to subvert the white male dominance of the industry as well as the community response to those attempts can be exemplified by a 2016 game titled One Deck Dungeon. A solo or cooperative two-player game, One Deck Dungeon possesses

\footnotetext{
315 Eli Brown, "A Plethora of Pastimes," Pastimes and Paradigms, last modified 2004, https://rmc.library.cornell.edu/games/plethora/index.html ${ }^{316}$ Carr, "Talk."
} 
the usual trappings of a fantasy dungeon delve and resembles many card-driven games derivative of the Dungeons \& Dragons intellectual property. However, what makes One Deck Dungeon distinct is the choice on the part of the producers to make all the heroes in the game female. Beyond this particularity, the female heroes are also sensibly armored and clothed, as opposed to the dominant representation of female heroes clad in bikini armor or otherwise impractical clothing. The game, too, was praised for its focused representation of women in a male-dominated genre. ${ }^{317}$

The game was also met with critical backlash from the community for the same reason. The exclusive portrayal of women characters had some players proclaim the game had "gone overboard" and "imbalanced" the distribution of the sexes by its design, while at least one thread devoted to the game was locked and removed from view for its heated and derisive comments. ${ }^{318}$ Implied by this contention is that inclusivity is welcomed as long as it poses no threat to the status quo. One Deck Dungeon subverts the status quo by consciously choosing an all-female cast within a genre that has been historically dominated — and at times exclusive — to males.

This polarity of praise and negativity is ultimately emblematic of the state of the board game industry. On the one hand, players and producers desire more inclusivity and diversity in board game designs, but simultaneously there are tensions and obstacles that come with those choices. What strikes me about the discussions that occur about games such as One Deck Dungeon is their visibility. A game is released with an all-female cast, and it becomes more discussed and reviewed than comparable games in the genre or

\footnotetext{
${ }^{317}$ Cf. Rahdo Runs Through, “One Deck Dungeon: Final Thoughts,” YouTube video, April 21, 2019, 7:09, https://www.youtube.com/watch?v=wZwgJ2U49yl

${ }^{318}$ Cf. "Why Are All Heroes in this Game Female?" boardgamegeek.com, February 4, 2017, https://boardgamegeek.com/thread/1721002/why-are-all-hero-characters-game-female
} 
category. But it is also telling that a game that has no playable female characters receives little critical attention on its representative choices. ${ }^{319}$ The implication is, then, that white male privilege is perpetuated by its "invisible" naturalness. It would appear commonsensical and natural that a game set in history or Tolkienesque fantasy would be dominated by white males while aims to destabilize this naturalness become marked or visible. One Deck Dungeon, in short, is representative of controversy in identity politics in game design, and games simulating an expansive male presence with a docile, stationary, or even absent female presence are largely noncontroversial.

Barriers to play are not always physical. More often, they are subtle and implied. Many modern board games offer a metaphorical "welcome mat" for their white male players because white male privilege is unremarkably endorsed and invisibly unchecked. By the same logic, these same games suggest that those who do not identify as white males are not welcome. Reperforming this endorsement and exclusion in games risks expanding these sentiments beyond the material locus of play into the broader community. Despite design choices to make games appear more inclusive, many players still feel excluded from play. These choices have proven only to superficially address concerns. Endorsing white privilege contributes as barriers to play, and these are worsened by the language, actions, and "tests" that constitute symbolic barriers to play.

\footnotetext{
${ }^{319}$ Cf. "Backtalk." Istanbul, for instance. While there has been criticism of Istanbul for its lack of female representation, the producers' suggestion that the lack of representation is indicative of the setting is false in both time and place.
} 


\subsection{INCLUSION AND EXCLUSION IN THE COMMUNITY}

What brings people together to engage in and enjoy a common event is rarely a physical boundary, nor is it a constructed boundary such as a national border. As we see in the board game industry, for example, Eurogame players are not limited to Europe, and American-style players are not limited to America. Instead, the organizing principles that encompass players are subtle and symbolic, and the boundaries of the community are enforced through symbolic violence. While these exclusionary practices can be sustained through a feedback loop, this loop also demonstrates the means by which players and producers can alter the same practices.

Without physical barriers marking membership in the community, we best understand how board gamers establish what Benedict Anderson calls "horizontal comradeship" 320 through their allegiance to centralizing symbols. Symbols and symbolic actions dually facilitate the broader community's sense of kinship and the limitations of its borders. ${ }^{321}$ Take, for example, the organizing power of the meeple. The meeple, as mentioned previously regarding the material components of Carcassonne (Chapter III), has expanded throughout the board game community not simply as a material component of many games but as a symbol. It presents as a recognizable value-object that is emblematic for the community at large. ${ }^{322}$ It functions as a centralizing locus that reveals

\footnotetext{
${ }^{320}$ Benedict Anderson, Imagined Communities: Reflections on the Origin and Spread of Nationalism (1983, repr. New York: Verso, 2003), 7.

${ }^{321}$ Anderson, 6-7. Anderson suggested that communities are imagined, limited, and sovereign. They are imagined in the sense that members do not know everyone within the community but have a connection to one another. Symbols, rituals, and practices centralize this communion, and each member's allegiance to those ideas creates a sense of belonging despite not necessarily knowing one another. These communities are also limited in the sense that they exhibit "finite, if elastic, boundaries" beyond which other communities lie.

${ }^{322}$ In a way similar to how flags unify national consciousness.
} 
allegiance to the broader community. We can

see evidence of this through the many ways

in which the meeple presents as a symbolic

"stand-in" for the broader community, from

company logos, to T-shirt designs and other

apparel, and names of businesses; players see

the image or hear its utterance and

automatically recognize their access and

kinship. Despite players not knowing or able

to know many of the broader community's

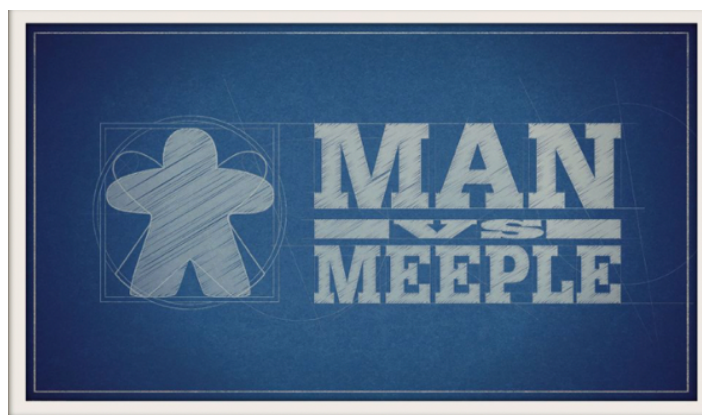

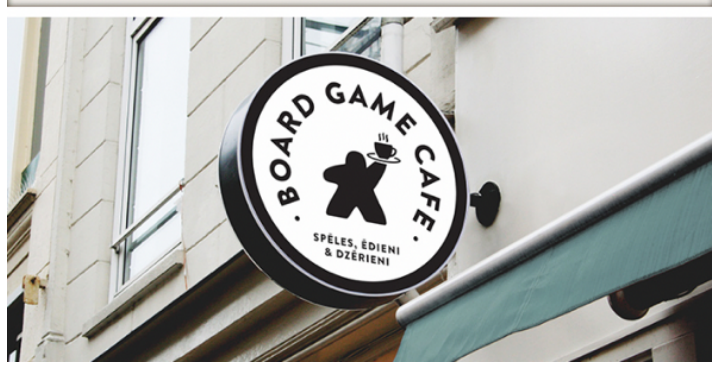

Figure 6.1 The symbolic, inclusive power of the meeple on a YouTube title card and a business sign

players, they can share a sense of communal belonging through symbols like the meeple.

Pierre Bourdieu's notion of the habitus suggests that individuals gain social capital by acquiring practices and attitudes within a given social sphere. ${ }^{323}$ That capital allows for the fluidity and ease with which individuals are able to move within and negotiate a social space. What we observe with the meeple is the use of social capital to clarify membership, but we also observe the boundaries of the community the meeple creates. Out of context, only community members comprehend the significance of the symbol, and beyond the limitations of this symbol, "non-gamers" reside. Its ability to

\footnotetext{
${ }^{323}$ Pierre Bourdieu, Distinction: A Social Critique of the Judgement of Taste (1979, repr. Cambridge: Harvard University Press, 1984), 170. The habitus is the set of practices and attitudes that are acquired from an individual's social sphere or spheres that contributes to a person's social capital. The habitus is both systematic and systematically distinct in that the performed practices are inscribed according to internalized schema and in that these practices are clarified from other systems of expression. The habitus represents the unwritten regulatory practices that manifest through language, practices, and distinguishing attitudes. One's signifying practices both characterize and emerge from the codified regulatory relationships of the habitus.
} 
"speak" is limited, in Anderson's sense; there exists a conceptual "beyond" wherein the meeple exhibits little to no signification. ${ }^{324}$

The boundaries of the community, constituted by limitations of its centralizing symbols, exhibit opportunities for players and producers to be either inclusive or exclusive. While inclusive practices help players entering the community establish connections to the centralized symbols of the hobby - as evidenced by introductory media platforms such as the YouTube channel TableTop ${ }^{325}$ _exclusionary practices make players feel unwelcome. Applying Bourdieu's assertions about symbolic violence, we can observe what he calls "tacit complicity"326 to establish a power disequilibrium between community members and those excluded from it. In the board game community, this power disequilibrium manifests as subtle gestures and actions $\mathrm{s}^{327}$ that disempower those seeking inclusion. For instance, when players use community-defined terminology such as $\mathrm{AP}^{328}$ or cube pusher, ${ }^{329}$ someone who may be new to the community and not know the meanings of the terms may feel unwelcomed, "tested," or even ridiculed.

\footnotetext{
${ }^{324}$ This does not suggest that a person, by learning the significance of the symbol, is automatically included amongst the membership of the broader community; rather, one accumulates, through these symbolic relationships, cultural capital with which they may more fluidly negotiate the community space. ${ }^{325}$ Geek \& Sundry, "TableTop: Carcassonne," YouTube video, December 26, 2013, 33:48, https://www.youtube.com/watch?v=G6VpW4Vljr8. The channel, published by Geek \& Sundry, features actor Wil Wheaton as its host. As a representative of a broader geek community with ties to the Star Trek franchise as well as The Big Bang Theory, Wheaton has accumulated social capital that allows him to engage within several geek community spheres. In this episode, Wheaton introduces the meeple and connects the featured game to other prominent titles.

${ }^{326}$ Pierre Bourdieu, On Television (1996, repr. New York: Norton, 1998), 17. As he states, "Symbolic violence is violence wielded with tacit complicity between its victims and its agents, insofar as both remain unconscious of submitting to or wielding it."

${ }^{327}$ Pierre Bourdieu, The Logic of Practice (1980, repr. Stanford: Stanford University Press, 1990), 126-127. He characterizes symbolic violence as "euphemized" and a recognizable misrecognition of violence. It is "gentle" and "invisible" while being felt or understood.

${ }^{328}$ AP stands for analysis paralysis, a derisive term used for a player who mentally exhausts their choices on their turn and consequently extends gameplay beyond appreciable limits.

${ }^{329}$ A derisive nickname for Eurogame players, so named for the common wooden cubes that represent a wide variety of different material resources.
} 
Symbolic violence manifests as continual unwritten routines which diminish another group's power, and practices, attitudes, and speech acts all exhibit the potential for symbolic violence. Such hostilities are not intended to be remarkable, but a tacit understanding maintains the boundaries of exclusion.

Applying what Slavoj Žižek has put forth regarding symbolic violence, this relatively invisible hostility is not a disruption to the normal state of the community, it is the normal state of the community. ${ }^{330}$ Žižek's assertion about symbolic violence helps us to understand how performances amongst board game community members can be interpreted as a continuously coordinated routine which polices the borders of the community. In one way we can see this operating is through the prominence of designer authorship on many game boxes. We are able to associate a specific title to favored designers easily. However, many widely appealing games are designed by women, but their names do not appear on the cover. Award-winning games like SET (1988) and Qwirkle (2006) were both designed by women, but neither has the designer name listed on the box art. This symbolically diminishes the importance of women in the hobby.

This symbolic violence is often subtle and manifests in small gestures. Bloggers and designers like Gil Hova discuss "invisible ropes" within the community, suggesting that minute acts imply exclusion. ${ }^{331}$ In one instance, a female player of color lamented a gaming session where a male player attempted to infantilize her strategy while suggesting

\footnotetext{
${ }^{330}$ Slavoj Žižek, Violence (New York: Picador, 2008), 1-2. Subjective forms of violence-those enacted by an agent upon a victim - are seen as disruptions to the normal state of things, while objective formsideological and symbolic forms - operate continuously as inherent to the normal state of things. ${ }^{331}$ Gil Hova, "Women in Gaming Vs. Invisible Ropes," Formal Ferret Games, October 27, 2014, https://gil.hova.net/2014/10/27/women-in-gaming-vs-invisible-ropes/. He includes condescending "help" from white male players at the table, a lack of representation, and the inaction of well-intentioned but passive men in the hobby as exemplary acts.
} 
continually improvements to her turns. ${ }^{332}$ An Asian player, in another interaction, felt marked by her ethnic characteristics when a player at a convention had stepped away from a publisher's booth after purchasing an import title and asked her to translate the game's rules, which were written in Japanese, instead of asking the nearby employees of the game's publisher. ${ }^{333}$ And while broader issues of systemic sexism and racism undergird these interactions, as Žižek makes clear, ${ }^{334}$ the tasks within many board game designs at best do little to address these systemic issues and at worst condone them.

Borrowing from Stuart Hall's communicative model, the construction of meaning does not solely reside within the locus of authorship; rather, the intended "encoded" meaning is "decoded" at various stages of reception. ${ }^{335}$ What is most applicable from Hall's argument is that "decodings do not follow inevitably from encodings [...]"336 and decoding can engender opposition, which in turn impacts reproduction via feedback. ${ }^{337}$ This allows us to dismantle the board game production process to better elucidate selection and curation in the design of the game when juxtaposed against audience reception. We have already witnessed this level of feedback operating within the community, particularly in the revision of Five Tribes (Chapter IV), but as the results of that opposition demonstrate, the feedback does less to open the door to a more inclusive

\footnotetext{
332 "Backtalk: Inclusive."

333 "Backtalk: Inclusive."

334 Žižek, 2. Subjective violence masks an underlying objective, ideological, or institutional violence.

335 Stuart Hall, "Encoding/Decoding," in Media Studies: A Reader, ed. Paul Marris, Sue Thornham (1973, repr. New York: New York University Press, 2004), 51. Hall envisions a four-staged approach to communicative models - production, circulation, distribution/consumption, and reproduction-each of which is linked to the others but relatively distinct and autonomous. He uses the example of a historical event being translated to a news broadcast message - "the event must become a 'story' before it can become a communicative event."

${ }^{336}$ Hall, "Encoding," 59.

${ }^{337}$ Hall, "Encoding," 60. He suggests that the "local" or "situational" level of receipt can be characterized by a negotiated framework that includes both "adaptive and oppositional elements."
} 
membership than it does to remove feelings of white guilt from the design. While designs themselves cannot account for the extent of exclusionary practices within the community, they can be seen to contribute to this exclusion by continually valorizing white privilege and diminishing the importance of others. If these tasks and rewards within games are consciously and rigorously considered and transformed, the community would demonstrate a better willingness to include others.

\subsection{A “WELCOME MAT” FOR WHITE PRIVILEGE}

Demographic analyses of the board game community are nascent at best, but what information we do have continually demonstrates that white males from America (US and Canada, particularly) and Europe dominate the industry with less than five percent of respondents identifying as residents of Africa or Latin America. ${ }^{338}$ While game conventions and organized play have begun to appear outside of Europe and America, they remain exceptions to the community's broader proclivities. ${ }^{339}$ The general lack of appeal outside of gaming's dominant regions may have several contributable factors, but the ideology decoded from game design elements has been shown to be a part of the problem.

Through geography, representation, and invisible politics of whiteness, ${ }^{340}$ designs have done little to show that the hobby should be of interest to those beyond its largely

\footnotetext{
338 Booth. Ninety percent of respondents identified as white, and sixty-nine percent identified as male. While these statistics are skewed by the language and platform of the survey, they provide a glimpse into the unequal world of board gaming.

${ }^{339}$ Kenechukwu Ogbuagu, "I Started West Africa's First Board Game Convention," ICS, August 2, 2018, https://www.volunteerics.org/blogs/i-started-west-africas-first-board-game-convention. In 2016, board game advocate Kenechukwu Ogbuagu began the first board game convention in West Africa ${ }^{340}$ Chapters III, IV, and V respectively.
} 
white community. The city of Istanbul presents a telling example. Games are a significant part of the culture of Istanbul, but those played tend to be traditional and casual classics. ${ }^{341}$ Modern board games have not secured a significant foothold in the region. ${ }^{342}$ However, given the symbolic violence demonstrated against Turks in a game like Istanbul (Chapter III), this lack of enthusiasm does not surprise. The continual references to greed and criminality in the game exemplify the type of symbolic violence both Bourdieu and Žižek cautioned. It logically follows that players would be less inclined to participate in games that depicted their culture in such debasing light.

By contrast, designs allow white racial identity to flourish unchecked. Narratives in games like Puerto Rico (Chapter III) and Mombasa (Chapter V) are told from the vantage point of colonialism. Beyond being associated with an unsavory past, both diminish the importance of the indigenous populations, instead focusing attention on industry and economy. For titles like these, nonwhites do not figure as significant elements within the narrative and are routinely ignored. Further, games like Concordia (Chapter V) centralize the narrative on the spread of white dominance while this spatialized power is rendered unremarkable from a racial standpoint. Whiteness is given as a matter of fact and common sensical; it is natural, inevitable, and simply normal as these narratives would suggest.

By and large, modern board games do not explicitly endorse white supremacy or valorize white privilege. However, the rewards and goals within the game imply that

\footnotetext{
341 Michael Crane, "Tavla in Turkey," Backgammon Galore! January, 2000, https://bkgm.com/articles/Crane/TavlalnTurkey/index.html. A variant of Backgammon is unrivaled in its popularity in Istanbul.

342 "Where to Game In: Istanbul, Turkey," EntroGames, February 18, 2019, https://www.entrogames.com/2019/02/where-to-game-in-istanbul-turkey/. Many titles are burdened by substantial import costs and limitedly available in the city's more touristy areas.
} 
white dominance is valued as a goal. When all points and goals are directed toward the valorized feats of white characters and bodies, there is no need to be explicit. When discussing geographical space, the depicted geographies within board game designs were shown to exhibit a "territorial allegiance" to white ideology, to use Henri Lefebvre's term. By this point, we can expand this notion to suggest the social play space of board gaming exhibits the same allegiance. These games present as a metaphorical "welcome mat" for white dominance and white privilege. Whether the player's notions of superiority are conscious or not, the proclivity of game design invites players into a space where those sentiments will at least go unchallenged.

\subsection{OTHERS UNWELCOME: JUDEN RAUS (1938) AND SECRET HITLER (2016)}

In 1938 an infamous game was published in Nazi Germany known as Juden Raus. Described as an amalgam of Monopoly (1933) and Halma (1883), players were tasked with collecting token representing Jewish persons and removing them from the board. The words "Off to Palestine" adorn the board. The game is explicit in its prejudicial intentions. There is no room within the design to mistake who ideologically belongs versus who does not. In some way, the antiquated racism of the game comparably demonstrates how the board game industry has moved

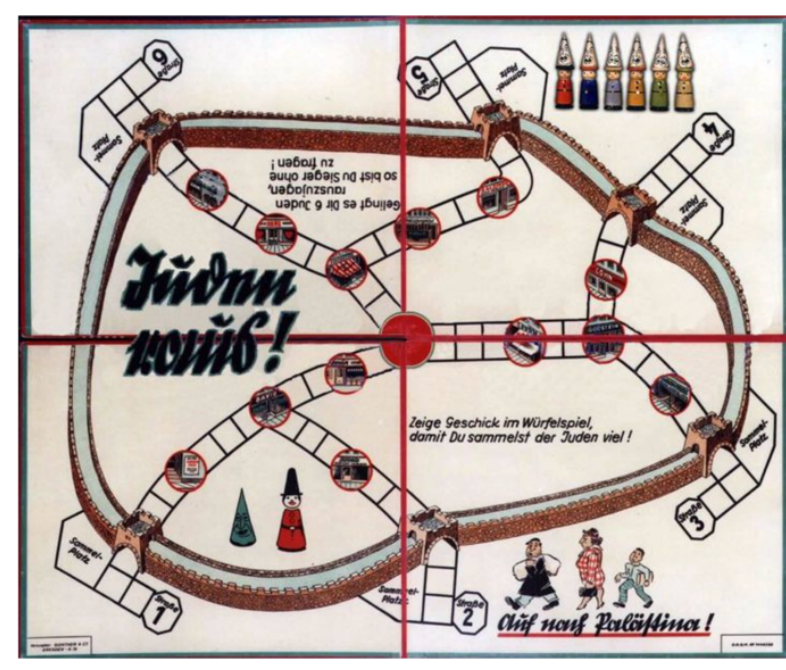

Figure 6.2 The words "Jews get out" and "Off to Palestine" adorn this 1938 board game (Juden Raus) 
beyond the thinly-veiled didacticism of earlier designs. In another way, however, the game reveals the industry's movement away from explicit hostility toward more implicit symbolic violence.

As a case in point, consider the 2016 game Secret Hitler, a team-based party game. In Secret Hitler, each player is secretly given a role: they may be assigned a fascist, a liberal, or Hitler himself. While the fascists know who everyone is, Hitler and the liberals know none of each other's roles. ${ }^{343}$ The goal of the game is to figure out who is on whose team and pass a series of laws. The fascists win if they pass a specified number of fascist laws or elect Hitler as chancellor; the liberals win if they pass a specified number of liberal laws or assassinate Hitler.

Games like Secret Hitler show that exclusion and symbolic violence remain desirable in play. They are "a joke" or "part of the fun." While not as explicitly confrontational as Juden Raus, it recalls genocide and white nationalism in a similar way. ${ }^{344}$ The creators' intentions for the game were to be subversive and spark conversation, ${ }^{345}$ but despite subversive intentions, players have attested to finding the theme unsettling or avoiding play altogether, suggesting that the game's "humor" risks normalizing white supremacy. ${ }^{346}$ The broader implication exhibited by the contrasts

\footnotetext{
${ }^{343}$ Before play, all players close their eyes. A moderator instructs fascists to open their eyes and the player playing as Hitler to raise their thumb while keeping their eyes closed. Once the fascists have identified all roles, all eyes are closed before everyone reopens their eyes.

344 "I Played It... Once: Secret Hitler," Boardgamegeek.com, December 18, 2016, https://boardgamegeek.com/thread/1691956/ive-played-it-once-secret-hitler. Players have found the game difficult to introduce to other players or have insisted on using "paste ups" to cover the game materials with less volatile themes, such as the Harry Potter franchise or pirates.

${ }^{345}$ On the game's website, the designers, under the Frequently Asked Questions section, suggest that players who don't "think there's anything funny or cool about fascism" can send complaints to the White House.

${ }^{346}$ Jonah Engel Bromwich, "Secret Hitler, a Game that Simulates Fascism's Rise, Becomes a Hit," New York Times, Sept. 5, 2017, https://www.nytimes.com/2017/09/05/business/secret-hitler-game.html. This
} 
between Juden Raus and Secret Hitler is that symbolic violence has become more implicit and presumably innocuous in modern board games. ${ }^{347}$

The same symbolic violence operates within the community when current issues of race and ethnicity are at the fore. When identities are presented in stereotypical or insensitive ways - such as the case of people of color within Eldritch Horror (Chapter IV) - players may feel their presence is unwelcome. Indeed, when players bring up the issue of race on forums, they are often subjected to disparagement for being "sickeningly politically correct"348 or "choosing" to bring race into the hobby. ${ }^{349}$ Unfortunately, following Dyer's assertion that white individuals often do not see themselves racially, ${ }^{350}$ racial politics are not a choice for many players. Tellingly, the fault is usually placed upon a player's "sensitivities" and rarely upon the design or the community. ${ }^{351}$ However, as we have seen, the unilateral perspectives centering on white experience or exoticizing nonwhite experience are an example of symbolic violence that both characterizes and encloses the industry's white male dominance. Hova's assertion of 'invisible ropes'

article has pointed out that sales of the game have flourished alongside public interests in dystopian narratives and unease surrounding the US Presidential election.

${ }^{347}$ Disparagement has become welcomed into the mainstream, as evidenced by such games as Cards Against Humanity (2009). The apparent humor of these games, however, function to secure the social boundaries of the magic circle. Those who are "in on the joke" are welcomed, but those who are not are excluded.

348 "People of Color on BGG," boardgamegeek.com, January 9, 2009, https://boardgamegeek.com/thread/370650/people-color-bgg. User comments to the original post exhibit this volatility.

349 "Is It a Problem that Most Boardgame Designers Are White?" boardgamegeek.com, February 27, 2017, https://boardgamegeek.com/thread/1736196/it-problem-most-boardgame-designers-are-white/page/1. The extensive comments devolve into vitriol, and users suggest that the hostility exhibited keeps people of color from bringing up such topics.

${ }^{350}$ Dyer, White, 3.

351 "Offensive Theme?" boardgamegeek.com, January 22, 2018, https://boardgamegeek.com/thread/1925238/offensive-theme/page/1. Players are told to "just let it go" and to let everyone who is not offended enjoy the game. 
clarifies this. Subtle gestures, from representation to the way people speak to or about one another within the hobby, keep people at a distance from that hobby. ${ }^{352}$

Even though the policing of ideological borders within the board gaming community have become less explicit than games like Juden Raus, these ideologies persist. Opposition and hostility currently manifest in sometimes subtle and symbolic gestures. Without explicitly saying so, the community clarifies who belongs versus who does not. While there may be many causes for such hostilities, from traditional conceptions of the community or systemic apprehension, we cannot overlook how board game designs themselves play a part. Exclusion, debasement, and disparagement are inscribed into the games themselves through their abuses of geography, representation, and racial politics. These practices only exacerbate the exclusivity and boundary policing of the broader community.

\subsection{CONCLUDING REMARKS}

In this dissertation, I have intentionally focused on issues of race and ethnicity here, but these are far from the only issues that arise within board game designs. Assuredly, one could inspect modern board games for a host of social, political, or even environmental issues. To exemplify this possibility, I have highlighted three major avenues that could be explored in future analyses of board games - the representation of women, gender roles, and heteronormativity. ${ }^{353}$ With the issues of race and ethnicity

\footnotetext{
352 Hova.

353 These are exemplary possibilities but are no way exhaustive. For brevity, I have kept this list concise, but there are a multitude of other avenues, and I have no intention of diminishing their importance by omitting them from this list. Ableism, ageism, toxic masculinity, capitalism, ecocriticism, and non-Western market production and consumption would all be equally valid topics for future scrutiny.
} 
explored here, these collectively elucidate industry tensions between inclusion and exclusion.

The representation of women has been hovering as an absent presence, for looking into the function and representation of ethnicities and races begs the question of how women are represented. Despite ongoing efforts to be inclusive to women in board gaming, there remain several problematic issues with representing women generally. For instance, women continue to be sexualized in board games. One need not look further than the buxom bikini-clad warriors of Kingdom Death: Monster (2015) or the pillowstraddling maids of Tanto Cuore (2009) to see this operating. Sexual signifiers such as these serve no narrative purpose, and by reducing women to sexualized objects, the industry implies that men are active, the doers, and the consumers while women are static, passive, and looked upon.

In addition to the sexualized objectification of women in board games, there are also problematic issues with playable female roles. While instances arise wherein women are portrayed as scientists (Pandemic, 2008) and athletes (Bottom of the $\left.9^{\text {th }}, 2015\right)$ as well as instances where underrepresented historical women are celebrated, ${ }^{354}$ there are just as many instances where women are confined to disparaging and stereotypical roles. Examples abound from Ladies \& Gentlemen (2013) to Marrying Mr. Darcy (2014), both of which present a nostalgic view of patriarchy. In Ladies \& Gentlemen, a team-based game, women shop while men earn money. In Marrying Mr. Darcy, the female characters attempt to make themselves alluring wives for potential suitors. While admittedly tongue-in-cheek, these games ultimately reduce a serious issue of sexism

\footnotetext{
${ }^{354}$ Cf. Steampunk Rally, designed by Orin Bishop, Roxley Games, 2015. Players may take on the roles of Hertha Ayrton and Lise Meitner alongside the likes of Albert Einstein and Nikola Tesla.
} 
down to a joke, apparently made more palatable through the temporal distance of their narratives, and risk perpetuating problematic gender roles that are still endured today. When we observe issues such as the diminished importance of female designers through the omission of their authorship or the publicly decried games that have themes that are "too feminine," 355 we also observe the potential real-world harm board game narratives can endorse.

Relationships between men and women are considered as default in board gaming, which we can observe from classics like The Game of Life (1959) to more modern games such as The Pursuit of Happiness (2015). Despite this prevalent heteronormative presentation, modern games have attempted to be more inclusive to the LGBTQ community. ${ }^{356}$ When designer Jacob Jaskov developed his game Fog of Love (2017), a board game take on the romantic comedy genre, he asserted that players could simulate same-sex relationships in the game, ${ }^{357}$ but players identifying as LGBTQ have noted that their enjoyment of the game is constrained by the stereotypical hijinks itinerant to heterosexual relationships, such as a toilet seat being left up, and they best enjoyed the game by "playing in" to the role of a heterosexual couple. ${ }^{358}$ Added to this recurrent reminders of "tradition" throughout the game also mark LGBTQ players as "allowed" but

\footnotetext{
${ }^{355}$ Cf. "My Impressions: Rococo," boardgamegeek.com, May 17, 2014, https://boardgamegeek.com/thread/1173292/my-impressions-rokoko. While the reviewer presents a generally positive overview of the game, which centers on dressmaking, the comments below mention players who refuse to try the game due to its theming.

${ }^{356}$ I use LGBTQ for conciseness while acknowledging more complete initialisms, such as LGBTQIAPK and LGBTQQIP2SAA, more appropriately and accurately reflect the culture. The shortening to LGBTQ is not intended as a dismissal of other identifiers within the culture.

357 "Fog of Love: FAQ" (n.d.), fogoflove.com, retrieved from https://www.fogoflove.com/faq. Additionally, the game offers variant box cover art depicting same-sex relationships.

${ }^{358}$ Alex Colby, "Fog of Love and the "Gay Option," Meeple Mountain, June 18, 2018, https://www.meeplemountain.com/articles/fog-of-love-and-the-gay-option/
} 
not "expected." ${ }^{359}$ Despite the praiseworthy efforts of the game's designer to be more inclusive in its play options, this circumstance is a scarcity in the industry, ${ }^{360}$ and games more generally ignore topics such as sexual orientation.

Collectively, these three avenues toward future scrutiny, in conjunction with the issues of race and ethnicity that have been argued throughout, highlight what work toward inclusion still needs to be done in the hobby. To echo a previous assertion, it is not my intention that players and prospective players should stop enjoying games. However, players and producers need to be more conscious of what they are being tasked to do in and through games. While identity politics are not on the surface of every player's mind when playing a game, those politics are at work. Vocal concern and opposition can transform designs to become more inclusive. The feedback loop does work. Players can transform the implicit politics of the industry, but when those changes are superficial, as in the case of Five Tribes, silenced submission only perpetuates the problem. In some ways, the industry is moving in the right direction. Identity politics are recurring themes within board game criticism, sparking serious conversation. Podcasts like Blue Peg, Pink Peg and Our Turn! have periodically tackled issues of identity and representation in games and the broader community. While their actions, and the actions of vocal players, are commendable, the community as a whole can do more.

\footnotetext{
359 Colby, "Fog."

${ }^{360}$ Dead of Winter (2014) and Sentinels of the Multiverse (2011) also present as exceptions to the norm.
} 


\section{REFERENCES}

“A Black Player on Freedom.” Boardgamegeek.com, April 14, 2014. https://boardgamegeek.com/thread/1155831/black-player-freedom

Alcoff, Linda Martín. The Future of Whiteness. Malden, MA: Polity, 2015.

“Alternative to Roll and Move.” Boardgamegeek.com, June 26, 2017. https://boardgamegeek.com/thread/1802679/alternative-roll-and-move

Althusser, Louis. "Ideology and Ideological State Apparatuses." In Lenin and Philosophy and Other Essays, 85-126. Translated by Ben Brewster. 1971. Reprint, New York: Monthly Review Press, 2001.

"AmeriTrash Vs. EuroGame: Are They Just Names for Genres, or Fact?" Boardgamegeek.com, April 25, 2012. https://boardgamegeek.com/blogpost/9913/ ameritrash-vs-eurogame-are-they-just-names-genres.

Anderson, Benedict. Imagined Communities: Reflections on the Origin and Spread of Nationalism. 1983. Reprint, New York: Verso, 2003.

Android: Netrunner. Designed by Richard Garfield. Fantasy Flight Games, 2012.

"Any Other Women Having the Same Problem.." Gencon.com. Last Modified March 2020. https:/www.gencon.com/forums/15-general-info-2016/topics/1653-anyother-women-having-the-same-problem

Appelcline, Shannon. "Bruno Faidutti: Professor of Chaos.” Mechanics-andmeeples.com, May 22, 2006. https://www.mechanics-andmeeples.com/2006/05/22/bruno-faidutti-professor-of-chaos/

Baldwin, James. "Color." In The Price of the Ticket: Collected Nonfiction, 1948-1985, 319-324. New York: St. Martin's Press, 1985.

Baltes, Boris B., and Cort W. Rudolph. "Examining the Effect of Negative Turkish Stereotypes on Evaluative Workplace Outcomes in Germany." Journal of Managerial Psychology 25 no. 2 (2009): 148-158.

Berger, Thomas U. Cultures of Antimilitarism: National Security in Germany and Japan. Baltimore: Johns Hopkins University Press, 1998. 
Bogost, Ian. Persuasive Games: The Expressive Power of Videogames. Cambridge: MIT Press, 2007.

Bolding, Jon. "A Cancelled Board Game Revealed How Colonialism Inspires and Haunts Games." Vice.com, April 12, 2019. https://www.vice.com/en_us/article/vb9gd9/acancelled-board-game-revealed-how-colonialism-inspires-and-haunts-games

Booth, Paul. "Who's at the Table? Board Game Players and Communities." Meeple Mountain, Aug. 27, 2019. https://www.meeplemountain.com/articles/whos-at-thetable-board-game-players-and-communities/

Bora Bora. Designed by Stefan Feld. Ravensberger Spielverlag, 2013.

Borit, Cornel, Melania Borit, and Petter Olsen. "Representations of Colonialism in Three Popular, Modern Board Games: Puerto Rico, Struggle of Empires, and Archipelago." Open Library of Humanities 4 no. 1 (2018): 1-40.

Bourdieu, Pierre. Distinction: A Social Critique of the Judgement of Taste. 1979. Reprint, Cambridge: Harvard University Press, 1984.

---. The Logic of Practice. 1980. Reprint, Stanford: Stanford University Press, 1990.

---. Outline of a Theory of Practice. 1977. Reprint, Cambridge: Cambridge University Press, 2013.

---. On Television. 1996. Reprint, New York: Norton, 1998.

Bromwich, Jonah Engel. "Secret Hitler, a Game that Simulates Fascism's Rise, Becomes a Hit." New York Times, Sept. 5, 2017. https://www.nytimes.com/2017/09/05/business/secret-hitler-game.html

Brown, Eli. “A Plethora of Pastimes.” Pastimes and Paradigms. Last modified 2004. https://rmc.library.cornell.edu/games/plethora/index.html

Butler, Judith. Gender Trouble. New York: Routledge, 1990.

Caillois, Roger. Man, Play, and Games. Translated by Meyer Barash. 1958. Reprint, Chicago: University of Illinois Press, 2001.

Carcassonne. Designed by Klaus-Jürgen Wrede. Rio Grande Games, 2000.

Carr, Sax. “A Talk About Inclusion in Gaming.” Geek \& Sundry, December 16, 2016. https://geekandsundry.com/a-talk-about-inclusion-in-gaming/

Carrington, Ben. Race, Sport and Politics: The Sporting Black Diaspora. Thousand Oaks: Sage, 2010. 
Catan: The Official Website for the World of Catan. Catan GmbH. Last modified March 2, 2020. https://www.catan.com/about-us/partners\#

Colby, Alex. "Fog of Love and the "Gay Option," Meeple Mountain, June 18, 2018. https://www.meeplemountain.com/articles/fog-of-love-and-the-gay-option/

Concordia. Designed by mac Gerdts. PD Games, 2013.

"The Corrosive Passive Bigotry of Mombasa's Failed Thematic Perspective."

Boardgamegeek.com, May 2016.

https://boardgamegeek.com/thread/1582537/corrosive-passive-bigotrymombasas-failed-thematic/page/1

Cosmic Encounter. Designed by Bill Eberle, Jack Kittredge, Bill Norton, Peter Olotka, and Kevin Wilson. 1977. Reprint, Fantasy Flight Games, 2008.

Crane, Michael. "Tavla in Turkey.” Backgammon Galore! January, 2000. https://bkgm.com/articles/Crane/TavlaInTurkey/index.html

Dalton, Dawn. "The Evolution of the Meeple." Geek \& Sundry, August 29, 2017. https://geekandsundry.com/the-evolution-of-the-meeple/

de Certeau, Michel. The Practice of Everyday Life. 1984. Reprint, Berkeley: University of California Press, 1988.

“Designing with a Full-Time Job?” Boardgamegeek.com, May 21, 2018. https://boardgamegeek.com/thread/1996796/designing-full-time-job.

Dewar, Gwen. "Board Games for Kids: Can They Teach Critical Thinking?” Parenting Science, November 2012. https://www.parentingscience.com/board-games-forkids.html.

The Dice Tower. "Backtalk 16: Inclusive Gaming." YouTube Video. November 21, 2016. 19:57. https://www.youtube.com/watch?v=hO9bEIR81Zc\&t=285s

---. "Board Game Breakfast - Saving the Local Game Store." YouTube Video. October 22, 2017. 38:01. https://www.youtube.com/ watch?v=sXpsHyLSTOY

---. "Freedom: The Underground Railroad - with Tom Vasel." YouTube Video. December 12, 2013. 11:34. https://www.youtube.com/watch?v=BC-f7GZlwnk

---. "HAVOK in Homestead Gaming Marathon, Part 1." YouTube Video. May 21, 2016. 3:53:19. https://www.youtube.com/watch?v=bofPt3YQ2mQ 
Douglas, Mary. Purity and Danger: An Analysis of Concepts of Pollution and Taboo. 1966. Reprint, New York Routledge, 1994.

“Do You Want the Truth Reviews Istanbul.” Boardgamegeek.com, July 6, 2015. https://boardgamegeek.com/thread/1367819/do-you-want-truth-reviews-istanbul

Draper Kevin. "Should Board Gamers Play the Roles of Racists, Slavers, and Nazis?" New York Times, August 1, 2019. https://www.nytimes.com/2019/08/01/style/board-games-cancel-culture.html

Duffy, Owen. "Board Games' Golden Age: Sociable, Brilliant and Driven by the Internet." The Guardian, Nov. 25, 2014. https://www.theguardian.com/technology/2014/nov/25/board-games-internetplaystation-xbox.

Dyer, Richard. "White." In The Matter of Images: Essays on Representation, 126-148. 1993. Reprint, New Hork: Routledge, 2002.

---. White. 1997. Reprint, New York: Routledge, 2008.

Eldritch Horror. Designed by Corey Konieczka and Nikki Valens. Fantasy Flight Games, 2013.

El Grande. Designed by Wolfgang Kramer and Richard Ulrich. Rio Grande Games, 1995.

Entman, Robert M. and Andrew Rojecki. The Black Image in the White Mind: Media and Race in America. Chicago: University of Chicago Press, 2000.

Euwals, Rob, and Jaco Dagevos, Mérove Gijsberts, and Hans Roodenburg. "Immigration, Integration and the Labour Market: Turkish Immigrants in Germany and the Netherlands." IZA Discussion Papers 2677 (2007).

Everett, Anna, and S. Craig Watkins. "The Power of Play: The Portrayal and Performance of Race in Video Games." In The Ecology of Games: Connecting Youth, Games, and Learning, 141-166. Edited by Katie Salen Cambridge: MIT Press, 2008.

Fanon, Frantz. "The Lived Experience of the Black Man.” In Black Skin, White Masks, 89-119. 1952. Reprint, New York: Grove Press, 2008.

---. The Wretched of the Earth. 1963. Reprint, New York: Grove Press, 2004.

Five Tribes. Designed by Bruno Cathala. Days of Wonder, 2014. 
Forbeck, Matt. "Metaphor vs. Mechanics.” In The Kobold Guide to Board Game Design, 19-23. Edited by Mike Selinker. Kirkland, WA: Open Design, 2011.

Foucault, Michel. The Archaeology of Knowledge and The Discourse on Language. 1972. Reprint, New York: Vintage, 2010.

---. Discipline and Punish: The Birth of the Prison. 1975. Reprint, New York: Vintage, 1995.

---. “Nietzsche, Genealogy, History.” In The Foucault Reader, 76-100. Edited by Paul Rabinow. New York: Pantheon, 1983.

---. The Order of Things: An Archaeology of the Human Sciences. 1966. Reprint, New York: Vintage, 1994.

---. "Questions on Geography." 1976. Reprint, in Power/Knowledge: Selected Interviews \& Other Writings 1972-1977. New York: Vintage, 1980.

Foucault, Michel and Jay Miskowiec. “Of Other Spaces.” diacritics 16 no. 1 (1986): 2227.

Freedom: The Underground Railroad. Designed by Brian Mayer. Academy Games, 2012.

The Game Boy Geek. "Freedom: The Underground Railroad - With the Game Boy Geek.” YouTube Video, August 27, 2013. 16:40. https://www.youtube.com/watch?v=bmyniDbKXDs

Geek \& Sundry. “TableTop: Carcassonne.” YouTube Video. December 26, 2013. 33:48. https://www.youtube.com/watch?v=G6VpW4Vljr8.

Glenn, Stephen. "Interview with Reiner Knizia—Fall 2002." http://www.convivium.org.uk/kgfgi

Gonzalez, Susan. 'Director Spike Lee Slams 'Same Old' Black Stereotypes in Today's Films.” Yale Bulletin \& Calendar, March 2,2001. http://archives.news.yale.edu/v29.n21/story3.html

Graham, Luke."Millenials are Driving the Board Games Revival.” CNBC, December 22, 2016. https://www.cnbc.com/2016/12/22/millennials-the-board-games-revivalcatan-pandemic.html

Gramsci, Antonio. Selections from the Prison Notebooks. 1971. Reprint, New York: International Publishers, 2014. 
Hall, Stuart. "Encoding/Decoding." In Media Studies: A Reader, edited by Paul Marris, Sue Thornham, 51-61. 1973. Reprint, New York: New York University Press, 2004.

---. "The Spectacle of the 'Other."' In Representation: Cultural Representations and Signifying Practices, 223-290. Edited by Stuart Hall. Thousand Oaks: Sage, 1997.

Hamlin, David. "The Structures of Toy Consumption: Bourgeois Domesticity and Demand for Toys in Nineteenth-Century Germany." Journal of Social History 36 no. 4 (1999): 857-869.

Harford, Tim. "Why We Still Love Board Games.” FTMagazine, July 16, 2010. https://www.ft.com/content/1aab09a4-8fb2-11df-8df0-00144feab49a

Harley, J.B. "Maps, Knowledge, and Power." 1988. Reprint, in The New Nature of Maps: Essays in the History of Cartography, 51-82. Edited by Paul Laxton. Baltimore: Johns Hopkins University Press, 2002.

Hocking, Clint. "Ludonarrative Dissonance in Bioshock." ClickNothing, October 7, 2007. https://clicknothing.typepad.com/click_nothing/2007/10/ludonarrative-d.html

hooks, bell. "Eating the Other" Desire and Resistance.” In Black Looks: Race and Representation, 21-40. 1992. Reprint, New York: Routledge, 2015.

---. Reel to Real: Race, Sex, and Class at the Movies. New York: Routledge, 1996.

Hooper, David and Kenneth Whyld. The Oxford Companion to Chess. $2^{\text {nd }}$ edition. New York: Oxford University Press, 1992.

Hova, Gil. "Women in Gaming Vs. Invisible Ropes." Formal Ferret Games, October 27, 2014. https://gil.hova.net/2014/10/27/women-in-gaming-vs-invisible-ropes/.

Huber, Joe. "How Acquire Became Acquire.” OpinionatedGamers, May 29, 2014. https://opinionatedgamers.com/2014/05/29/how-acquire-became-acquire/

Huizinga, Johan. Homo Ludens: A Study of the Play-Element in Culture. 1949. Reprint, Kettering, OH: Angelico Press, 2016.

“I Don’t Really 'Get' Small World.” Boardgamegeek.com, November 1, 2014. https://boardgamegeek.com/thread/1262434/i-dont-really-get-small-world

“I Played It... Once: Secret Hitler.” Boardgamegeek.com, December 18, 2016. https://boardgamegeek.com/thread/1691956/ive-played-it-once-secret-hitler 
"Is It a Problem that Most Boardgame Designers Are White?" Boardgamegeek.com, February 27, 2017. https://boardgamegeek.com/thread/1736196/it-problem-mostboardgame-designers-are-white/page/1

Istanbul. Designed by Rüdiger Dorn. Pegasus Spiele, 2014.

Jahromi, Neima. "The Twenty-Five Year Journey of Magic: The Gathering." The New Yorker, August 28, 2018. https://www.newyorker.com/culture/culture-desk/thetwenty-five-year-journey-of-magic-the-gathering

Jamaica. Designed by Malcolm Braff, Bruno Cathala, and Sébastien Pauchon. GameWorks, 2007.

Johnson, E. Patrick. Appropriating Blackness: Performance and the Politics of Authenticity. Durham: Duke University Press, 2003.

Jolin, Dan. "The Rise and Rise of Tabletop Gaming." The Guardian, September 25, 2016. https://www.theguardian.com/technology/2016/sep/25/board-games-backtabletop-gaming-boom-pandemic-flash-point

Juden Raus. (Game Uncredited). Günter \& Co., 1938.

Juul, Jesper. Half-Real: Video Games between Real Rules and Fictional Worlds. Cambridge, MIT Press, 2011.

---. "The Magic Circle and the Puzzle Piece." In Conference Proceedings of the Philosophy of Computer Games 2008, 56-67. Edited by Stephan Günzel, Michael Liebe, and Dieter Mersch. Potsdam: University Press, 2008.

Kapell, Matthew Wilhelm. "The Ludic and Narrative as Dialectic About 'What Games Do.'" Introduction to The Play Versus Story Divide in Game Studies: Critical Essays, edited by Matthew Wilhelm Kapell, 1-15. Jefferson, NC: McFarland, 2016.

Kristeva, Julia. Powers of Horror: An Essay on Abjection. New York: Columbia University Press, 1982.

Kruzman, Diana. "Bored with Digital Games? Join the Board Game Renaissance." USA Today, July 31, 2017. https://www.usatoday.com/story/life/2017/07/31/boreddigital-games-join-board-game-renaissance/476986001/

Lane, Rick. "The Making of Cosmic Encounter, the Greatest Boardgame in the Galaxy." Eurogamer.net, June 3, 2016. http://www.eurogamer.net/articles/2016-03-06-themaking-of-cosmic-encounter-the-greatest-boardgame-in-the-galaxy 
Lefebvre, Henri. The Production of Space. 1974. Reprint, Cambridge, MA: Blackwell, 2000.

---. "Reflections on the Politics of Space." Translated by Michael J. Enders. Antipode 8 no. 2 (1976): 30-37.

Leonard, Elisabeth Anne. "Race and Ethnicity in Science Fiction." 1988. Reprint, in The Cambridge Companion to Science Fiction, edited by Edward James and Farah Mendelsohn, 253-263. New York: Cambridge University Press, 2003.

Lind, Michael. Vietnam: The Necessary War. 1999. Reprint, New York: Simon \& Schuster, 2002.

Lipsitz, George. The Possessive Investment in Whiteness: How White People Profit from Identity Politics. Philadelphia: Temple University Press, 2006.

"Looking for Good Asian-Themed Games." Boardgamegeek.com, August 9, 2017. https://boardgamegeek.com/thread/1827199/looking-good-asian-themed-games

Martin, Eric. "Five Tribes Revised: Slaves Are Out, Fakirs In.” Boardgamegeek.com, March 25, 2015. https://boardgamegeek.com/blogpost/40219/five-tribes-revisedslaves-are-out-fakirs

Maull, Hanns W. "Foreign Policy: From 'Civilian Power' to 'Trading State?'” In The Routledge Handbook of German Politics and Culture, edited by Sarah Colvin, 409-424. New York: Routledge, 2015.

Mihealsick, Mike. "Eurogames Vs. Ameritrash: What's the Difference?" Board Game Resource, Apr. 28, 2016. https://www.boardgameresource.com/eurogames-vsameritrash/

Mills, Charles W. The Racial Contract. 1997. Reprint, Ithaca: Cornell University Press, 1999.

Mombasa. Designed by Alexander Pfister. Pegasus Spiele, 2015.

“My Impressions: Rococo.” Boardgamegeek.com, May 17, 2014. https://boardgamegeek.com/thread/1173292/my-impressions-rokoko

Nakamura, Lisa. Cybertypes: Race, Ethnicity, and Identity on the Internet. New York: Routledge, 2002.

Neyfakh, Leon. "Inside the Board Game Renaissance.” Boston Globe, March 11, 2012. https:// www.bostonglobe.com/ideas/2012/03/11/inside-board-gamerenaissance/XXRfS0Ble3X9BGgrZlA7 wO/story.html 
O'Callaghan, Joseph F. Reconquest and Crusade in Medieval Spain. Philadelphia: University of Pennsylvania Press, 2003.

Ochs, Rhiannon. "The Confusing Hierarchy of the Board Game Community." Whose Turn Is It Anyway, October 29, 2014. http://whoseturnisitanyway.com/theconfusing-hierarchy-of-the-board-game-community/

“Offensive Theme?" Boardgamegeek.com, January 22, 2018. https://boardgamegeek.com/thread/1925238/offensive-theme/page/1

Ogbuagu, Kenechukwu. "I Started West Africa's First Board Game Convention." ICS, August 2, 2018. https://www.volunteerics.org/blogs/i-started-west-africas-firstboard-game-convention

Pandemic. Designed by Matt Leacock. Z-Man Games, 2008.

"People of Color on BGG." boardgamegeek.com, January 9, 2009. https://boardgamegeek.com/thread/370650/people-color-bgg

Pobuda, Tanya. "Assessing Gender and Racial Representation in the Board Game Industry." Analog Game Studies, December 2, 2018. https://via.hypothes.is/http://analoggamestudies.org/byline/tanya-pobuda/

“The Political Insensitivity of Archipelago.” Boardgamegeek.com, December 6, 2012. https://boardgamegeek.com/thread/894504/political-insensitivity-archipelago

Puerto Rico. Designed by Andreas Seyfarth. Rio Grande Games, 2002.

“Puerto Rico: Isn’t This Game a Little Racist?” Boardgamegeek.com, February 22, 2013. https://boardgamegeek.com/thread/935394/isnt-game-little-racist

Rahdo Runs Through. "One Deck Dungeon: Final Thoughts," YouTube video, April 21, 2019, 7:09, https://www.youtube.com/watch?v=wZwgJ2U49yI

Raphel, Adrienne. "The Man Who Built Catan.” The New Yorker, February 12, 2014, https://www.newyorker.com/business/currency/the-man-who-built-catan

Sackson, Sid. "The No Game.” In A Gamut of Games. 1969. Reprint, Mineola, NY: Dover, 2011: 184-185.

Said, Edward. Orientalism. 1978. Reprint, New York: Vintage, 1994.

Secret Hitler. Designed by Mike Boxleiter, Tommy Maranges, Max Temkin. Goat Wolf \& Cabbage, 2016. 
Shapiro, David. “To Boldly Go. ..” The Games Journal, August 2003, http://www.thegamesjournal.com/articles/ToBoldlyGo.shtml

Slesin, Suzanne. "Currents: At 50, Still Climbing, Still Sliding." New York Times, July 15, 1993. https://www.nytimes.com/1993/07/15/garden/currents-at-50-stillclimbing-still-sliding.html

Small World. Designed by Phillippe Keyaerts. Days of Wonder, 2007.

Soja, Edward W. Postmodern Geographies: The Reassertion of Space in Critical Social Theory. Brooklyn: Verso, 1989.

---. Thirdspace: Journeys to Los Angeles and Other Real-and-Imagined Places. Cambridge: Blackwell, 1996.

Steampunk Rally. Designed by Orin Bishop. Roxley Games, 2015.

"Stronghold Games: Overview." Boardgamegeek.com, n.d. https://boardgamegeek.com/boardgamepublisher/11652/stronghold-games

Through the Ages: A New Story of Civilization. Designed by Vlaada Chvátil. CGE Games, 2007.

Tynes, John. "Prismatic Play: Games as Windows on the Real World." Electronicbookreview, March 26, 2008. https://electronicbookreview.com/essay/ prismatic-play-games-as-windows-on-the-real-world/

Urry, John and Jonas Larsen. The Tourist Gaze 3.0. Los Angeles: Sage, 2011.

Verstraen, Julie. "The Rise of Board Games.” Medium.com, April 21, 2018. https://medium.com/@Juliev/the-rise-of-board-games-a7074525a3ec

Werneck, Tom. "The Impact of the Award "Spiel des Jahres" on the Development of the Board Games Market in Germany." VilaWeb, N.d. https://www.vilaweb.cat/media/continguts/000/055/359/359.pdf.

“What Does Metagame Mean?" boardgamegeek.com, February 11, 2008. https://boardgamegeek.com/thread/292324/what-does-metagame-mean

"What Games Depict Slaves/Slavery." Boardgamegeek.com, June 8, 2015. https://boardgamegeek.com/thread/1382715/what-games-depictslavesslavery/page/1 
"Where to Game In: Istanbul, Turkey." EntroGames, February 18, 2019. https://www.entrogames.com/2019/02/where-to-game-in-istanbul-turkey/

“Why Are All Heroes in this Game Female?" Boardgamegeek.com. February 4, 2017. https://boardgamegeek.com/thread/1721002/why-are-all-hero-characters-gamefemale

"Why We're Getting Rid of 'Puerto Rico."” Boardgamegeek.com, July 28, 2017. https://boardgamegeek.com/thread/1820171/why-were-getting-rid-puerto-rico

Williams, Raymond. "Culture is Ordinary." 1958. Reprint, in Resources of Hope: Culture, Democracy, Socialism, 3-14. Brooklyn: Verso, 1989.

---. “Dominant, Residual, and Emergent.” In Marxism and Literature, 121-127. 1977. Reprint, Oxford: Oxford University Press, 2009.

Wise, Tim. White Like Me: Reflections on Race from a Privileged Son. Brooklyn: Soft Skull Press, 2005.

"The Women and Men that Lead Games." Best 50 Years in Gaming, 2020. http://best50yearsingaming.com/exhibits/show/runninggames/leadinggames

Wong, Calvin. "10 Things You Didn't Know about The Settlers of Catan." Boardgameprices.com, September 13, 2016. https://www.boardgameprices.com/articles/10-things-you-didnt-know-about-TheSettlers-of-Catan

Woods, Stewart. Eurogames: The Design, Culture and Play of Modern European Board Games. Jefferson, NC: McFarland, 2012.

Yancy, George. Black Bodies, White Gazes: The Continuing Significance of Race. New York: Rowman \& Littlefield, 2008.

Young, Iris Marion. "The Five Faces of Oppression.” In Oppression, Privilege, and Resistance: Theoretical Perspectives on Racism, Sexism, and Heterosexism, 3762. Edited by Lisa Heldke and Peg O’Connor. New York: McGraw Hill, 2004.

Zander, Megan. "The Surprising Benefits Your Kids Get from Playing Board Games." Scholastic.com, Nov. 22, 2019. https:/www.scholastic.com/parents/kidsactivities-and-printables/activities-for-kids/arts-and-craft-ideas/benefits-boardgames.html

Zimmerman, Eric. "Jerked Around by the Magic Circle - Clearing the Air Ten Years Later." Gamasutra.com, Feb. 7, 2012. https://www.gamasutra.com/view/feature/135063/jerked_around_by_the_magic_c ircle_.php. 
Žižek, Slavoj. Violence. New York: Picador, 2008. 


\section{CURRICULUM VITAE}

NAME:

Darrell A. Johnson

ADDRESS:

208 Bent Tree Dr

Vine Grove, KY 40175

EDUCATION: $\quad$ Ph.D., Comparative Humanities

University of Louisville

May 2020

M.A.T., Secondary Education

Bellarmine University

May 2019

M.A. English

University of Louisville

May 2012

B.A. Humanities

University of Louisville

May 2009

B.A. English

University of Louisville

Dec. 2003

EXPERIENCE: Hardin County Schools, James T. Alton Middle School Teacher of Record, Rank II 2018-2019

University of Louisville, Comparative Humanities Dept. Graduate Teaching Assistant 2016-2018

Ivy Tech Community College, Sellersburg Instructor 2013-2014 
Sullivan College of Technology and Design

Instructor

2012-2014

Jefferson Community and Technical College, Louisville

Instructor

2012-2014

\section{CONFERENCE PAPERS:}

"Time-Management Strategies for the Graduate Student Parent." Association of Humanities Academics, University of Louisville, Feb. 2018.

“White's Move: 'Toured' and Re-formed Identities in the Modern Board Game Experience," Literature and Culture since 1900, University of Louisville, February 2018.

"No Shelter Here: Unstable Geographical Space in Jeff Nichols' Take Shelter." PCA/ACA, Chicago, IL, April 2014.

AWARDS: $\quad$ School of Interdisciplinary Graduate Studies

Fellowship

2014-2016

Jefferson Community and Technical College, Dept. of English Best Teaching Practices Award

2012-2013.

\section{PROFESSIONAL ORGANIZATIONS AND SERVICES:}

Association of Humanities Academics

Interim President, Vice President, Treasurer

2016-2018

Jefferson Community and Technical College

Committee to Increase Engagement Among First-Year Students Member

2012-2013 